HEURISTIC BASED TRADING SYSTEM ON FOREX DATA USING

TECHNICAL INDICATOR RULES

A THESIS SUBMITTED TO

THE GRADUATE SCHOOL OF NATURAL AND APPLIED SCIENCES

$\mathrm{OF}$

MIDDLE EAST TECHNICAL UNIVERSITY

BY

MURAT ÖZTÜRK

IN PARTIAL FULFILLMENT OF THE REQUIREMENTS

FOR

THE DEGREE OF MASTER OF SCIENCE

IN

COMPUTER ENGINEERING

FEBRUARY 2015 

Approval of the thesis:

\section{HEURISTIC BASED TRADING SYSTEM ON FOREX DATA USING TECHNICAL INDICATOR RULES}

submitted by MURAT ÖZTÜRK in partial fulfillment of the requirements for the degree of Master of Science in Computer Engineering Department, Middle East Technical University by,

Prof. Dr. Gülbin Dural Ünver

Dean, Graduate School of Natural and Applied Sciences

Prof. Dr. Adnan Yazicı

Head of Department, Computer Engineering

Prof. Dr. İsmail Hakkı Toroslu

Supervisor, Computer Engineering Department, METU

Dr. Güven Fidan

Co-supervisor, Argedor Information Technologies

\section{Examining Committee Members:}

Prof. Dr. Göktürk Üçoluk

Computer Engineering Department, METU

Prof. Dr. İsmail Hakkı Toroslu

Computer Engineering Department, METU

Dr. Güven Fidan

Argedor Information Technologies

Dr. Onur Tolga Şehitoğlu

Computer Engineering Department, METU

Mustafa Onur Özorhan, M.Sc.

Central Bank of the Republic of Turkey

Date: 
I hereby declare that all information in this document has been obtained and presented in accordance with academic rules and ethical conduct. I also declare that, as required by these rules and conduct, I have fully cited and referenced all material and results that are not original to this work.

Name, Last Name: $\quad$ MURAT ÖZTÜRK

Signature 


\begin{abstract}
HEURISTIC BASED TRADING SYSTEM ON FOREX DATA USING TECHNICAL INDICATOR RULES
\end{abstract}

\author{
Öztürk, Murat \\ M.S., Department of Computer Engineering \\ Supervisor $\quad$ : Prof. Dr. İsmail Hakkı Toroslu \\ Co-Supervisor : Dr. Güven Fidan
}

February 2015, 115 pages

The foreign exchange market, which is widely known as Forex or FX, is the largest financial market with a daily transactional volume of $\$ 5$ trillion. Due to the huge structure of the market, price analysis on FX market draws attention of many scientists and practitioners. There are 2 main analysis approaches: Fundamental and technical analysis. Fundamental analysis focuses on the macroeconomic factors such as interest rate to explain the market movements. Technical analysis deals with past market price data to forecast the future prices. Technical analysis involves two main approaches: Chart analysis and technical indicator based price analysis. Chart analysis deals with detection of patterns in price charts. Technical indicators transform the price time series data into another time series data to explore patterns. Technical indicators are widely used in FX and other financial markets which are the building blocks of many trading systems. A trading system is based on technical indicators or pattern-based approaches which produces buy/sell signals to trade in the market.

In this thesis, a heuristic based trading system on Forex data is developed using popular technical indicators. The system grounds on selecting and combining the trading rules based on indicators using heuristic methods. The selection of the trading rules is realized by using Genetic Algorithm and a local search method. A weighted majority voting method is proposed to combine the technical indicator based trading rules to form a single trading rule. The experiments are conducted on 2 major currency pairs 
in 3 different time frames where promising results are achieved.

Keywords: Forex, Technical Analysis, Technical Indicator, Trading Rule, Heuristic Methods, Genetic Algorithm, Time Series Analysis 


\title{
$\ddot{0} \mathbf{z}$
}

\section{FOREX VERISII ÜZERINDE TEKNIKK GÖSTERGE KURALLARINA DAYALI KEŞİFSEL YÖNTEM TABANLI ALIM-SATIM SISTEMI}

\author{
Öztürk, Murat \\ Yüksek Lisans, Bilgisayar Mühendisliği Bölümü \\ Tez Yöneticisi : Prof. Dr. İsmail Hakkı Toroslu \\ Ortak Tez Yöneticisi : Dr. Güven Fidan
}

Şubat 2015,115 sayfa

Döviz alım-satım piyasası, yaygın olarak bilinen ismiyle Forex veya FX, günlük 5 trilyon \$'lık işlem hacmiyle dünyanın en büyük finansal piyasasıdır. Piyasanın devasa yapısından dolayı, FX piyasasında fiyat analizi birçok bilim adamı ve piyasa oyuncusunun dikkatini çekmektedir. Başlıca 2 analiz yaklaşımı bulunmaktadır: Temel ve Teknik Analiz. Temel analiz, piyasa hareketlerini açıklamak amacıyla faiz oranı gibi makroekonomik unsurlara odaklanır. Teknik analiz, gelecekteki fiyatları tahmin etmek amacıyla geçmiş piyasa fiyat verileriyle ilgilenir. Teknik analiz 2 temel yaklaşım içermektedir: Grafik analizi ve teknik gösterge tabanlı fiyat analizi. Grafik analizi, fiyat grafiklerinde örüntülerin tespitiyle ilgilenir. Teknik göstergeler, örüntü keşfetmek amacıyla fiyat zaman serisi verisini farklı bir zaman serisi verisine dönüştürür. Birçok alım-satım sisteminin yapıtaşı olan teknik göstergeler, FX ve diğer finansal piyasalarda yaygın olarak kullanılmaktadır. Bir alım-satım sistemi, piyasada işlem yapmak amacıyla alım/satım sinyalleri üreten, teknik gösterge veya örüntü temelli yaklaşımlara dayalı bir sistemdir.

Bu tezde, teknik göstergeler kullanılarak, Forex verisi üzerinde keşifsel yöntem tabanlı bir alım sistemi geliştirilmiştir. Sistem, keşifsel yöntemleri kullanarak, teknik gösterge tabanlı alım-satım kurallarının seçimine ve birleştirilmesine dayanır. Alımsatım kurallarının seçimi, Genetik Algoritma ve yerel arama yöntemleri kullanılarak gerçekleştirilmiştir. Tek bir alım-satım kuralı oluşturmak amacıyla, teknik gösterge 
tabanlı alım-satım kurallarını birleştiren bir ağırlıklı çoğunluk oylama yöntemi önerilmiştir. Deneyler 3 farklı zaman dilimindeki 2 ana döviz çifti ile yapılmış ve gelecek vadeden sonuçlar elde edilmiştir.

Anahtar Kelimeler: Forex, Teknik Analiz, Teknik Gösterge, Alım-Satım Kuralı, Keşifsel Yöntemler, Genetik Algoritma, Zaman Serisi Analizi 
To my dear mother and father (rest in peace) Emel, Hayrettin 


\section{ACKNOWLEDGMENTS}

Firstly, I am grateful and would like to thank my supervisor Professor İsmail Hakkı Toroslu for giving me the opportunity to work with him. I would like to express my sincere gratitude for his encouragement, guidance, support and friendship throughout my thesis study.

I would also like to thank my co-supervisor Dr. Güven Fidan for his support and guidance during this study.

I would like to thank Professor Göktürk Üçoluk, Dr. Onur Tolga Şehitoğlu and M.Sc. Mustafa Onur Özorhan for accepting to be members of my examining committe.

I am grateful to all my friends. I would like to acknowledge my friends Ömer, Ahmet, Abdullah and Aybike for their friendship. I owe much to Ömer and Ahmet for their constant support on resolving problems I have encountered during my thesis study.

I am deeply grateful to my mother for her tolerance, patience and love. I would not have completed this study without her support. 


\section{TABLE OF CONTENTS}

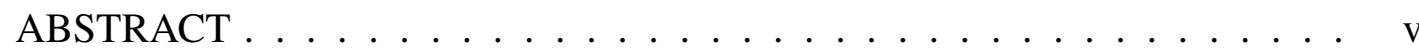

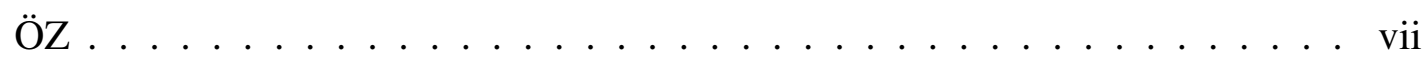

ACKNOWLEDGMENTS. .....................

TABLE OF CONTENTS . . . . . . . . . . . . . . . . . . xi

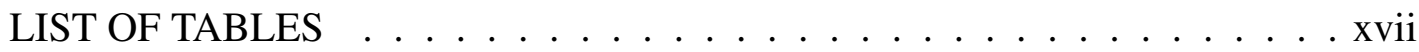

LIST OF FIGURES . . . . . . . . . . . . . . . . . . . . . . . . . xix

LIST OF ABBREVIATIONS . . . . . . . . . . . . . . . . . . . xx

\section{CHAPTERS}

$1 \quad$ INTRODUCTION $\ldots \ldots \ldots \ldots \ldots$

2 BACKGROUND ON FOREX AND TECHNICAL ANALYSIS . . . 3

$2.1 \quad$ Brief History of Forex $\ldots \ldots \ldots . \ldots 3$

$2.2 \quad$ Participants of Forex Market $\ldots \ldots . . \ldots 4$

$2.3 \quad$ Mechanics of Currency Trading and Trading Terminology . . 4

$2.3 .1 \quad$ Traded Currencies in Forex . . . . . . . . . . 4

2.3.2 How To Trade in Forex and Trading Terminology . 5

$2.4 \quad$ Forecasting Future Prices: Fundamental and Technical Anal- 
$3 \quad$ RELATED WORK $\ldots \ldots \ldots \ldots \ldots \ldots$

$4 \quad$ TECHNICAL INDICATORS $\ldots \ldots \ldots \ldots \ldots$

$4.1 \quad$ Moving Average $\ldots \ldots \ldots \ldots \ldots$

$4.2 \quad$ Moving Average Envelopes $\ldots \ldots \ldots \ldots$

$4.3 \quad$ TEMA $\ldots \ldots \ldots \ldots \ldots \ldots \ldots \ldots$

$4.4 \quad$ Bollinger Bands $\ldots \ldots \ldots \ldots \ldots$

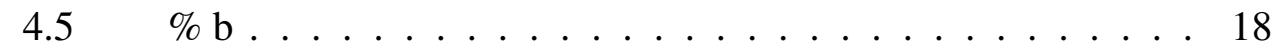

$4.6 \quad$ Bandwidth $\ldots \ldots \ldots \ldots$

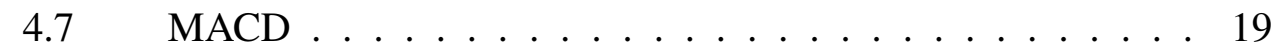

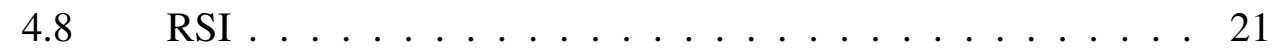

$4.8 .1 \quad$ Figurelli RSI $\ldots \ldots \ldots \ldots \ldots \ldots \ldots$

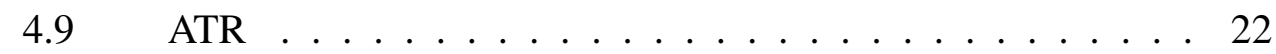

$4.10 \quad$ Chandelier Exit . . . . . . . . . . . . . . 23

$4.11 \quad$ Psychological Line . . . . . . . . . . . . . . . . . 24

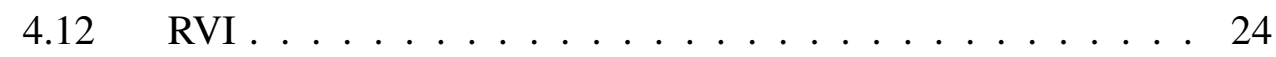

4.13 Stochastic Oscillator . . . . . . . . . . . . 25

4.14 Ultimate Oscillator. . . . . . . . . . . . . . . . 26

4.15 Rate of Change $\ldots \ldots \ldots \ldots \ldots \ldots \ldots$

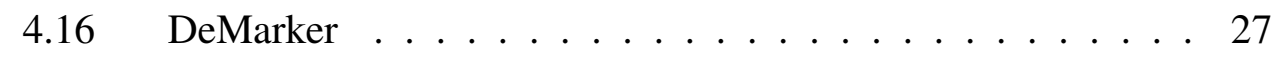

$4.17 \quad$ Relative Vigor Index $\ldots \ldots \ldots \ldots \ldots$

$4.18 \quad \mathrm{MFI} \ldots \ldots \ldots \ldots \ldots \ldots$ 


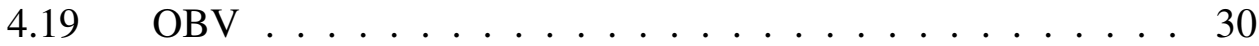

$4.20 \quad \mathrm{ADL} \ldots \ldots \ldots \ldots \ldots \ldots \ldots \ldots \ldots \ldots$

4.21 Chaikin Oscillator . . . . . . . . . . . . . . . . 31

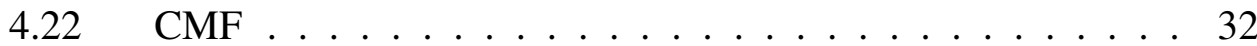

$4.23 \quad$ EMV $\ldots \ldots \ldots \ldots \ldots \ldots \ldots \ldots \ldots$

5 TRADING RULES BASED ON TECHNICAL INDICATORS . . . . 35

$5.1 \quad$ Crossover Rules . . . . . . . . . . . . . . . . . . 36

$5.1 .1 \quad$ Moving Average Price Crossover . . . . . . . . . . 36

5.1 .2 Double Moving Average Crossover $\ldots . . . . .37$

5.1 .3 Triple Moving Average Crossover . . . . . . . . 38

$5.1 .4 \quad$ Moving Average Envelopes Crossover . . . . . . . 39

5.1 .5 TEMA Crossover . . . . . . . . . . . . . 40

$5.1 .6 \quad$ MACD Crossover . . . . . . . . . . . . . . 40

$5.1 .7 \quad$ RSI Crossover . . . . . . . . . . . . . . . 40

$5.1 .8 \quad$ Figurelli RSI Crossover $\ldots \ldots \ldots \ldots \ldots$. . . . . 41

5.1 .9 Chandelier Exit Crossover $\ldots \ldots \ldots$. . . . . . 41

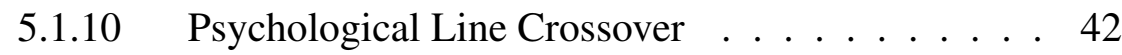

$5.1 .11 \quad$ RVI Crossover . . . . . . . . . . . . . . . 42

5.1 .12 Stochastics Oscillator Crossover . . . . . . . . . 43

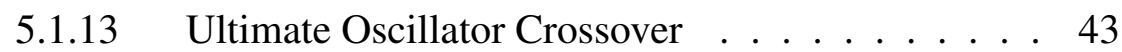

5.1 .14 Rate of Change Crossover . . . . . . . . . . . 43 
5.1 .15 DeMarker Crossover . . . . . . . . . . . . . . . 44

$5.1 .16 \quad$ Relative Vigor Index Crossover $\ldots \ldots \ldots$. . . . . 44

$5.1 .17 \quad$ MFI Crossover . . . . . . . . . . . . . 45

5.1 .18 OBV Crossover . . . . . . . . . . . . . . . . 45

5.1 .19 ADL Crossover . . . . . . . . . . . . . . . 46

5.1 .20 Chaikin Oscillator Crossover . . . . . . . . . . . . 46

$5.1 .21 \quad$ CMF Crossover . . . . . . . . . . . . . . . 47

5.1 .22 EMV Crossover . . . . . . . . . . . . . . . 47

$5.2 \quad$ Rules Based on Bollinger Bands, \%b and Bandwidth Indicators 47

$5.2 .1 \quad$ W-Type Bottom Pattern . . . . . . . . . . . . . 48

$5.2 .2 \quad$ M-Type Top Pattern . . . . . . . . . . . . . . . . . 49

5.2 .3 Method III-Reversals . . . . . . . . . . . . . 50

$5.2 .4 \%$ b-MFI $\ldots \ldots \ldots \ldots \ldots \ldots \ldots$

$5.2 .5 \% \mathrm{~b}(\mathrm{CMF})$ Crossover $\ldots \ldots \ldots \ldots \ldots$

$5.2 .6 \quad$ The Squeeze and Expansion $\ldots \ldots \ldots$. . . . . 52

$5.3 \quad$ Divergence Rules $\ldots \ldots \ldots \ldots \ldots \ldots$

$5.3 .1 \quad$ Rules Based on Bullish Divergences . . . . . . . 54

$5.3 .2 \quad$ Rules Based on Bearish Divergences . . . . . . . . 54

$6 \quad$ TRADING SYSTEM $\ldots \ldots \ldots$

$6.1 \quad$ The Framework of The Proposed Trading System . . . . . . 59

$6.2 \quad$ Testing Each Trading Rule For Qualification . . . . . . . . 60 
$6.2 .1 \quad$ Trading Simulation Module $\ldots . . . . . . .661$

$6.2 .2 \quad$ GA Module . . . . . . . . . . . . . 63

6.3 Combining The Qualified Rules . . . . . . . . . . . . . . 64

$6.3 .1 \quad$ Genetic Algorithm Module . . . . . . . . . . . . . 66

$6.3 .2 \quad$ Local Search Module . . . . . . . . . . . . . . . 68

$6.3 .3 \quad$ Weighting Module . . . . . . . . . . . . . 68

$6.3 .4 \quad$ Combination Module . . . . . . . . . . . . . . 69

$6.4 \quad$ Testing The Performance Of The Combined Trading System. 69

$6.5 \quad$ A Sample Run of The Trading System . . . . . . . . . . . 71

7 EXPERIMENTS . . . . . . . . . . . . . . . 75

$7.1 \quad$ Experimental Environment $\ldots \ldots \ldots 75$

$7.2 \quad$ Investment Conditions . . . . . . . . . . . . . 75

$7.3 \quad$ Evaluation Metrics $\ldots \ldots \ldots \ldots$. . . . . . . . 76

$7.4 \quad$ Data Sets . . . . . . . . . . . . . 76

7.5 Results and Discussion . . . . . . . . . . . . 77

7.5.1 Experiments on EUR/USD: 1 Year Data . . . . . 78

7.5.1.1 Results . . . . . . . . . 78

7.5.1.2 Discussion . . . . . . . . . . 79

7.5.2 Experiments on EUR/USD: 6 Months Data . . . . 81

7.5.2.1 Results . . . . . . . . . . . 81

7.5.2.2 Discussion . . . . . . . . . 81 
7.5.3 Experiments on GBP/USD: 6 Months Data . . . . 83

7.5.3.1 Results . . . . . . . . . . 84

7.5.3.2 Discussion . . . . . . . . . 85

$8 \quad$ CONCLUSION AND FUTURE WORK $\ldots \ldots \ldots$. . . . . . . . . 87

REFERENCES . . . . . . . . . . . . . . . . . . . . . 89

APPENDICES

A EXPERIMENTS ONEUR/USD DATA BETWEEN 01.01.2013-31.12.2013 (1 YEAR $) \ldots \ldots \ldots \ldots \ldots \ldots$

B EXPERIMENTS ONEUR/USD DATA BETWEEN 01.01.2013-30.06.2013 (6 MONTHS) $\ldots \ldots \ldots \ldots \ldots \ldots$

C EXPERIMENTS ON GBP/USD DATA BETWEEN 01.01.2014-30.06.2014 (6 MONTHS) $\ldots \ldots \ldots$. . . . . . . . . . . . . 109 


\section{LIST OF TABLES}

\section{TABLES}

Table $2.1 \quad$ ISO codes for major and exotic currencies [6] $\ldots \ldots \ldots$. . . . . . . . 5

Table 2.2 Most actively traded major and cross currency pairs [7] $\ldots . . . . .5$

Table $6.1 \quad$ Results of phase $1 \ldots \ldots \ldots \ldots \ldots$. . . . . . . . . . 71

Table 6.2 Results of combining rules using GA $\ldots \ldots$. . . . . . . . . . . 72

Table 6.3 Results of combining rules using local search . . . . . . . . . . . 73

Table 7.1 Qualified and unqualified rules . . . . . . . . . . . . . . . 79

Table 7.2 Experiment results using net profit $\ldots \ldots$. . . . . . . . . . . . . 80

Table 7.3 Experiment results using average profit per trade . . . . . . . . . . . 80

Table 7.4 Qualified and unqualified rules . . . . . . . . . . . . . . 82

Table 7.5 Experiment results using net profit $\ldots \ldots \ldots$. . . . . . . . . . . 83

Table 7.6 Experiment results using average profit per trade . . . . . . . . . . . 83

Table 7.7 Qualified and unqualified rules . . . . . . . . . . . . . . . 84

Table 7.8 Experiment results using net profit $\ldots \ldots \ldots$. . . . . . . . . . . . . 85

Table 7.9 Experiment results using average profit per trade $\ldots . . . \ldots . .85$

Table A.1 Experiment results using net profit (threshold=25) . . . . . . . . . . . 94

Table A.2 Experiment results using net profit (threshold=50) . . . . . . . . . . 95

Table A.3 Experiment results using net profit (threshold=75) . . . . . . . . . . 96

Table A.4 Experiment results using average profit per trade (threshold=25) . . 97

Table A.5 Experiment results using average profit per trade (threshold=50) . . 98 
Table A.6 Experiment results using average profit per trade (threshold=75) . . 99

Table B.1 Experiment results using net profit (threshold=25) . . . . . . . . . . 102

Table B.2 Experiment results using net profit (threshold=50) . . . . . . . . . . 103

Table B.3 Experiment results using net profit (threshold=75) . . . . . . . . . . 104

Table B.4 Experiment results using average profit per trade (threshold=25) . . 105

Table B.5 Experiment results using average profit per trade (threshold=50) . . 106

Table B.6 Experiment results using average profit per trade (threshold=75) . . 107

Table C.1 Experiment results using net profit (threshold=25) . . . . . . . . . 110

Table C.2 Experiment results using net profit (threshold=50) . . . . . . . . . 111

Table C.3 Experiment results using net profit (threshold=75) . . . . . . . . . . 112

Table C.4 Experiment results using average profit per trade (threshold=25) . . 113

Table C.5 Experiment results using average profit per trade (threshold=50) . . 114

Table C.6 Experiment results using average profit per trade (threshold=75) . . 115 


\section{LIST OF FIGURES}

\section{FIGURES}

Figure $2.1 \quad$ EUR/USD Exchange Rate Between 2002-2005 [8] . . . . . . . . . 6

Figure 2.2 EUR/USD Bid and Ask Prices [7] . . . . . . . . . . . . . . . . 6

Figure 2.3 Examples of 4 Types of Charts . . . . . . . . . . . . . . . . . 9

Figure 4.1 MACD, Signal Line and MACD Histogram [11] . . . . . . . . . . 20

Figure 4.2 True Range (TR) $[11] \ldots \ldots \ldots \ldots \ldots$

Figure $5.1 \quad$ Moving Average Price Crossover [11] . . . . . . . . . . . . . . . . 37

Figure 5.2 Double Moving Average Crossover [11] . . . . . . . . . . . . . . . 38

Figure 5.3 Triple Moving Average Crossover [51] . . . . . . . . . . . . . . . . 39

Figure 5.4 W-Type Bottom Pattern [34] $\ldots \ldots \ldots$

Figure 5.5 M-Type Top Pattern [34] $\ldots \ldots \ldots$. . . . . . . . . . . . . . . . . . . 50

Figure 5.6 Regular and Hidden Bullish Divergences [9] . . . . . . . . . . . . 54

Figure 6.1 The Framework Of The Overall Trading System . . . . . . . . . . 60

Figure 6.2 Testing Each Trading Rule For Qualification . . . . . . . . . . . . 61

Figure 6.3 Chromosome Representation of RSI Crossover Rule . . . . . . . . 64

Figure 6.4 Combining Rules Using Genetic Algorithm As The Selection Ap-

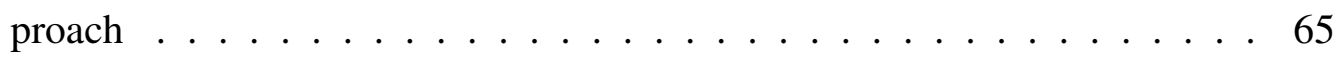

Figure 6.5 Combining Rules Using Local Search As The Selection Approach . 66

Figure 6.6 Chromosome Representation of A Candidate Combined Rule . . . 67

Figure 6.7 Selection of Trading Rules with Local Search . . . . . . . . . . . . 68 


\section{LIST OF ABBREVIATIONS}

$\begin{array}{ll}\text { ADL } & \text { Accumulation Distribution Line } \\ \text { ATR } & \text { Average True Range } \\ \text { BP } & \text { Buying Pressure } \\ \text { CMF } & \text { Chaikin Money Flow } \\ \text { EMA } & \text { Exponential Moving Average } \\ \text { EMV } & \text { Ease Of Movement } \\ \text { EUR } & \text { Euro } \\ \text { FX } & \text { Forex, Foreign Exchange } \\ \text { GA } & \text { Genetic Algorithm } \\ \text { GBP } & \text { Great British Pound } \\ \text { LWMA } & \text { Linear Weighted Moving Average } \\ \text { MACD } & \text { Moving Average Convergence Divergence } \\ \text { MFI } & \text { Money Flow Index } \\ \text { OBV } & \text { On-Balance Volume } \\ \text { ROC } & \text { Rate Of Change } \\ \text { RS } & \text { Relative Strength } \\ \text { RSI } & \text { Relative Strength Index } \\ \text { RVI } & \text { Relative Volatility Index } \\ \text { SMA } & \text { Simple Moving Average } \\ \text { SMMA } & \text { Smoothed Moving Average } \\ \text { TEMA } & \text { Triple Exponential Moving Average } \\ \text { TR } & \text { True Range } \\ \text { USD } & \text { States Dollar } \\ & \end{array}$




\section{CHAPTER 1}

\section{INTRODUCTION}

Forex (FX in short) which stands for foreign exchange is the biggest financial market in the world with a daily transaction exceeding $\$ 5$ trillion. The transactions in Forex are based on exchanging currencies between parties. The participants in Forex are widespread including banks, corporations, brokers-dealers, individuals etc. EUR/ USD is the most traded currency pair in Forex market.

Many practitioners and scientists are closely interested in price forecasting in Forex. In this context, the analysis approaches are divided into two groups: fundamental and technical analysis. Fundamental analysis deals with the macroeconomic factors to explain and forecast the changes in price. Technical analysis aims to forecast the price changes using historical market data. Technical analysis approaches can be grouped as chart analysis and technical indicator based price analysis. Chart analysis focuses on the price charts with the aim of finding recurrent patterns in price. Technical indicators transform the historical time series price data to another time series data to detect patterns, identify trends, measure volatility in price and define the relationship between price and volume.

The unstable and chaotic structure of price in Forex market complicates forecast analysis. This leads to the usage of optimization methods. Genetic algorithm and heuristic methods are among the most remarkable of these methods. Genetic algorithm is an optimization method that generates solutions which evolve by time [1, 2]. Genetic algorithm is based on evolution and genetics. Heuristic methods yields nearly but not necessarily optimal solution with reasonable computational effort and time. Heuristic methods can be categorized as decomposition, inductive, reduction, constructive and 
local search methods [3].

In this thesis, a heuristic based trading system is developed using trading rules based on technical indicators. The system is based on testing the technical indicator based trading rules for qualification, selection among these qualified rules and combining the selected rules. Genetic algorithm is used in the qualification test of the trading rules. The selection of the qualified rules are realized using both genetic algorithm and a local search method. A weighted majority voting method is proposed to combine the trading rules. Training data is used in all these phases and the system is tested using test data. The experiments are conducted on 2 major currency pairs in 3 different time frames and the experimental results are promising which are discussed in detail.

The rest of the thesis is composed of seven chapters. Chapter 2 introduces the fundamentals of Forex and technical analysis. Chapter 3 presents the related studies on using technical indicators to forecast in Forex market. Technical indicators are introduced and the indicators used in the thesis are elaborated in Chapter 4 . Chapter 5 gives detailed explanation of the trading rules based on technical indicators discussed in Chapter 4. Chapter 6 presents and elaborates on the proposed trading system. Chapter 7 presents the results of the experiments conducted on 2 currencies in 3 time frames. Chapter 8 gives a summary of the thesis, discusses the results and concludes with the future directions. 


\section{CHAPTER 2}

\section{BACKGROUND ON FOREX AND TECHNICAL ANALYSIS}

Forex (or FX in short) which stands for Foreign Exchange simply is a financial market where the currencies are exchanged simultaneously between 2 parties [4]. It is the biggest financial market with a daily transactional volume of more than $\$ 5$ trillion [5]. Forex is a decentralized market unlike other markets such as stock market. Its decentralized structure makes it available to trade in a 24 hours basis which differs from the other financial markets [4].

\subsection{Brief History of Forex}

Modern structure of foreign exchange history is rather new compared with old fashioned exchanging currencies. The Forex history starts in 1944 with the acceptance of Bretton Woods Accord signed by all member countries of all Allied Nations of World War II. The motivation behind this agreement was to create a stable economic and financial system. The agreement brought remarkable changes in the financial system: US Dollar became the backbone of the currency trading where it was fixed to gold price and the other currencies fixed to US Dollar. As a result, the US Dollar had the ability to be convertible to all the currencies and gold price, thus became the popular currency throughout the world. This agreement stayed in charge since 1973. In 1973, the old agreement was officially terminated and the Bretton Woods II was accepted. The new system was not fixing the US Dollar to the gold and other currencies; instead the currency prices can fluctuate freely against each other driven with the market forces. Since then, Forex market grew up by time and had its recent 
widespread and enormous structure [6].

\subsection{Participants of Forex Market}

Forex is the biggest and most widespread financial market in the world therefore it has plenty of participants. The participants can be grouped as corporations, banks (specially central banks), brokers-dealers, other financial institutions such as hedge funds, retail brokers and traders such as small non-bank institutions and individuals. The participants may trade in forex market for various reasons: while an individual wants to make money in the short term, a corporation which imports/exports goods overseas wants to mitigate the exchange risk [6].

\subsection{Mechanics of Currency Trading and Trading Terminology}

Forex market has its own characteristics which differ from other markets. First and remarkably, there is no centralized structure that the currencies are exchanged; instead currencies are exchanged directly between two parties (over-the-counter) [6]. Second, Forex is a spot market which deals in the current price where a futures contract deals in the future price of a financial instrument [4]. Third, exchanging currencies come in pairs: therefore buying a currency means selling the counter currency simultaneously. Finally, a trader may use leverage in his/her trading which increases the risk/reward of the transaction.

\subsubsection{Traded Currencies in Forex}

In Forex market, various currencies are traded (exchanged) in pairs between each other. The currencies can be grouped in two: Major and exotic currencies. The list of these currencies are given in table 2.1. The currency pairs can be grouped in two: Major currency pairs and cross currency pairs. The list of the most actively traded currency pairs of both groups are given in table 2.2. Among the currency pairs in both groups, the most actively traded are EUR/USD which is followed by USD/JPY 
and GBP/USD [5]. The EUR/USD exchange rate between 2002 and 2005 is given in figure 2.1

Table 2.1: ISO codes for major and exotic currencies [6]

(a) Major Currencies

\begin{tabular}{|l|c|}
\hline US dollar & USD \\
\hline Euro & EUR \\
\hline Japanese yen & JPY \\
\hline British pound & GBP \\
\hline Australian dollar & AUD \\
\hline Swiss franc & CHF \\
\hline Canadian dollar & CAD \\
\hline Hong Kong dollar & HKD \\
\hline
\end{tabular}

(b) Exotic Currencies

\begin{tabular}{|l|c|}
\hline Polish zloty & PLN \\
\hline Turkish lira & TLR \\
\hline South African rand & ZAR \\
\hline Brazilian real & BRL \\
\hline Danish krone & DKK \\
\hline New Taiwan dollar & TWD \\
\hline Hungarian forint & HUF \\
\hline Chinese yuan renminbi & CNY \\
\hline
\end{tabular}

Table 2.2: Most actively traded major and cross currency pairs [7]

(a) Major currency pairs

\begin{tabular}{|l|l|l|}
\hline ISO Currency Pair & Countries & Long Name \\
\hline EUR/USD & Eurozone/U.S. & Euro-Dollar \\
\hline USD/JPY & U.S./Japan & Dollar-Yen \\
\hline GBP/USD & United Kingdom/U.S. & Sterling-Dollar \\
\hline USD/CHF & U.S./Switzerland & Dollar-Swiss \\
\hline
\end{tabular}

(b) Cross currency pairs

\begin{tabular}{|l|l|l|}
\hline ISO Currency Pair & Countries & Long Name \\
\hline EUR/CHF & Eurozone/Switzerland & Euro-Swiss \\
\hline EUR/GBP & Eurozone/United Kingdom & Euro-Sterling \\
\hline EUR/JPY & Eurozone/Japan & Euro-Yen \\
\hline GBP/JPY & United Kingdom/Japan & Sterling-Yen \\
\hline
\end{tabular}

\subsubsection{How To Trade in Forex and Trading Terminology}

There are various participants in Forex market as pointed out in 2.2. Individuals can trade in Forex market by means of broker firms. After opening an account in a broker, an individual can start to trade in Forex market. Broker firms supply trading software which allows individual traders to trade online in Forex market.

When an individual decides to trade a currency pair using the broker's software, he/she sees two prices for each currency. The price on the left is called the bid and 


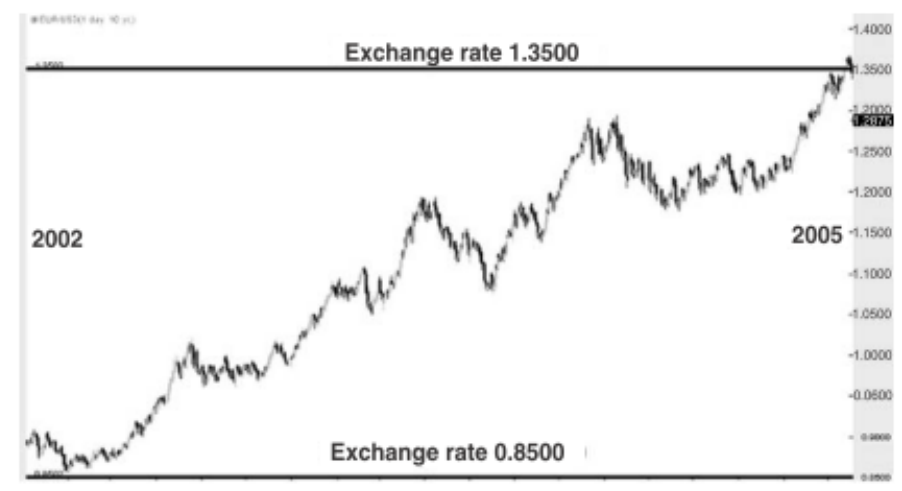

Figure 2.1: EUR/USD Exchange Rate Between 2002-2005 [8]

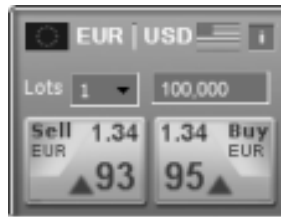

Figure 2.2: EUR/USD Bid and Ask Prices [7]

the price on the right is called the ask price. The bid price is the price which you can sell the base currency whereas the ask price is the price which you can buy the base currency [7]. The bid and ask prices are illustrated in figure 2.2. The difference between the ask and bid prices is called spread. The smallest unit of price in any currency pair is called pip. For example in EUR/USD, the value of 1 pip is 0.0001 [4]. Some brokers/dealer also use fractional pips called pipette where 1 pip equals 10 pipettes [9].

After selecting a currency pair for trading, one should place an order to initiate a trade. An order is an instruction to the broker to take a specific transaction [4]. There are 3 primary order types: Market order, take-profit order and stop loss order. A market order is an order which is executed immediately with the current price. Takeprofit and stop-loss orders are pending orders executed after a specified price level is reached which gains profit and stops loss, respectively [7].

In order to start a trade in FX, one should open a position. There are two options to open a position: either buying the base currency and selling quote currency (going long) or selling the base currency and buying the quote currency (going short) 
[8]. The base and quote currencies are the first and second currencies in a currency pair, respectively. For example, EUR is the base and USD is the quote currencies in EUR/USD currency pair [4]. After a trade is initiated, it can be closed by making a counter trade. As an example, if a trader goes long in EUR/USD (buy EUR and sell USD), he/she should sell EUR and buy USD to close the trade. A trader can use leverage in the trading. Leverage is the ratio which allows to trade large amount with a small amount of money [4]. For example, if one trades $\$ 1000$ with a leverage 1:100 in EUR/USD, the amount of trading transaction will be $\$ 100000$ instead of $\$ 1000$.

The profit/loss of a trading transaction is calculated by subtracting the final value from the initial value of the currency pair. Suppose the trader goes long $\$ 100000$ in EUR/USD with a buying price of 1.2850 and closes his position with a selling price of 1.2870. The difference is 0.0020 which is 20 pips. Because the initial position is long and price increased, the transaction is profitable and the profit is $100000 * 0.0020=$ $\$ 200$. Therefore the trader wants the price of the currency pair to increase when he/she is long and decrease when he is short in order to get profit.

\subsection{Forecasting Future Prices: Fundamental and Technical Analysis}

There are two main types of analysis used to forecast future prices in Forex and similar financial instruments (such as stock market, gold and valuables market etc.): Fundamental Analysis and Technical Analysis. Fundamental Analysis deals with the cause of market movement [10] by focusing on the macroeconomic factors that affects the prices to move higher or lower. These fundamental factors can be listed as follows [7]:

- Economic data reports

- Interest rate levels

- Monetary policy

- International trade flows

- International investment flows 
On the other hand, technical analysis is the study of past market action for the purpose of forecasting future prices. Technical Analysis deals with the effect of market action on future prices [10]. Technical Analysis is based on the following three premises:

- Market action discounts everything: It means any factor that can affect the prices is already reflected in the price.

- Prices move in trends: The purpose of the technical analysis is to detect a price trend in the early phases of development.

- History repeats itself: Technical analysis uses patterns which have shown success in the past and assumes they will work in the future [10].

Technical Analysis involves two main approaches: Chart analysis and price analysis using technical indicators. Chart analysis involve detection of patterns in price charts. These patterns can be graphical formations such as double bottom, head and shoulders as well as trend lines with the support and resistance levels [6]. There are 4 main types of charts used by traders: Bar chart, line chart, candlestick chart and point and figure chart. A bar chart represents the opening, highest, lowest and closing prices (open, high, low and close in technical analysis jargon, respectively) by vertical bars. A line chart involves only the close prices as points connected to form a line. In a candlestick chart, there are two parts: the thin line (shadow) represents the price range between high and low whereas the wider portion (real body) represents the price range between open and close. If the close is higher than the open, the real body is white which shows an increase in price. If the close is lower than the open, the real body is black which shows a decrease in price [10]. A point and figure chart makes the increase and decrease in prices more visible. The x's shows rising prices whereas o's represents the declining prices in successive periods. All the aforementioned charts are illustrated in figure 2.3 .

The other approach involves using technical indicators to forecast the future price action. A technical indicator applies a mathematical formula(s) to a series of price data which produces another series of data points in order to explore patterns in the data. Price data can be open, high, low or close data as well as volume data [11]. Technical indicators will be covered in detail in Chapter 4. 


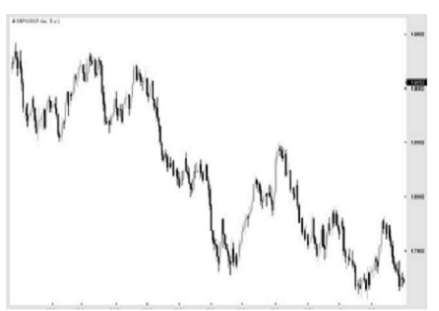

(a) Line Chart [8]

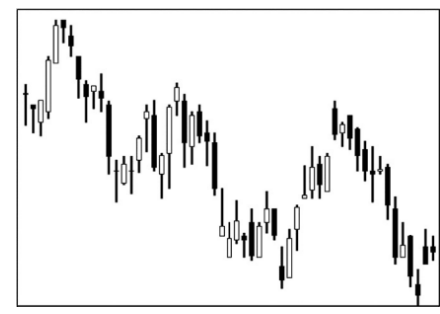

(c) Candlestick Chart [4]

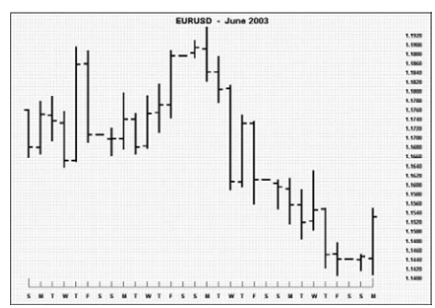

(b) Bar Chart [4]

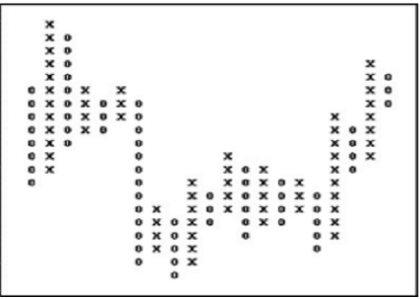

(d) Point and Figure Chart [4]

Figure 2.3: Examples of 4 Types of Charts 


\section{CHAPTER 3}

\section{RELATED WORK}

There are numerous studies on using technical analysis and technical indicators in forecasting financial markets and specially Forex market. One of the earliest study is given in [12] where a significant excess return is obtained. In the literature, many forecasting/trading models are proposed using technical indicators in combination with various machine learning methods where genetic algorithm is of special interest. The hybrid genetic algorithm-technical indicators models are applied on stock data in [13], [14], [15] and on equity data in [16]. The rest of the related work includes the hybrid approaches which uses technical indicators and the applied domain is forex currencies.

Neely et al. in [17] used genetic algorithm to optimize the randomly created trading rules in their pioneering work. The trading rules are created randomly using price data in combination with basic arithmetical and logical operations and represented as trees. Following, the genetic algorithm operations are applied on these trading rules and best of these rules are experimented.

In [18], technical indicators are combined using genetic algorithm and reinforcement learning to form a hybrid trading system on EUR/USD intraday data. In the proposed model, the training data is split into 2 sections. The trading rules based on technical indicators are optimized by genetic algorithm in the first section and the best of these rules are selected. The combination of the selected rules are then optimized using reinforcement learning in the second section and tested.

In [19], Dempster and Jones developed a system which uses genetic programming 
to combine multiple technical indicators on GBP/USD currency pair. The authors split the rules into buy and sell rules and used genetic programming to combine the individual technical indicator-based trading rules with an array of Boolean operators to form a system rule. They also used an active cash management system which exits a trade when the trading loss exceeds the user defined threshold.

A hybrid method is proposed which combines Multiple Kernel Regression and genetic algorithm with the overbought/oversold indicators in [20]. Multiple kernel regression is applied to obtain the exchange rate predictions where technical indicators are supplied as input to the multiple kernel regression. The trading rule is constructed using genetic algorithm where it is applied to the results of the multiple kernel regression with the technical indicator and buy/sell parameters.

Hirabayashi et al. developed a trading system which combines technical indicators using genetic algorithm in [21]. The technical indicator values with upper and lower buy/sell limits of each and the trade parameters are represented in chromosomes to form a combined trading rule.

In [22], a hybrid method is proposed which combines technical indicators, Recurrent Self Organizing Map (RSOM) and Support Vector Regression (SVR) using genetic algorithm. RSOM is applied to segment the training data into several regions and SVR is applied to the segmented data to form a trading rule. Trading rules are defined based on technical indicators and the RSOM-SVR rule is combined in genetic algorithm to produce the best results.

A hybrid model which combines technical indicators, Artificial Neural Network (ANN) and genetic algorithm is proposed by Thinyane and Millin in [23]. Firstly, trading rules based on technical indicators are defined. The buy/sell signals of the trading rules are then fed into an ANN to form a combined trading rule. Following, the combined trading rule is optimized using genetic algorithm.

A combined model is proposed in [24] where technical indicators and genetic algorithm are used. The trading rules which are based on technical indicators are defined in two categories: rules to open and exit position. These rules are then represented in a chromosome and optimized to adapt to give the best profits. 
Brito and Oliveira proposed a method which combines technical indicators using genetic algorithm in a comparative study [25]. The authors use 4 technical indicators to form 15 trading rules and they optimize all the rules individually using genetic algorithm. They experiment the 15 trading rules on 9 most traded forex currencies and compare the results with a hybrid system including Support Vector Regression and Self Organizing Map.

In [26], the authors propose a method which combines technical indicators, Multiple Kernel Learning (MKL) and Differential Evolution (DE). The proposed method uses 3 different currency pairs including EUR/USD to form a trading rule applied to EUR/USD pair. MKL is used to predict changes in the target currency pair and DE is used to form a trading rule in combination with the technical indicators which is then combined with MKL.

Deng et al. developed a model based on technical indicators which are combined using genetic algorithm in [27]. The authors set buy and sell parameters for 3 technical indicators and other trading parameters which is represented in a chromosome as a trading rule. The proposed model is applied to the training data and optimized. Following, the optimized trading rules are applied to the test data to obtain the performance.

In [28], the technical indicators are optimized using Artificial Neural Network (ANN) to form a combined trading system. The ANN is composed of four layers: The input layer of of the trading signals based on the selected technical indicators, 2 hidden layers and one output layer. The proposed model is trained and the resultant trading rule is applied to hourly data of 9 currency pairs.

Deng and Sakurai proposed a method in [29] which combines Relative Strength Index (RSI) indicator in different time frames with genetic algorithm on EUR/USD currency pair. 30 minute, 1 and 2 hour RSI indicator values combined with the various weight parameters are represented as chromosomes which forms the trading rules. The trading rules are then optimized with the genetic algorithm methods and the best trading rule is selected to be tested. 


\section{CHAPTER 4}

\section{TECHNICAL INDICATORS}

Technical indicators apply mathematical formula(s) to price time series data to produce another time series data as pointed out in chapter 2. They are the vital tools of technical analysts to forecast future price trends and action. They can be used to clarify the price trend as well as measure volatility and define the interrelationship between price and volume data. They provide a means to understand the past market action and use that information to predict future prices. One important advantage of technical indicators is the availability of their usage in many financial instruments including Forex, stock market, futures market etc [30].

Technical market indicators can be classified into three groups: trend, momentum and volatility based indicators. Trend indicators follow the price action and commonly referred as lagging indicators. Moving average and MACD are examples of trend indicators. Momentum indicators display the rate of change in price and commonly referred to as leading indicators. RSI and Stochastic Oscillator are examples of momentum indicators. Volatility based indicators are based on the rapid changes in volatility in price. Bollinger Bands and Chandelier Exit are examples of volatility based indicators [11, 30].

In the following sections of this chapter, the indicators used in the thesis will be covered in detail. 


\subsection{Moving Average}

Moving Average is an indicator which shows the average price value in a specified period. Moving average is a lagging indicator which smooths the price data and makes the current trend more visible. There are 4 known types of moving averages: Simple, Exponential, Smoothed, Weighted. Simple Moving Average is the default strategy which is based on the arithmetic average of the prices [11, 31, 32]. The calculation of all 4 moving average types [31] are as follows:

$$
\begin{gathered}
S M A=S U M(\text { Close }, N) / N \\
E M A=(\text { Close } * P)+(E M A(\text { prev }) *(1-P)) \\
S M M A=(S M M A(\text { prev }) *(N-1)+\text { Close }) / N \\
L W M A=S U M(\text { Close } * i, N) / S U M(i, N)
\end{gathered}
$$

In equation (4.1), $S M A$ stands for simple moving average, Close is the close price, $N$ is the number of periods and $S U M($ Close,$N)$ is the sum of the close prices in $N$ periods. In equation (4.2), EMA stands for exponential moving average, Close is the current period close price, $E M A($ prev $)$ is the previous period's exponential moving average value and $P$ is the percentage of using the close price value. In equation (4.3), $S M M A$ is the smoothed moving average of the current period, $S M M A($ prev) is the smoothed moving average of the previous period, Close is the current period close price and $N$ is the smoothing period. In equation (4.4), LWMA stands for linear weighted moving average, $N$ is the smoothing period, $S U M(C l o s e * i, N)$ is the weighted sum of the close prices in $N$ periods and $\operatorname{SUM}(i, N)$ is the total sum of weight coefficients in $N$ periods.

\subsection{Moving Average Envelopes}

Moving average envelopes is an indicator which consists of percentage based envelopes placed equally above and below (upper and lower envelopes, respectively) the moving average of price. Similar to Bollinger Bands indicator, the aim is to cover 
most of the price action; price action outside the envelopes signals attention [11]. The calculation of the indicator is as follows:

$$
\begin{gathered}
\text { Upper Envelope }=S M A(\text { Close }, N)+(S M A(\text { Close }, N) * \text { percentagefactor }) \\
\text { Lower Envelope }=S M A(\text { Close }, N)-(S M A(\text { Close }, N) * \text { percentagefactor }) \\
\text { MovingAverage }=S M A(\text { Close }, N)
\end{gathered}
$$

where UpperEnvelope denotes the upper envelope value, LowerEnvelope denotes the lower envelope value, Moving Average denotes the moving average placed between upper and lower envelopes, $N$ denotes the number of periods, $S M A(C l o s e, N)$ is the simple moving average of close prices in $\mathrm{N}$ periods, percentagefactor is the percentage to calculate the upper/lower envelopes. The period and type of moving average and percentage factor ( $N, S M A$ and percentage factor, respectively) are subject to change.

\subsection{TEMA}

TEMA which stands for Triple Exponential Moving Average is an indicator developed by Patrick G. Mulloy [33]. TEMA grounds on exponential moving average as its name implies. It uses single, double and triple exponential moving average of the price; thereby tries to mitigate the sudden price changes and provide a better smoothing [30, 33]. The calculation of the indicator is as follows:

$$
T E M A=3 * E M A 1-3 * E M A 2+E M A 3
$$

where $E M A 1$ is the exponential moving average of the close price, EMA2 is the exponential moving average of $E M A 1$ and $E M A 3$ is the exponential moving average of $E M A 2$ in p periods. 


\subsection{Bollinger Bands}

Bollinger Bands is an indicator developed by John Bollinger which consists of 3 bands: a moving average of price in a specified period (i.e. the middle band) and 2 trading bands placed above and below this moving average (upper and bollinger bands, respectively) [34]. The calculation of upper and lower bollinger bands is based on the standard deviation of the price in the specified period of the moving average. The upper and lower bands widen or narrow depending on the volatility of the price [11, 34]. The standard calculation of bollinger bands is as follows:

$$
\begin{gathered}
\text { MiddleBand }=S M A(\text { Close }, 20) \\
\text { UpperBand }=S M A(\text { Close }, 20)+S D(\text { Close }, 20) * 2 \\
\text { LowerBand }=S M A(\text { Close }, 20)-S D(\text { Close }, 20) * 2
\end{gathered}
$$

where

$$
S D=\sqrt{\frac{\sum\left(x_{i}-\mu\right)^{2}}{N}}
$$

In equation (4.8), SD denotes the standard deviation, $x$ is data point, $\mu$ is the average of data points and $N$ is the number of points. In equations 4.5, (4.6) and (4.7), $S M A(C l o s e, 20)$ is the simple moving average of close prices in 20 periods, $S D($ Close, 20$)$ is the standard deviation of close prices in 20 periods, MiddleBand, UpperBand and LowerBand denote the middle, upper and lower bollinger bands values, respectively.

The standard calculation is based on the recommended settings by John Bollinger. The type, period of moving average and standard deviation factor (i.e. SMA, 20, 2 in the above calculation, respectively) are subject to change.

\section{$4.5 \% \mathrm{~b}$}

$\% \mathrm{~b}$ is an indicator developed by John Bollinger [34]. It is derived from Bollinger Bands indicator which aims to address the relative position of the price compared 
with the upper and lower bands of the bollinger bands indicator [34]. The calculation of the indicator is as follows:

$$
\% b=\frac{\text { Close }- \text { Lower B B }}{\text { Upper BB - Lower BB }}
$$

where $C$ lose is the close price value, $\operatorname{Upper} B B$ and Lower $B B$ are upper and lower bollinger bands values, respectively.

\subsection{Bandwidth}

Bandwidth is an indicator developed by John Bollinger [34]. It is derived from Bollinger Bands similar to \% b indicator. It is used to identify the width of the distance between upper and lower Bollinger Bands; when the width is narrow, it is a sign of either an uptrend or downtrend. It is also the keystone of The Squeeze rule [34]. The calculation of the indicator is as follows:

$$
\text { Bandwidth }=\frac{\text { Upper } B B-\text { Lower } B B}{\text { MiddleB } B}
$$

where $U$ pper $B B$, Middle $B B$ and Lower $B B$ are upper, middle and lower Bollinger Bands values, respectively.

\subsection{MACD}

MACD, Moving Average Convergence/Divergence in long, is an indicator developed by Gerald Appel in late 1970s [35]. There are 3 components used in the calculation of MACD: the shorter and the longer moving average in a specified period, signal line. The difference of shorter and longer moving averages is known as MACD line. The signal line is the moving average of the MACD line in the specified period. Additionally, MACD histogram which is developed by Thomas Aspray, is used as a visual tool ; it is the difference of MACD line and signal line. The MACD line, signal line and MACD histogram are illustrated in figure 4.1 


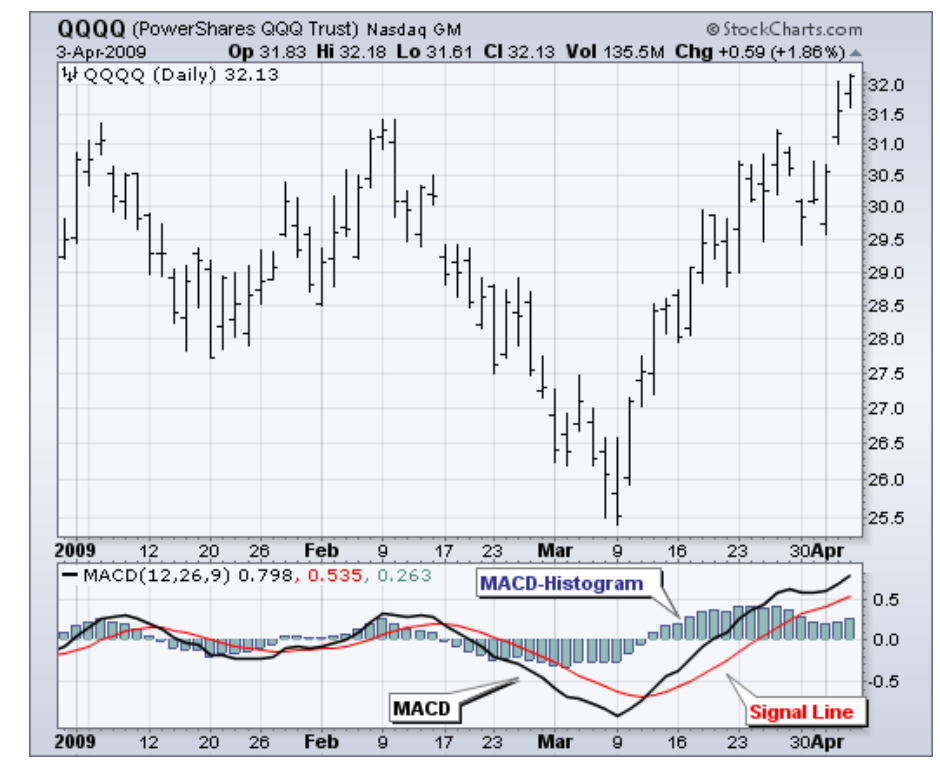

Figure 4.1: MACD, Signal Line and MACD Histogram [11]

The short and long term moving averages points out two different aspects of price: Short term moving average will reflect the price changes more rapidly while the long term moving average will make the current trend more visible. In this context, MACD indicator shows the strength and reflect the changes in the direction of the current trend [35, 11]. The calculation of MACD indicator with standard settings are as follows:

$$
\begin{gathered}
\text { MACDLine }=E M A(C l o s e, 12)-E M A(C l o s e, 26) \\
\text { SignalLine }=E M A(C l o s e, 9) \\
M A C D H \text { istogram }=\text { MACDLine }- \text { SignalLine }
\end{gathered}
$$

where $E M A(C l o s e, 9), E M A(C l o s e, 12)$ and $E M A(C l o s e, 26)$ are the exponential moving average of close prices in 9, 12 and 26 periods, respectively.

The period and type of moving averages are recommended by the author; they are subject to change. 


\subsection{RSI}

RSI which stands for Relative Strength Index is an indicator developed by J. Welles Wilder [36]. RSI grounds on Relative Strength (RS), which is the ratio of average gain divided by average loss in a specified period. RSI is a momentum indicator which reflects the speed and changes in price. It is also used to identify the overbought/oversold levels of price. RSI values oscillate between 0 and 100; 0 indicates the price is oversold and 100 indicates the price is overbought [11, 36]. The calculation of RSI indicator with standard settings is as follows:

$$
\begin{gathered}
\text { AverageGain }=((\text { AverageGain }(\text { prev })) * 13+\text { Gain }) / 14 \\
\text { AverageLoss }=((\text { AverageLoss }(\text { prev }) * 13+\text { Loss }) / 14 \\
R S=\text { AverageGain/AverageLoss } \\
R S I=100-\frac{100}{(1+R S)}
\end{gathered}
$$

In equations 4.9), 4.10) and 4.11), AverageGain and AverageLoss are the current average gain and loss in $N$ periods (i.e. 14 in the above calculation), AverageGain (prev) and AverageLoss(prev) are the previous period's average gain and loss, Gain and Loss are the positive and negative difference (in absolute value) between the current and previous period's close price, respectively. In equation 4.12, $R S$ is the relative strength and $R S I$ denotes the RSI value, respectively. In the standard calculations, the period is 14 which is subject to change.

\subsubsection{Figurelli RSI}

Figurelli RSI is an indicator derived from RSI which is developed by Rogerio Figurelli. The subtle difference from the original RSI is the introduction of a gain variable to detect the overbought/oversold conditions in longer time frames (e.g. 120) [37]. The calculation of the indicator is given in algorithm 1 . 


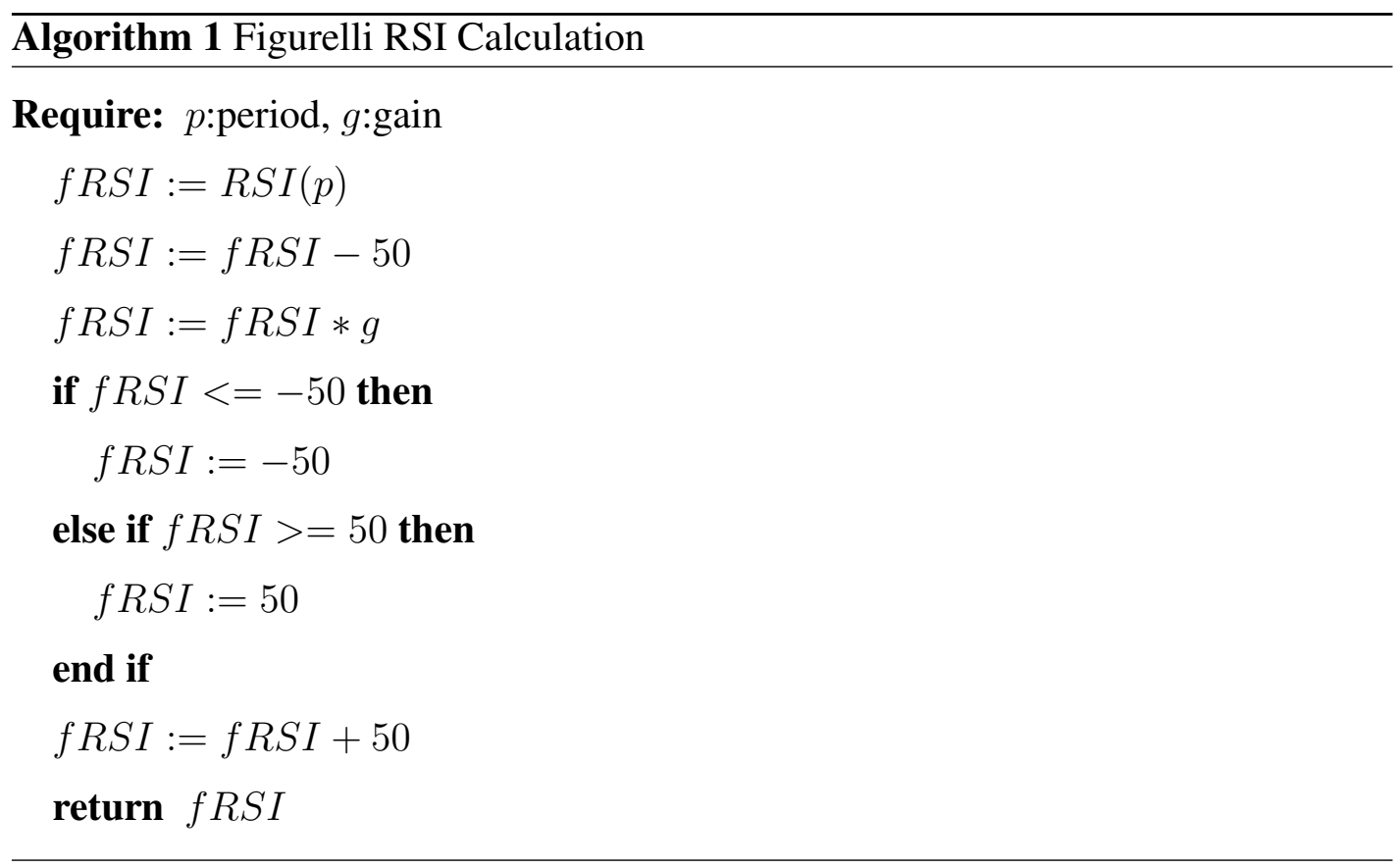

\subsection{ATR}

ATR, Average True Range in long, is an indicator developed by J. Welles Wilder [36]. It grounds on True Range (TR). TR is defined as the greatest of the following:

- Current period's highest price less the current period's lowest price

- Absolute value of current period's highest price less the previous period's close price

- Absolute value of current period's lowest price less the previous period's close price.

TR is illustrated in figure 4.2. True Range is a means of measuring the volatility of the price; the volatility (and hence the TR) increases/decreases directly proportional to the market activity. ATR is the smoothed moving average of the TR values [11, 36]. The standard calculation of ATR indicator is as follows:

$$
A T R=\frac{A T R(\text { prev }) \times(n-1)+T R}{n}
$$


where $A T R$ and $T R$ are the current period's ATR and TR value, $A T R($ prev) is the previous period's ATR value and $n$ is the moving average period.

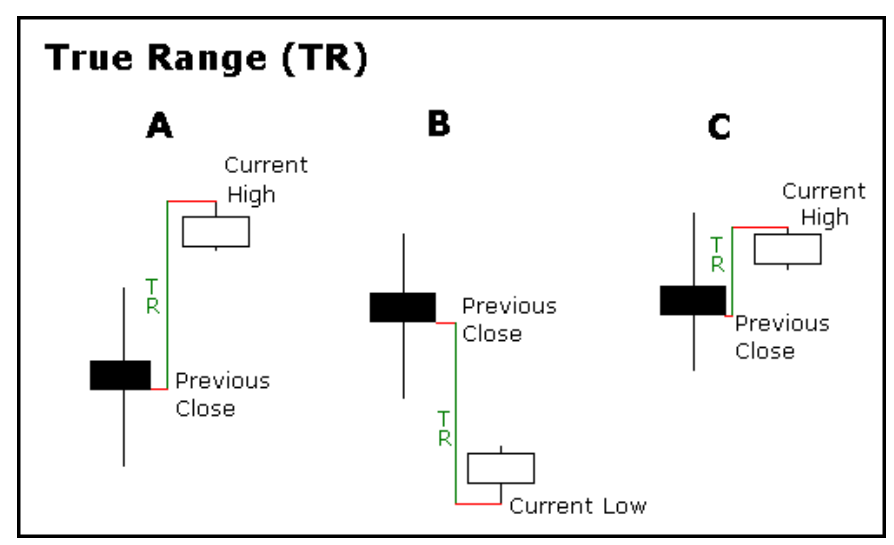

Figure 4.2: True Range (TR) [11]

\subsection{Chandelier Exit}

Chandelier Exit is an indicator first addressed and developed by Charles Lebeau and featured by Alexander Elder [38, 39]. It aims to keep the trend as much as possible and prevent an early exit in a long/short position. It is a volatility based indicator which grounds on the ATR (Average True Range) indicator. It consists of long and short exit points. When the price is in an uptrend, the long exit is placed below the highest price and when the price is in a downtrend, the short exit is placed above the lowest price in a specified period [11, 38, 39]. The standard calculation of the indicator is as follows:

$$
\begin{aligned}
& \text { ChandelierExit }(\text { long })=\text { Highest }(\text { Close }, 22)-\operatorname{ATR}(22) * 3 \\
& \text { ChandelierExit }(\text { short })=\operatorname{Lowest}(\text { Close }, 22)+A T R(22) * 3
\end{aligned}
$$

where $\operatorname{ATR}(22)$ is the average true range value in 22-periods, Highest(Close, 22) and Lowest (Close, 22) are the highest and lowest prices in 22-periods, respectively. The period (i.e. 22) and multiplier (i.e. 3) in the above calculation is the subject to change. 


\subsection{Psychological Line}

Psychological Line is an indicator developed by Ken Muranaka [40]. The indicator's values may range from 0 to 100 . It is a simple indicator which shows the number of increasing/decreasing prices over a specified period; thereby is a means for determining the overbought/oversold price level [30, 40]. The standard calculation of the indicator is as follows:

$$
P I=\frac{n}{12} * 100
$$

where $n$ is the number of days that the price is closed higher than the previous period. $n$ and the number of comparison days (i.e. 12) in the above calculation are subject to change.

\subsection{RVI}

RVI, which stands for Relative Volatility Index is an indicator developed by Donald Dorsey [41]. RVI values may range from 0 to 100 . The calculation of RVI is similar to RSI; RVI uses standard deviation of price changes where RSI uses average gain/average loss ratio. RVI is useful in measuring the direction (either up or down) of volatility and can be used as a confirming indicator with other indicators such as RSI, MACD [30, 41, 42]. The calculation of the indicator is as follows:

$$
\begin{aligned}
& U S D= \begin{cases}S D(\text { Close }, S) & \text { Close }>\text { Close }(\text { prev }) \\
0 & \text { Close } \leq \text { Close }(\text { prev })\end{cases} \\
& D S D= \begin{cases}S D(\text { Close }, S) & \text { Close }<\text { Close }(\text { prev }) \\
0 & \text { Close } \geq \text { Close }(\text { prev })\end{cases} \\
& U=S M M A(U S D, N) \\
& D=S M M A(D S D, N)
\end{aligned}
$$




$$
R V I=100 * \frac{U}{U+D}
$$

In equations 4.13) and 4.14, $S$ is the standard deviation period, $S D(C l o s e, S)$ is the standard deviation of the close price values in $S$ period, $U S D$ is the upward standard deviation, $D S D$ is the downward standard deviation, Close is the current period close price and Close (prev) is the previous period close price, respectively. In equations (4.15) and 4.16, $U$ and $D$ denotes upward and downward price changes, $N$ is the smoothed moving average period, $S M M A(U S D, N)$ and $S M M A(D S D, N)$ is the smoothed moving average of $U S D$ and $D S D$ values in $\mathrm{N}$ periods, respectively. In equation (4.17), $R V I$ stands for relative volatility index. The standard values of $S$ and $N$ suggested by the author are 10 and 14 which are subject to change.

\subsection{Stochastic Oscillator}

Stochastic Oscillator (a.k.a. Lane's Stochastics) is an indicator developed by George Lane in late 1950s [11]. Stochastic Oscillator values may range from 0 to 100 . It points the location of the price in the highest high price - lowest low price range. Stochastic Oscillator consists of 2 components: $\% \mathrm{~K}$ and $\% \mathrm{D}$. \% $\mathrm{K}$ corresponds to the base calculation -the location of the price- and $\% \mathrm{D}$ smooths the $\% \mathrm{~K}$ value. There are 2 versions of Stochastic Oscillator: Fast and slow; they differ in smoothing \% $\mathrm{K}$ value [11, 30]. The standard calculation of the indicator is as follows:

$$
\begin{gathered}
\% K=\frac{\text { Close }-L L(p)}{H H(p)-L L(p)} * 100 \\
\% D=S M A(\% K, 3)
\end{gathered}
$$

where $S M A(\% K, 3)$ is the simple moving average of $\% K$ in 3 periods, Close is the current close price, $p$ is the number of look back periods, $L L(p)$ is the lowest price low and $H H(p)$ is the highest price high in p periods, respectively.

The standard calculation corresponds to the Fast Stochastic Oscillator. If \%K value is smoothed, it is called Slow Stochastic Oscillator. The $\mathrm{p}$ in $\% \mathrm{~K}$ calculation, the smoothing period (i.e. 3), type (i.e. SMA) are standard values suggested by the author; these are subject to change. 


\subsection{Ultimate Oscillator}

Ultimate Oscillator is an indicator developed in 1976 and featured and published in 1985 by Larry Williams [43]. Ultimate Oscillator values may range from 0 to 100. It is based on the average ratio of two components: BP (Buying Pressure) and TR (True Range, explained in ATR indicator). BP shows the direction of the price (upward or downward) whereas TR shows the magnitude of the gain/loss. Ultimate Oscillator calculates a weighted average of the average ratio of BP divided by TR in 3 different time frames; the shorter the time frame, the more the weighting [11, 43]. The calculation of the indicator is as follows:

$$
\begin{array}{r}
B P=\text { Close }-M I N(\text { Low }, \text { Close }(\text { prev })) \\
\text { Average } 7=\frac{S U M(B P, 7)}{S U M(T R, 7)} \\
\text { Average } 14=\frac{S U M(B P, 14)}{S U M(T R, 14)} \\
\text { Average } 14=\frac{S U M(B P, 14)}{S U M(T R, 14)} \\
U O=100 * \frac{(4 * \text { Average } 7)+(2 * \text { Average } 14)+\text { Average } 28}{4+2+1}
\end{array}
$$

In equation (4.18), $B P$ denotes the buying pressure, Close denotes the current close price, Low denotes the current low price and Close(prev) denotes the previous period close price, respectively. In equations 4.19, 4.20) and 4.21), $S U M(B P, N)$ is the sum of BP values in periods and $\operatorname{SUM}(T R, N)$ is the sum of TR values i $N$ periods, respectively. In equation 4.22, Average7, Average 14 and Average 28 denotes the average $B P$ to $T R$ ratios in 7, 14 and 28 periods and $U O$ denotes the ultimate oscillator value. The $N$ values (i.e. 7, 14 and 28) and the weights (i.e. 4, 2 and 1) are standard settings suggested by the author; these are subject to change.

\subsection{Rate of Change}

Rate of Change, shortly ROC, is an indicator which measures the percentage of direction of price (either upward or downward) in a direct way. It compares the current 
close price and the close price $\mathrm{n}$ periods ago; thereby provide a means to determine the price changes in a specified period [11, 30]. The calculation of the indicator is as follows:

$$
R O C=\frac{\text { Close }- \text { Close }(\text { prev }, N)}{C l o s e(\text { prev }, N)} * 100
$$

where $N$ is the period, $R O C$ is the rate of change value, Close is the current close price and $C l o s e($ prev,$N)$ is the close price $N$ periods ago.

\subsection{DeMarker}

DeMarker (a.k.a. TD DeMarker I) is an indicator developed by Thomas R. DeMark [44]. DeMarker values may range from 0 to 1 . DeMarker indicator depends on two components: the difference of current and previous price high (i.e. DeMax value) and current and previous price low (i.e. DeMin value). DeMarker measures the strength of the trend and price changes by comparing the moving average of price maxima and minima [44, 45]. The calculation of the indicator is as follows:

$$
\begin{gathered}
\text { DeMax }= \begin{cases}\text { High }- \text { High }(\text { prev }), & \text { High }>\text { High(prev }) \\
0, & \text { otherwise }\end{cases} \\
\text { DeMin }= \begin{cases}\text { Low }(\text { prev })-\text { Low }, & \text { Low }<\text { Low }(\text { prev }) \\
0, & \text { otherwise }\end{cases} \\
\text { DeMarker }=\frac{\text { SMA }(\text { DeMax }, N)}{S M A(D e M a x, N)+S M A(\operatorname{DeMin}, N)}
\end{gathered}
$$

In equation (4.23), DeMax denotes the DeMax value, High denotes the current price high and High(prev) denotes the previous period price high. In equation (4.24), DeMin denotes the DeMin value, Low denotes the current price low and Low (prev) denotes the previous period price low. In equation 4.25, DeMarker denotes the DeMarker value, $N$ is the moving average period, $S M A(\operatorname{DeMax}, N)$ 
and $S M A(\operatorname{DeMin}, N)$ denotes the simple moving average of DeMax and DeMin values in $N$ periods, respectively.

\subsection{Relative Vigor Index}

Relative Vigor Index is an indicator developed by John Ehlers [46]. The main idea behind the indicator is that the price tends to close higher than open price in a bull market and close lower than open price in a bear market. In a sense, the vigor (strength, energy) of the price comes to light in the price close. Relative Vigor Index basically grounds on the ratio of the difference of price close and open divided by the difference of price high and low in a specified period. There are two components of the indicator: RVI and RVI signal [31, 46]. The calculation of the indicator is as follows:

$$
\begin{array}{r}
\text { Num }=(\text { Close }- \text { Open })+2 *(\text { Close }(\text { prev }, 1)-\text { Open }(\text { prev }, 1)) \\
+2 *(\text { Close }(\text { prev }, 2)-\text { Open }(\text { prev }, 2))+(\text { Close }(\text { prev }, 3)-O p e n(\text { prev }, 3))
\end{array}
$$

$$
\begin{gathered}
\text { Denom }=(\text { High }- \text { Low })+2 *(\text { High }(\text { prev }, 1)-\text { Low }(\text { prev }, 1)) \\
+2 *(\text { High }(\text { prev }, 2)-\operatorname{Low}(\text { prev }, 2))+(\text { High }(\text { prev }, 3)-\text { Low }(\text { prev }, 3)) \\
R V i g I=\frac{S U M(N u m, p)}{S U M(\text { Denom }, p)} \\
\text { RVigISignal }=(\text { RVigI }+2 * R V i g I(\text { prev }, 1) \\
+2 * R V i g I(\text { prev }, 2)+R V i g I(\text { prev }, 3)) / 6
\end{gathered}
$$

In equation (4.26), Num denotes the numerator which is the weighted total of price close and open differences, Close and Open denote the current period's close and open prices, Close (prev, $n)$ and Open $($ prev, $n$ ) denote the close and open prices of $n$ periods ago, respectively. In equation (4.27), Denom denotes the denominator which is the weighted total of price high and low differences, High and Low denote the current period's highest and lowest prices, $\operatorname{High}($ prev, $n)$ and Low (prev, $n)$ denote the highest and lowest prices of $n$ periods ago, respectively. In equation (4.28), RVigI denotes the current period's RVigI (Relative Vigor Index) value, $S U M(N u m, p)$ and 
$S U M($ Denom, $p)$ are the sum of Num and Denom values in $p$ periods, respectively. In equation (4.29), RVigISignal and RVigI are the current period's RVigI signal and RVigI values, respectively and $R V I($ prev,$n)$ denotes the RVI value $n$ periods ago.

\subsection{MFI}

MFI, Money Flow Index in long, is a volume based indicator developed by Gene Quong and Avrum Soudack [47]. MFI values may range from 0 to 100. MFI grounds on money flow which consists of typical price and volume; typical price is calculated as the average of the close, highest and lowest price in a specified period. The authors entitled MFI as volume-weighted RSI when the indicator was published for the first time; hence it has similarities with RSI. RSI is based on RS which is the ratio of average gain divided by average loss. Similarly, MFI uses Money Flow Ratio, which is the ratio of positive money flow divided by negative Money flow.

MFI can be used to detect the overbought/oversold levels of the price; values close to 100 shows an overbought level and signals a sell while values close to 0 signals an oversold level and is a sign for buy. Volume brings in an early chance to detect the overbought/oversold levels since volume leads prices [11, 47]. The calculation of the indicator with the standard settings is as follows:

$$
\begin{gathered}
\text { TypicalPrice }=(\text { High }+ \text { Low }+ \text { Close }) / 3 \\
\text { RawMoneyFlow }=\text { TypicalPrice } * \text { Volume } \\
\text { PositiveMoneyFlow }= \begin{cases}\text { RawMoneyFlow, } & \text { Close }- \text { Close }(\text { prev })>0 \\
0, & \text { otherwise }\end{cases} \\
\text { NegativeMoneyFlow }= \begin{cases}\text { RawMoneyFlow, } & \text { Close }- \text { Close }(\text { prev })<0 \\
0, & \text { otherwise }\end{cases} \\
\text { MoneyFlowRatio }=\frac{S U M(\text { PositiveMoneyFlow }, 14)}{S U M(\text { NegativeMoneyFlow }, 14)}
\end{gathered}
$$




$$
M F I=100-\frac{100}{(1+\text { MoneyFlowRatio })}
$$

In equations (4.30) and 4.31, TypicalPrice and RawMoneyFlow denote the typical price and typical price used in the calculations, Volume is the volume in the current period, Close, High and Low are the close, highest and lowest price in the current period, respectively. In equations (4.32) and (4.33), Close is the current period's close price, Close (prev) is the previous period's close price, PositiveMoneyFlow denotes the raw money flow if the close price increases compared to the previous period and NegativeMoneyFlow denotes the raw money flow if the close price decreases compared to the previous period. In equations (4.34) and (4.35), SUM(PositiveMoneyFlow, 14) and SUM(NegativeMoneyFlow, 14) denote the sum of positive and negative money flows in the specified period (i.e. 4 above), MoneyFlowRatio denotes the ratio of sum of positive money flow divided by sum of negative money flow and MFI denotes the Money Flow Index value. In the standard calculations, the period is 14 which is subject to change.

\subsection{OBV}

OBV which stands for On-Balance Volume is an indicator developed by Joe Granville in 1963 [48]. It is an elementary indicator based on volume. OBV measures the running total of raw volume continuously; if the price increases compared to the previous period, the running total increases and vice versa. As the author stated, the volume precedes the price. Therefore, if the running volume total increases, it is a signal for a possible uptrend and if the running volume total decreases, it is a signal for a possible downtrend [11, 48]. The calculation of the indicator is as follows:

$$
O B V= \begin{cases}O B V(\text { prev })+\text { Volume }, & \text { Close }- \text { Close }(\text { prev })>0 \\ O B V(\text { prev })-\text { Volume }, & \text { Close }- \text { Close }(\text { prev })<0 \\ O B V(\text { prev }), & \text { otherwise }\end{cases}
$$

where Volume is the current period's volume, Close and Close(prev) are the current and previous period's close prices, $O B V$ and $O B V($ prev) are the current and 
previous period's on-balance volume values, respectively.

\subsection{ADL}

ADL which stands for Accumulation Distribution Line, is an indicator developed by Marc Chaikin [30]. ADL is an indicator which is based on money flow volume. Money flow volume measures the position of the close price relative to the maximum and minimum price of the period weighted with volume. ADL is calculated by taking a running total of the money flow volume values [11, 30]. The calculation of the indicator is as follows:

$$
\begin{gathered}
\text { MFMult }=\frac{(\text { Close }- \text { Low })-(\text { High }- \text { Close })}{H i g h-\text { Low }} \\
M F V o l=M F M u l t * \text { Volume } \\
A D L=A D L(\text { prev })+\text { MFVol }
\end{gathered}
$$

In equation (4.36), MFMult denotes the money flow multiplier, Close, High and Low denote the current period's close, highest and lowest prices, respectively. In equation (4.37), $M F V o l$ denotes the money flow volume and Volume denotes the current period's volume. In equation (4.38), $A D L$ and $M F V o l$ denote the current period's ADL and money flow volume and $A D L$ (prev) denotes the previous period's ADL value.

\subsection{Chaikin Oscillator}

Chaikin Oscillator is an indicator developed by Marc Chaikin [11]. Chaikin Oscillator is based on ADL which is one of the indicators developed by the same author. It is found simply by subtracting the longer period exponential moving average of ADL values from the shorter period exponential moving average ADL values in the specified periods. Chaikin Oscillator is a derived indicator which shows the momentum of ADL values; thereby shows the buying/selling pressure of increasing/decreasing 
ADL values in a smoothed manner [11]. The standard calculation of the indicator is as follows:

$$
\text { ChaikinOscillator }=E M A(A D L, 3)-E M A(A D L, 10)
$$

where ChaikinOscillator is the chaikin oscillator value, $E M A(A D L, 3)$ and $E M A$ $(A D L, 10)$ are the exponential moving average of ADL indicator values in 3 periods. The periods (i.e. 3 and 10 above) are standard settings suggested by the author; these are subject to change.

\subsection{CMF}

CMF, Chaikin Money Flow in long, is an indicator developed by Marc Chaikin [11]. It is an indicator based on Money Flow Volume mentioned in ADL indicator. It differs from ADL indicator in that the running total of Money Flow Volume values are calculated in ADL whereas the the total Money Flow Volume values are divided by the volume total in a specified period in CMF. CMF measures buying and selling pressure in a smoothed manner; thereby avoiding the pitfall of sudden price and volume changes [11]. The standard calculation of the indicator is as follows:

$$
\begin{gathered}
\text { MFMult }=\frac{(\text { Close }- \text { Low })-(\text { High }- \text { Close })}{\text { High }- \text { Low }} \\
M F V o l=M F M u l t * \text { Volume } \\
C M F=S U M(M F V o l, 20) / S U M(\text { Volume }, 20)
\end{gathered}
$$

In equation (4.39), MFMult denotes the money flow multiplier, Close, High and Low denote the current period's close, highest and lowest prices, respectively. In equation 4.40, $M F V$ ol denotes the money flow volume and Volume denotes the current period's volume. In equation (4.41), $C M F$ denotes the current period's CMF value, $S U M(M F V o l, 20)$ and $S U M($ Volume, 20$)$ denote the sum of money flow volume and volume values in 20 periods, respectively. The period is 20 in the standard calculations which is subject to change. 


\subsection{EMV}

EMV, which stands for Ease of Movement, is an indicator developed by Richard Arms [49]. EMV originates in the Equivolume charts of the author which incorporates the volume, highest and lowest price in a specified period. It is a volume based indicator which incorporates highest and lowest prices in a specified period to measure the "ease of movement" of close price. The close price is increasing relatively easy when the price range between high and low prices are relatively large and volume relatively small [11, 30, 49]. The calculation of the indicator is as follows:

$$
\begin{gathered}
\text { DistanceMoved }=\frac{\text { High }+ \text { Low }}{2}-\frac{\text { High }(\text { prev })+\text { Low }(\text { prev })}{2} \\
\text { BoxRatio }=\frac{\text { Volume }}{\text { High }- \text { Low }} \\
E M V=\frac{\text { DistanceMoved }}{\text { BoxRatio }}
\end{gathered}
$$

In equation 4.42 and (4.43), High, Low are the highest and lowest prices in the current period, DistanceMoved denotes high-low price range and BoxRatio is the box ratio which makes a reference to box ratio in Equivolume charts. In equation (4.44) $E M V$ denotes the EMV value which is the ratio of DistanceMoved divided by BoxRatio. 


\section{CHAPTER 5}

\section{TRADING RULES BASED ON TECHNICAL INDICATORS}

A trading rule is simply a rule which is based on the values of indicators and/or price in technical analysis parlance. It generates buy and sell signals according to the steps defined in. A signal is a suggestion to open a position in the market. There are 3 types of signals: Buy, sell and hold. A buy or sell signal is active which suggests to buy or sell while a hold signal is passive which means "do nothing". A trading rule may be straightforward such as comparing the indicator value with a limit value or may be complex such as looking for a special shaped pattern in the price.

In this chapter, the following three types of trading rules are explained: Crossover rules, rules based on Bollinger Bands, \%b and Bandwidth indicators, divergence rules. All three types are explained in the related sections.

A trading rule generates buy/sell signals in different fashions called trading strategy. In this thesis, two trading strategies are entitled: "Always in the market" and "First buy, then sell". In "Always in the market" strategy, a buy/sell signal is followed by a closing sell/buy signal (i.e. the opposite of the first signal), where the last signal doesn't only close the trade but also opens a new position. As an example, suppose DeMarker Crossover generates a buy signal. The next sell signal closes the active trade and also opens a short position (i.e. as a result of sell order). The second type of trading strategy "First buy, then sell" is rather simple. In "First buy, then sell" strategy, a buy signal should be generated to open a trade which is followed by a closing sell signal. 


\subsection{Crossover Rules}

Crossover Rules are trading rules which appear in two situations:

- When a time series (either indicator or price) crosses above/below another time series (either indicator or price)

- When an indicator time series crosses above/below a predefined threshold/limit value

In this section, 22 trading rules are explained. Among them, the following 6 rules differ in that they use volume information: MFI, OBV, ADL, Chaikin Oscillator, CMF and EMV Crossovers. In forex, volume information is not exactly known like other markets such as stock market, gold/valuable market etc. The reason is that forex has a decentralized market structure which makes it almost impossible to have the full volume information. On the other hand, many forex brokers provide tick volume. Tick volume is a term which denotes the number of changes in price in a specified period. Tick volume is generally used as volume information by traders in forex. Besides tick volume, 1-day ATR indicator values can be used as volume explained in [50]. In this thesis, tick volume and 1-day ATR values (entitled as ATR volume) are the choices provided as volume in the aforementioned rules. In detail, there are 5 choices for the selection of volume: Tick volume (alone), ATR volume (alone), arithmetic mean, harmonic mean and geometric mean of ATR and tick volume.

In all the trading rules covered in this section, "Always in the market" is the preferred trading strategy.

\subsubsection{Moving Average Price Crossover}

The moving average price crossover is a trading rule based on the moving average indicator [11]. Firstly, the moving average indicator values are calculated throughout the price data. In order to calculate the indicator values, two user defined parameters are needed: moving average period and type. Next, the indicator values are used to generate buy/sell signals using the following strategy: 
- When the current price crosses above the current moving average indicator value, a buy signal is generated.

- Conversely, when the current price crosses below the current moving average indicator value, a sell signal is generated [11].

The rule is illustrated in figure 5.1 .

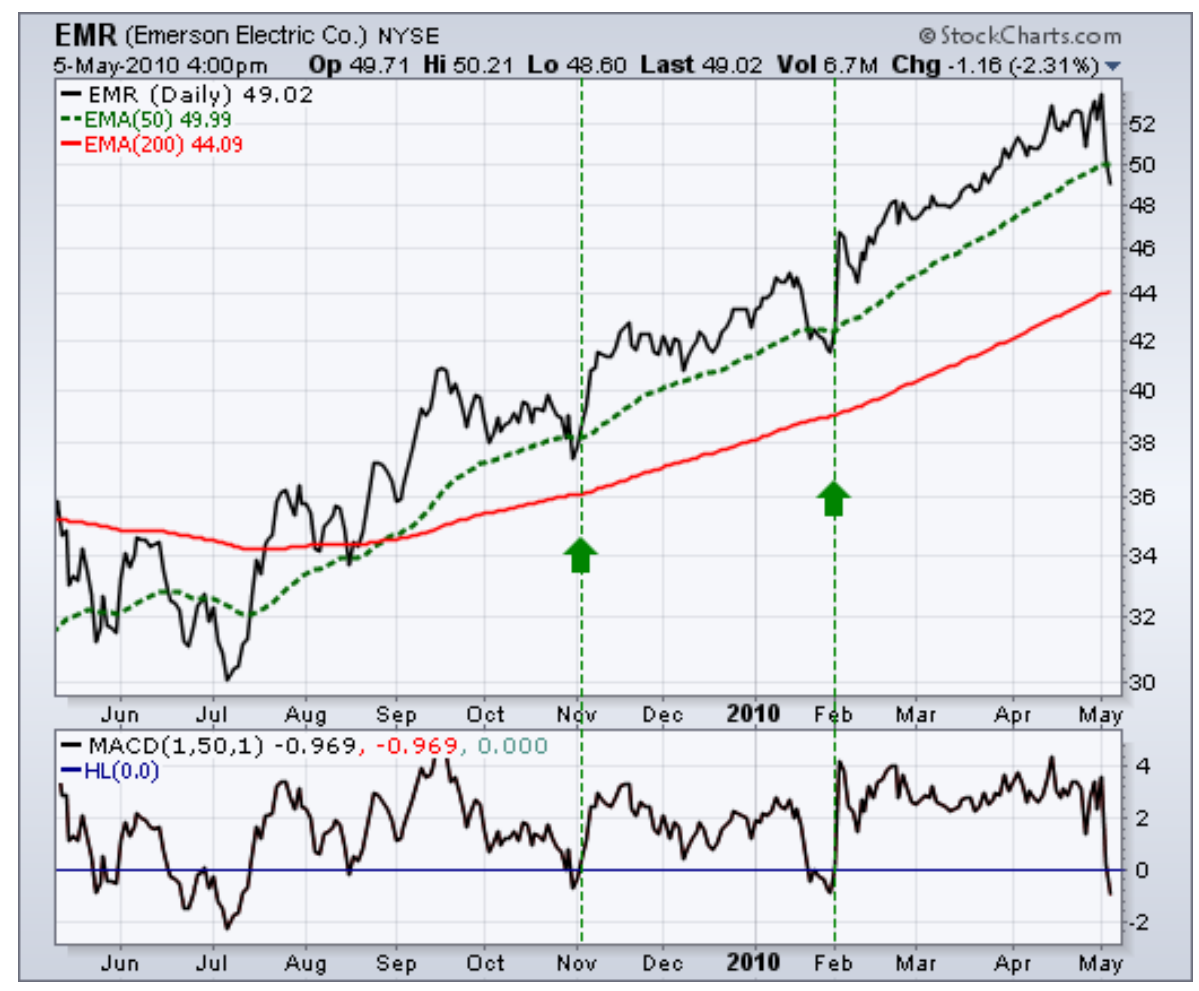

Figure 5.1: Moving Average Price Crossover [11]

\subsubsection{Double Moving Average Crossover}

The double moving average crossover is a trading rule based on the moving average indicator [10]. Firstly, the moving average indicator values for short and long period are calculated throughout the price data. In order to calculate these values, three user defined parameters are needed: short and long moving average period, moving average type. Next, the short and long period indicator values are used to generate buy/sell signals using the following strategy: 
- When the short period moving average value crosses above the long period moving average indicator value, a buy signal is generated.

- Conversely, when the short period moving average value crosses below the long period moving average indicator value, a sell signal is generated [11, 10].

The rule is illustrated in figure 5.2

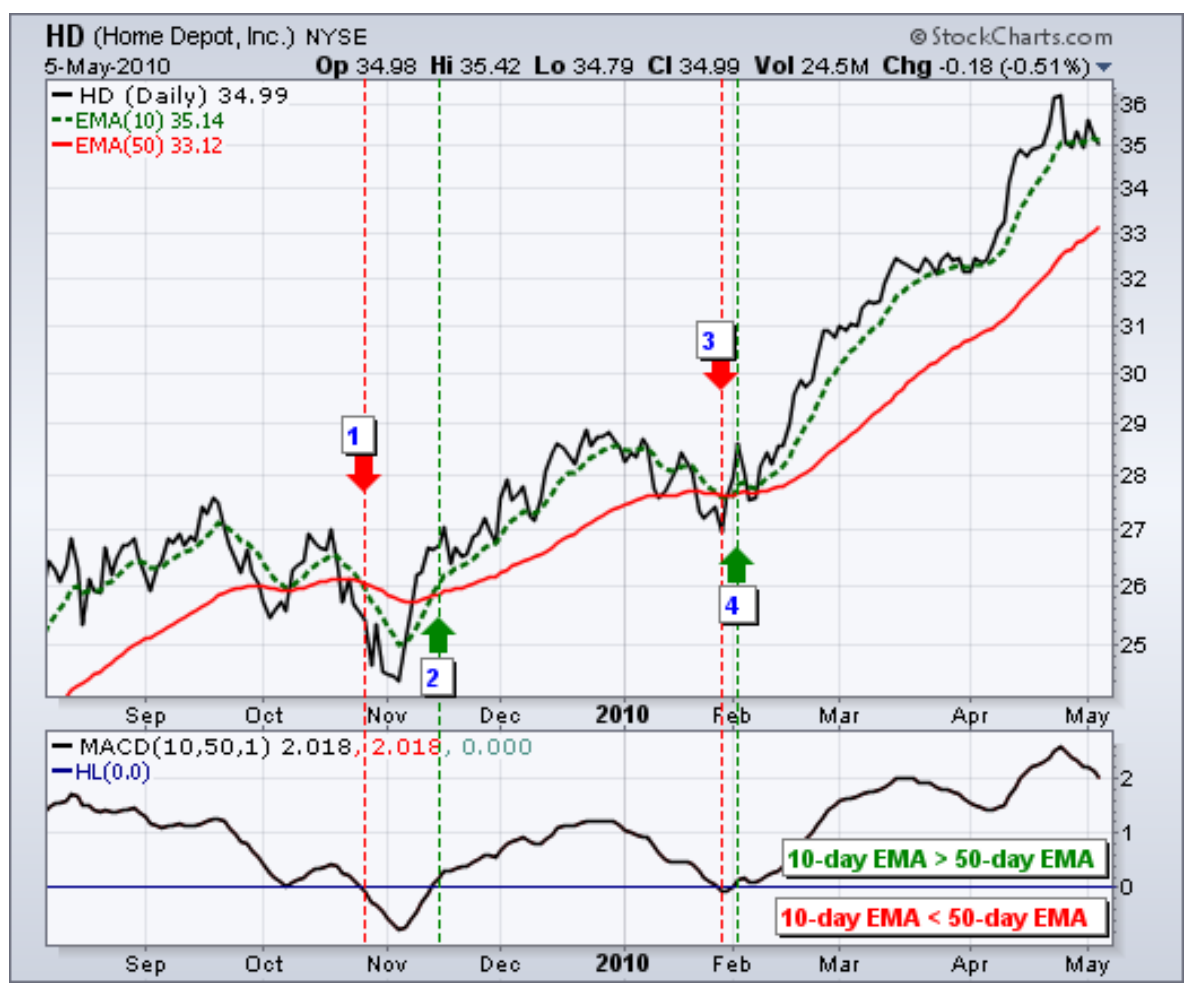

Figure 5.2: Double Moving Average Crossover [11]

\subsubsection{Triple Moving Average Crossover}

The triple moving average crossover is a trading rule based on moving average indicator [10]. Firstly, the moving average indicator values for short, medium and long period are calculated throughout the price data. In order to calculate these values, four user defined parameters are needed: short, medium and long moving average period, moving average type. Next, the short, medium and long period indicator values are used to generate buy/sell signals using the following strategy: 
- When the short period moving average value crosses above the medium and long period moving average indicator values, a buy signal is generated.

- Conversely, when the short period moving average value crosses below the medium and long period moving average indicator values, a sell signal is generated [11, 51, 10].

The rule is illustrated in figure 5.3 .

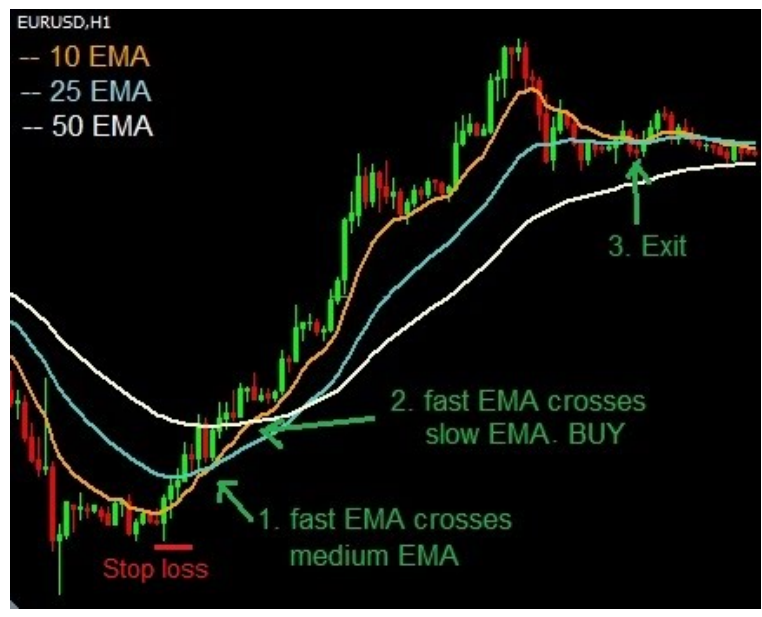

Figure 5.3: Triple Moving Average Crossover [51]

\subsubsection{Moving Average Envelopes Crossover}

Moving Average Envelopes Crossover is a trading rule based on moving average envelopes indicator [52]. Firstly, the moving average, upper and lower envelopes values of moving average indicator are calculated throughout the price data. In order to calculate the indicator values, three user defined parameters are needed: moving average period, moving average type and percentage factor. Next, the indicator values are used to generate buy/sell signals using the following strategy:

- When the moving average value crosses above the upper envelope value of moving average envelopes indicator, a buy signal is generated.

- When the moving average value crosses below the lower envelope value of moving average envelopes indicator, a sell signal is generated. [52]. 


\subsubsection{TEMA Crossover}

TEMA Crossover is a trading rule based on TEMA (Triple exponential moving average) indicator [33]. Firstly, the values of TEMA indicator are calculated throughout the price data. In order to calculate the indicator values, user defined moving average period parameter is needed. Next, the indicator values are used to generate buy/sell signals using the following strategy:

- When the current price crosses above the current TEMA indicator value, a buy signal is generated.

- Conversely, when the current price crosses below the current TEMA indicator value, a sell signal is generated [30, 33].

\subsubsection{MACD Crossover}

MACD Crossover is a trading rule based on MACD (Moving average convergence divergence) indicator [35]. Firstly, the MACD Line and Signal Line values of MACD indicator are calculated throughout the price data. In order to calculate the indicator values, three user defined parameters are needed: short, long and signal line moving average periods. Next, the indicator values are used to generate buy/sell signals using the following strategy:

- When the MACD Line value crosses above the Signal Line value of MACD indicator, a buy signal is generated.

- Conversely, when the MACD Line value crosses below the Signal Line value of MACD indicator, a sell signal is generated [11, 35].

\subsubsection{RSI Crossover}

RSI Crossover is a trading rule based on RSI (Relative strength index) indicator [36]. Firstly, the RSI indicator values are calculated throughout the price data. In order to calculate the indicator values, user defined period parameter (which is used to 
calculate average gain and loss) is needed. Next, user defined buy and sell limits are set. Using the indicator values and buy/sell limits, the strategy to generate buy/sell signals is as follows:

- When the RSI value crosses below the buy limit value, a buy signal is generated.

- When the RSI value crosses above the sell limit value, a sell signal is generated $[11,36]$.

\subsubsection{Figurelli RSI Crossover}

Figurelli RSI Crossover is a trading rule based on Figurelli RSI indicator [37]. Firstly, the Figurelli RSI indicator values are calculated throughout the price data. In order to calculate the indicator values, two user defined parameters are needed: period (which is used to calculate average gain and loss) and gain. Next, user defined buy and sell limits are set. Using the indicator values and buy/sell limits, the strategy to generate buy/sell signals is as follows:

- When the Figurelli RSI value crosses below the buy limit value, a buy signal is generated.

- When the Figurelli RSI value crosses above the sell limit value, a sell signal is generated [37].

\subsubsection{Chandelier Exit Crossover}

Chandelier Exit Crossover is a trading rule based on Chandelier Exit indicator [38, 39]. Firstly, the chandelier exit long and chandelier exit short values of Chandelier Exit indicator are calculated throughout the price data. In order to calculate the indicator values, two user defined parameters are needed: ATR period (to calculate ATR values) and multiplier. Next, the indicator values are used to generate buy/sell signals using the following strategy:

- When the current price crosses below the current chandelier exit long value, a buy signal is generated. 
- When the current price crosses above the current chandelier exit short value, a sell signal is generated [11, 38, 39].

\subsubsection{Psychological Line Crossover}

Psychological Line Crossover is a trading rule based on Psychological Line indicator [40]. Firstly, the Psychological Line indicator values are calculated throughout the price data. In order to calculate the indicator values, user defined period parameter is needed. Next, user defined buy and sell limits are set. Using the indicator values and buy/sell limits, the strategy to generate buy/sell signals is as follows:

- When the Psychological Line indicator value crosses below the buy limit value, a buy signal is generated.

- When the Psychological Line indicator value crosses above the sell limit value, a sell signal is generated [30, 40].

\subsubsection{RVI Crossover}

RVI Crossover is a trading rule based on RVI (Relative volatility index) indicator [41, 30]. Firstly, the RVI indicator values are calculated throughout the price data. In order to calculate the indicator values, two user defined parameters are needed: standard deviation period (to calculate the USD and DSD values) and smoothing period (to calculate $U$ and D values). Next, user defined buy and sell limits are set. Using the indicator values and buy/sell limits, the strategy to generate buy/sell signals is as follows:

- When the RVI indicator value crosses above the buy limit value, a buy signal is generated.

- When the RVI indicator value crosses below the sell limit value, a sell signal is generated [41, 42]. 


\subsubsection{Stochastics Oscillator Crossover}

Stochastics Oscillator Crossover is a trading rule based on Stochastics Oscillator indicator [30]. Firstly, the $\% \mathrm{~K}$ values of Stochastic Oscillator indicator are calculated throughout the price data. In order to calculate the indicator values, three user defined parameters are needed: look back period (to calculate $\% \mathrm{~K}$ values), moving average type and period (to smooth \% K values). Next, user defined buy and sell limits are set. Using the indicator values and buy/sell limits, the strategy to generate buy/sell signals is as follows:

- When the $\% \mathrm{~K}$ value crosses below the buy limit value, a buy signal is generated.

- When the $\% \mathrm{~K}$ value crosses above the sell limit value, a sell signal is generated [11].

\subsubsection{Ultimate Oscillator Crossover}

Ultimate Oscillator Crossover is a trading rule based on Ultimate Oscillator indicator [43]. Firstly, the Ultimate Oscillator indicator values are calculated throughout the price data. In order to calculate the indicator values, three user defined parameters are needed: short, medium and long period BP to TR ratio. Next, user defined buy and sell limits are set. Using the indicator values and buy/sell limits, the strategy to generate buy/sell signals is as follows:

- When the Ultimate Oscillator indicator value crosses below the buy limit value, a buy signal is generated.

- When the Ultimate Oscillator indicator value crosses above the sell limit value, a sell signal is generated [11, 30, 43].

\subsubsection{Rate of Change Crossover}

Rate of Change Crossover is a trading rule based on Rate of Change indicator [30]. Firstly, the Rate of Change indicator values are calculated throughout the price data. 
In order to calculate the indicator values, user defined period parameter is needed. Next, user defined buy and sell limits are set. Using the indicator values and buy/sell limits, the strategy to generate buy/sell signals is as follows:

- When the Rate of Change indicator value crosses below the buy limit value, a buy signal is generated.

- When the Rate of Change indicator value crosses above the sell limit value, a sell signal is generated [11, 30].

\subsubsection{DeMarker Crossover}

DeMarker Crossover is a trading rule based on DeMarker indicator [44]. Firstly, the DeMarker indicator values are calculated throughout the price data. In order to calculate the indicator values, user defined period parameter is needed. Next, user defined buy and sell limits are set. Using the indicator values and buy/sell limits, the strategy to generate buy/sell signals is as follows:

- When the DeMarker indicator value crosses below the buy limit value, a buy signal is generated.

- When the DeMarker indicator value crosses above the sell limit value, a sell signal is generated [44, 45].

\subsubsection{Relative Vigor Index Crossover}

Relative Vigor Index (RVigI in short) Crossover is a trading rule based on Relative Vigor Index indicator [46]. Firstly, the RVigI and RVigI Signal values of Relative Vigor Index indicator are calculated throughout the price data. In order to calculate the indicator values, user defined period parameter is needed. Next, user defined buy and sell limits are set. Using the indicator values and buy/sell limits, the strategy to generate buy/sell signals is as follows:

- When the RvigI value is less than the buy limit and RVigI value crosses above the RVigI Signal value, a buy signal is generated. 
- When the RvigI value is greater than the sell limit and RVigI value crosses below the RVigI Signal value, a sell signal is generated [31, 46].

\subsubsection{MFI Crossover}

MFI Crossover is a trading rule based on MFI indicator [47]. Firstly, the MFI indicator values are calculated throughout the price data. In order to calculate the indicator values, two user defined parameters are needed: period (to calculate Money Flow Ratio) and volume type. Next, user defined buy and sell limits are set. Using the indicator values and buy/sell limits, the strategy to generate buy/sell signals is as follows:

- When the MFI indicator value crosses below the buy limit value, a buy signal is generated.

- When the MFI indicator value crosses above the sell limit value, a sell signal is generated [11, 47].

\subsubsection{OBV Crossover}

OBV Crossover is a trading rule based on OBV indicator [48]. Firstly, the OBV indicator values are calculated throughout the price data. In order to calculate the indicator values, user defined volume type parameter is needed. Next, user defined moving average period and type of OBV values are set to create a moving average of OBV values. Using the OBV values and moving average of OBV values, the strategy to generate buy/sell signals is as follows:

- When the OBV indicator value crosses above its previous period's moving average value, a buy signal is generated.

- When the OBV indicator value crosses below its previous period's moving average value, a sell signal is generated [11, 30, 48]. 


\subsubsection{ADL Crossover}

ADL Crossover is a trading rule based on ADL indicator [30]. Firstly, the ADL indicator values are calculated throughout the price data. In order to calculate the indicator values, user defined volume type parameter is needed. Next, user defined moving average period and type of ADL values are set to create a moving average of ADL values. Using the ADL values and moving average of ADL values, the strategy to generate buy/sell signals is as follows:

- When the ADL indicator value crosses above its previous period's moving average value, a buy signal is generated.

- When the ADL indicator value crosses below its previous period's moving average value, a sell signal is generated [11, 30].

\subsubsection{Chaikin Oscillator Crossover}

Chaikin Oscillator Crossover is a trading rule based on Chaikin Oscillator indicator [11]. Firstly, the ADL indicator values are calculated throughout the price data. In order to calculate the ADL indicator values, user defined volume type parameter is needed. Next, Chaikin Oscillator indicator values are calculated using two user defined parameters: fast and slow EMA periods of ADL values. Following, user defined buy and sell limits are set. Using the Chaikin Oscillator indicator values and buy/sell limits, the strategy to generate buy/sell signals is as follows:

- When the Chaikin Oscillator indicator value crosses above the buy limit value, a buy signal is generated.

- When the Chaikin Oscillator indicator value crosses below the sell limit value, a sell signal is generated [11]. 


\subsubsection{CMF Crossover}

CMF Crossover is a trading rule based on CMF indicator [11]. Firstly, the CMF indicator values are calculated throughout the price data. In order to calculate the indicator values, two user defined parameters are needed: sum of Money flow volume period and volume type. Next, user defined buy and sell limits are set. Using the indicator values and buy/sell limits, the strategy to generate buy/sell signals is as follows:

- When the CMF indicator value crosses above the buy limit value, a buy signal is generated.

- When the CMF indicator value crosses below the sell limit value, a sell signal is generated [11].

\subsubsection{EMV Crossover}

EMV Crossover is a trading rule based on EMV indicator [49]. Firstly, the EMA of EMV indicator values are calculated throughout the price data. In order to calculate those values, two user defined parameters are needed: EMA period and volume type (to calculate Box Ratio). Next, user defined buy and sell limits are set. Using the indicator values and buy/sell limits, the strategy to generate buy/sell signals is as follows:

- When the EMA of EMV value crosses above the buy limit value, a buy signal is generated.

- When the EMA of EMV value crosses below the sell limit value, a sell signal is generated [11, 30, 49].

\subsection{Rules Based on Bollinger Bands, \% b and Bandwidth Indicators}

The trading rules based on Bollinger Bands, $\% \mathrm{~b}$ and Bandwidth indicators differ from other indicator rules in that they are rather complex and include various pat- 
terns. There are 6 rules to be covered in this section: W-Type Bottom Pattern and M-Type Top Pattern are based on Bollinger Bands, Method III-Reversals, \%b-MFI and $\% \mathrm{~b}(\mathrm{CMF})$ Crossover are based on $\% \mathrm{~b}$ and The Squeeze and Expansion is based on the Bandwidth indicator.

\subsubsection{W-Type Bottom Pattern}

W-Type Bottom Pattern is a trading rule based on capturing the 5-point W-shaped patterns categorized by Arthur Merrill [34, 53]. Firstly, the Bollinger Bands (BB) and $\% \mathrm{~b}$ indicator values are calculated throughout the price data. In order to calculate those values, three user defined parameters are needed: moving average period, type and standard deviation factor. Next, user defined \%b threshold is set. Using the BB indicator values, there are 4 successive steps to confirm a W-Type Bottom pattern:

- First, the price decreases below or touches the lower BB band, thereby setting the first low.

- Second, when the price increases above or touches the middle BB band, the highest price is set as the resistance point.

- Third, the price decreases below the middle BB band but hold above the lower BB band, thereby setting the second low.

- Finally, the price moves above the resistance point confirming the W-Type Bottom pattern [11, 34].

The pattern is illustrated in figure 5.4. In the light of the above explanations, the buy/sell strategy of the rule is as follows:

- When a W-Type Bottom pattern is confirmed, a buy signal is generated.

- When the price increases above the user defined \%b indicator threshold, a sell signal is generated.

"First buy, then sell" is preferred as the trading strategy. 


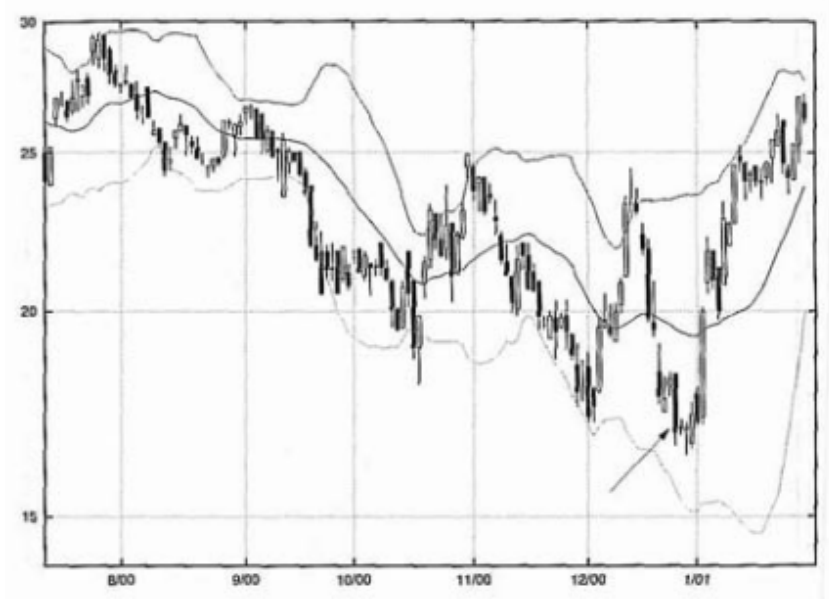

Figure 5.4: W-Type Bottom Pattern [34]

\subsubsection{M-Type Top Pattern}

M-Type Top Pattern is a trading rule based on capturing the 5-point M-shaped patterns categorized by Arthur Merrill [34, 53]. Firstly, the Bollinger Bands (BB) and $\% \mathrm{~b}$ indicator values are calculated throughout the price data. In order to calculate those values, three user defined parameters are needed: moving average period, type and standard deviation factor. Next, user defined $\%$ b threshold is set. There are 4 successive steps to confirm a M-Type Top pattern:

- First, the price increases above or touches the upper BB band, thereby setting the first high.

- Second, when the price decreases below or touches the middle BB band, the lowest price is set as the resistance point.

- Third, the price increases above the middle BB band but hold below the upper BB band, thereby setting the second high.

- Finally, the price moves below the resistance point confirming the M-Type Top pattern [11, 34].

The pattern is illustrated in figure 5.5. In the light of the above explanations, the buy/sell strategy of the rule is as follows: 
- When a M-Type Top pattern is confirmed, a sell signal is generated.

- When the price decreases below the user defined \%b indicator threshold, a buy signal is generated.

"First buy, then sell" is preferred as the trading strategy.

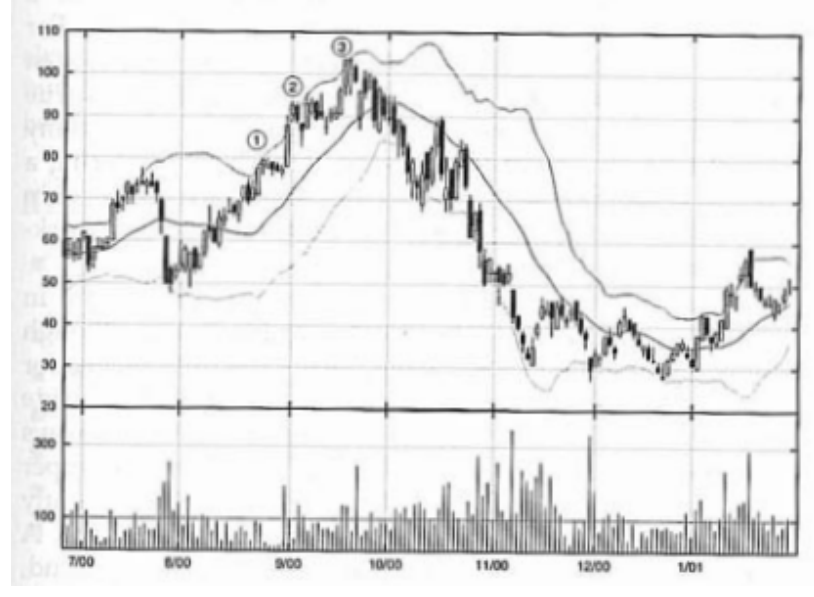

Figure 5.5: M-Type Top Pattern [34]

\subsubsection{Method III-Reversals}

Method III - Reversals [34] is a trading rule based on \%b and MFI indicators. Firstly, the $\% \mathrm{~b}$ and MFI indicator values are calculated throughout the price data. In order to calculate those values, four user defined parameters are needed: moving average period (to calculate both of the indicators), moving average type and standard deviation factor (to calculate \%b indicator) and volume type (to calculate MFI indicator). Next, user defined \%b and MFI buy/sell limits are set. Using the indicators values and buy/sell limits, the strategy to generate buy/sell signals is as follows:

- When \%b indicator value is less than user defined \%b buy limit and MFI indicator value is greater than user defined MFI buy limit, a buy signal is generated.

- When \%b indicator value is greater than user defined \%b sell limit and MFI indicator value is less than user defined MFI sell limit, a sell signal is generated [34]. 
"Always in the market" is preferred as the trading strategy.

\subsection{4 \%b-MFI}

\%b-MFI is a trading rule based on \%b and MFI indicators. Firstly, the \%b and MFI indicator values are calculated throughout the price data. In order to calculate those values, four user defined parameters are needed: moving average period (to calculate both of the indicators), moving average type and standard deviation factor (to calculate \%b indicator) and volume type (to calculate MFI indicator). Next, user defined $\% \mathrm{~b}$ and MFI buy/sell limits are set. Using the indicators values and buy/sell limits, the strategy to generate buy/sell signals is as follows:

- When \%b indicator value is less than user defined \%b buy limit and MFI indicator value is less than user defined MFI buy limit, a buy signal is generated.

- When \%b indicator value is greater than user defined \%b sell limit and MFI indicator value is greater than user defined MFI sell limit, a sell signal is generated.

"Always in the market" is preferred as the trading strategy.

\subsection{5 \%b(CMF) Crossover}

$\% \mathrm{~b}(\mathrm{CMF})$ Crossover is a trading rule based on the normalization of the CMF indicator values with \%b indicator [34]. In order to calculate the CMF values, two user defined parameters are needed: sum of Money flow volume period and volume type. Next, the CMF values are normalized with \%b indicator in the following fashion: The price data is used in the original calculation of $\% \mathrm{~b}$ indicator whereas the CMF data is used instead of price data in the normalization of CMF data with \%b indicator. The \%b indicator needs 3 user defined parameters: moving average period, type and standard deviation factor. Following, user defined buy and sell limits are set. Using the normalized CMF (\%b(CMF)) values and buy/sell limits, the strategy to generate buy/sell signals is as follows: 
- When the \%b(CMF) value crosses above the buy limit value, a buy signal is generated.

- When the \%b(CMF) indicator value crosses below the sell limit value, a sell signal is generated [11, 34].

"Always in the market" is preferred as the trading strategy.

\subsubsection{The Squeeze and Expansion}

The Squeeze and Expansion is a trading rule based on the squeeze and expansion of the upper and lower bands of BB indicator [34]. The Squeeze is based on the fact that Bollinger Bands squeeze (or narrow) when the volatility of the price decreases. This may be a signal of an uptrend/downtrend. On the other hand, the Expansion occurs when the Bollinger Bands expands where the high volatility comes into play. This may be and end of the current uptrend/downtrend which should be confirmed with some other indicator(s) [11, 34].

The rule depends on Bandwidth and CMF indicators. Firstly, the Bandwidth and CMF indicator values are calculated throughout the price data. In order to calculate those values, four user defined parameters are needed: moving average period (to calculate both of the indicators), moving average type and standard deviation factor (to calculate Bandwidth indicator) and volume type (to calculate CMF indicator). Next, user defined squeeze and expansion thresholds are set. Using the indicators values and squeeze and expansion thresholds, the strategy to generate buy/sell signals is as follows:

- When the bandwidth indicator value is less than the squeeze threshold:

- If the average of preceding and succeeding periods' CMF values are greater than 0 , a buy signal is generated.

- If the average of preceding and succeeding periods' CMF values are less than 0 , a sell signal is generated. 
- If a buy or sell signal is generated as a result of squeeze, the bandwidth indicator is checked. When the bandwidth indicator value is greater than the expansion threshold:

- If the position is long (buy signal generated in squeeze), a sell signal is generated and the trade is closed.

- If the position is short (sell signal generated in squeeze), a buy signal is generated and the trade is closed.

\subsection{Divergence Rules}

Divergence occurs when a significant price movement in a direction (upward or downward) is not confirmed with the indicator movement in the same direction [30, 54]. Technically, when the price is making higher highs or lower lows, the indicator should make higher highs or lower lows, similarly. If this is not the case, it is called a divergence. Generally, divergences are classified into two types: Regular, hidden. Regular divergence signals the end of a current trend [9, 54]. Regular Divergence occurs in two cases:

- Price is making lower lows, but the indicator is making higher lows (regular bullish divergence)

- Price is making higher highs, but the indicator is making lower highs(regular bearish divergence) [9].

On the other hand, hidden divergence confirms the current trend. Hidden Divergence occurs in two cases:

- Price is making higher lows, but the indicator is making lower lows (hidden bullish divergence)

- Price is making lower highs, but the indicator is making higher highs(hidden bearish divergence) [9]. 


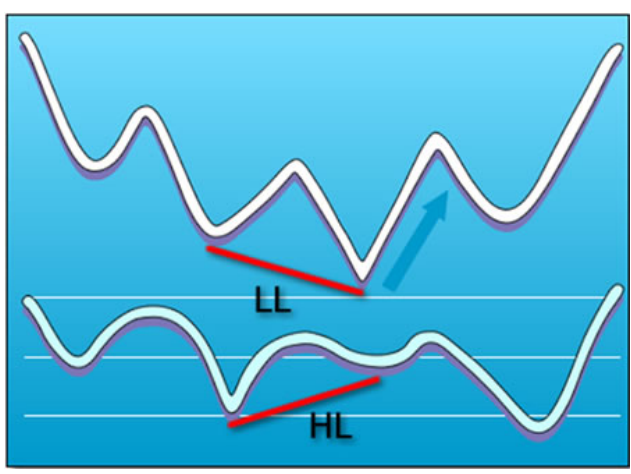

(a) Regular Bullish Divergence

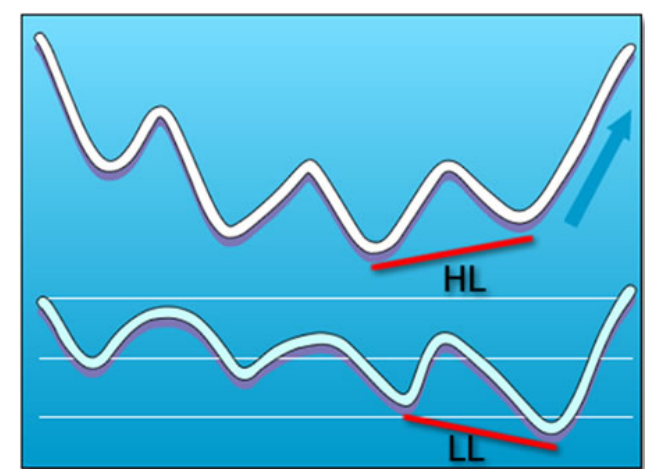

(b) Hidden Bullish Divergence

Figure 5.6: Regular and Hidden Bullish Divergences [9]

Regular bullish and hidden bullish divergences are illustrated in figures $5.6 \mathrm{a}$ and $5.6 \mathrm{~b}$, respectively [9].

\subsubsection{Rules Based on Bullish Divergences}

A bullish divergence is the type of divergence which signals an uptrend in prices [55]. It occurs in case of a reversal in the current downtrend (regular bullish divergence) or as a confirmation of the beginning of an uptrend (hidden bullish divergence).

Several indicators can be used to detect a bullish divergence. However, in this thesis, five indicators are used: RSI, Figurelli RSI, MFI, DeMarker and Ultimate Oscillator. Firstly, the selected indicator (one of the RSI, Figurelli RSI, MFI, DeMarker or Ultimate Oscillator) values are calculated throughout the price data. The parameters of the selected indicator are defined by the user. Next, user defined sell limit is set. Using the price low data, indicator values and sell limit, the strategy to generate buy/sell signals is given in algorithm 2 .

\subsubsection{Rules Based on Bearish Divergences}

A bearish divergence is the type of divergence which signals a downtrend in prices [55]. It occurs in case of a reversal in the current uptrend (regular bearish divergence) or as a confirmation of the beginning of a downtrend (hidden bearish divergence). 


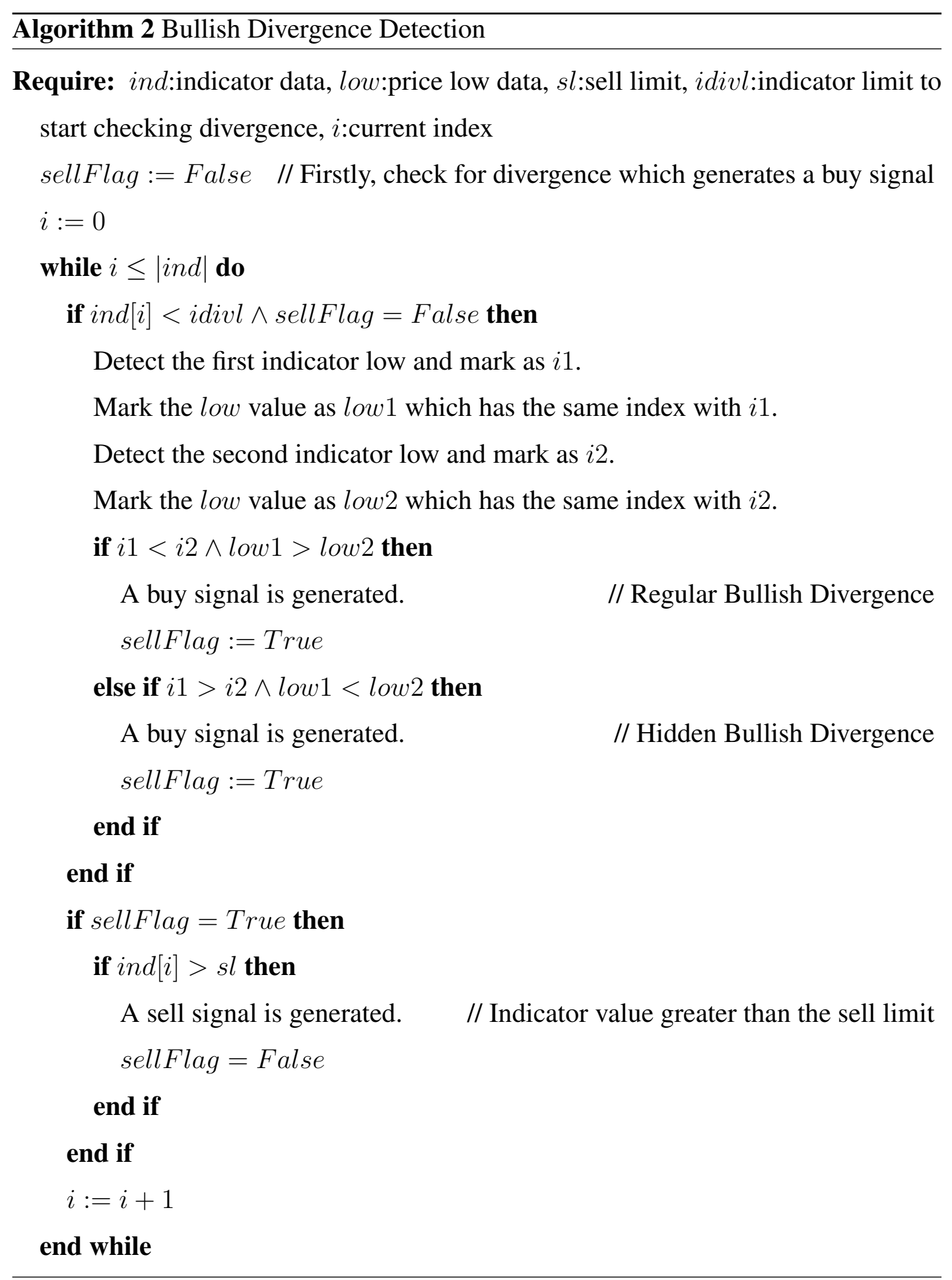


Several indicators can be used to detect a bearish divergence. Similar to bullish divergence, five indicators are used in this thesis: RSI, Figurelli RSI, MFI, DeMarker and Ultimate Oscillator. Firstly, the selected indicator (one of the RSI, Figurelli RSI, MFI, DeMarker or Ultimate Oscillator) values are calculated throughout the price data. The parameters of the selected indicator are defined by the user. Next, user defined buy limit is set. Using the price high data, indicator values and buy limit, the strategy to generate buy/sell signals is given in algorithm 3 . 


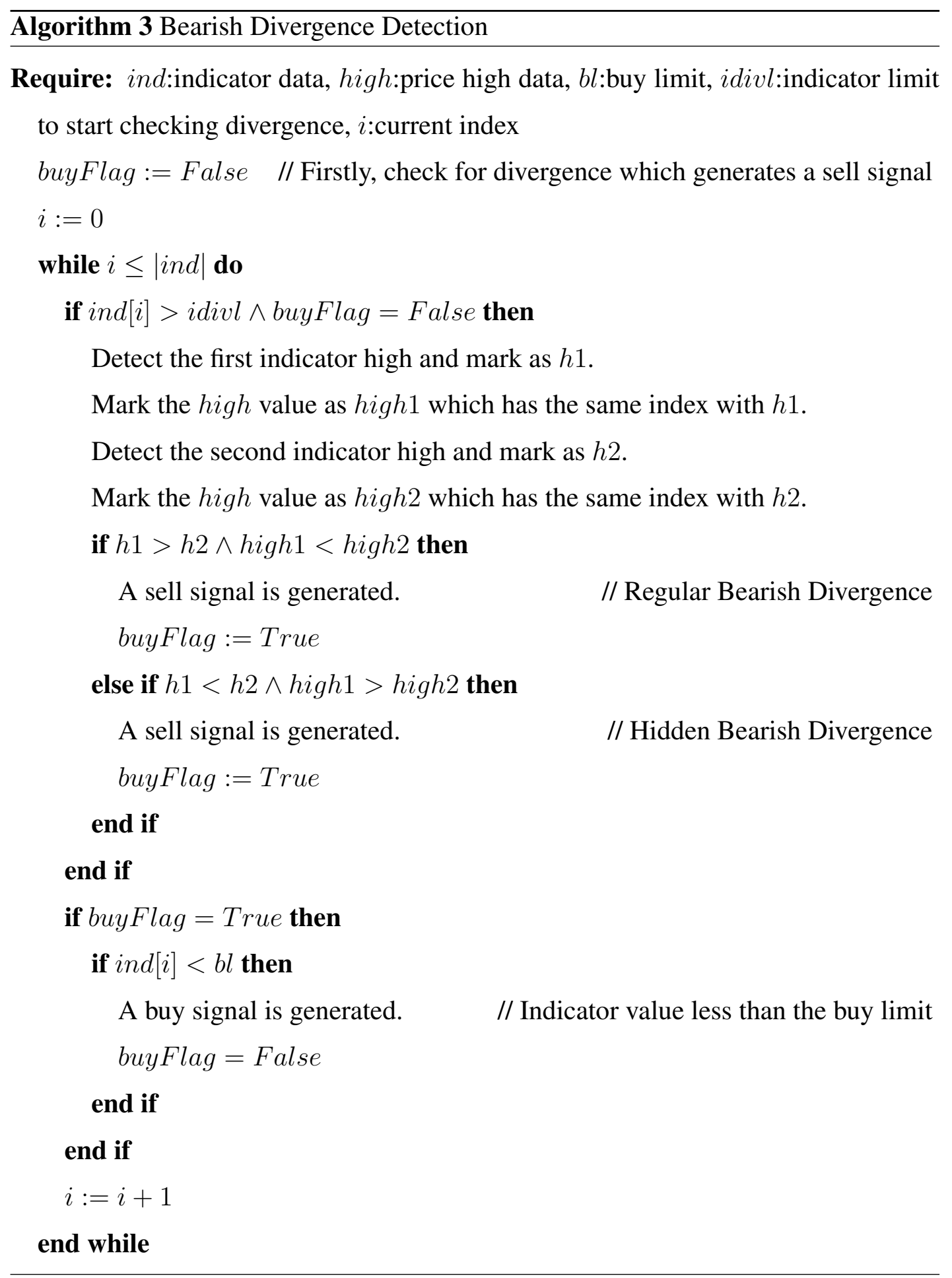




\section{CHAPTER 6}

\section{TRADING SYSTEM}

In this chapter, we present a hybrid trading system which uses Genetic Algorithm (GA), a local search and a weighted majority voting method to select and combine trading rules based on technical indicators discussed in the previous chapter to generate buy/sell signals. The trading system uses time series price data of any currency pair. The time series data of the given currency pair should be split as training and test to input into our system.

The motivation behind combining trading rules instead of using individually comes from the technical analysis domain. When a trading rule generates a buy/sell signal, the analyst wants to be confident about the generated signal. For this purpose, the analyst checks whether a second signal (preferably based on a different approach) confirms the first rule's decision. A parallel approach in machine learning domain is also observed with the ensemble methods where various types of classifiers are combined to obtain better performance than any constituent classifier used alone.

In the following section, the framework of the proposed system together with its components will be explained briefly.

\subsection{The Framework of The Proposed Trading System}

Our proposed trading system is composed of three phases: Testing Each Trading Rule For Qualification, combining the qualified rules and testing the performance of the combined trading system. Training data is used in the construction of the trading 
system in the first and second phases. Test data is used to obtain the performance of the system in the final phase. In the first phase, the best parameter(s) of each rule explained in chapter 5 which satisfy the predefined criteria are obtained using Genetic Algorithm. The output of the first phase is the set of trading rules with the best parameter(s) which satisfy the predefined criteria. In the second phase, the qualified rules obtained from the first phase are combined. The trading rules to be combined are selected among qualified rules using GA and a local search method. The combination of the qualified trading rules is realized with an algorithm based on the weighted majority voting of the constituent rules. In the final phase, the combined trading system is experimented on the test data and the performance of the system is obtained. An overview of the framework of the proposed system is illustrated in figure 6.1. In the following sections, the phases of the framework will be explained in detail.
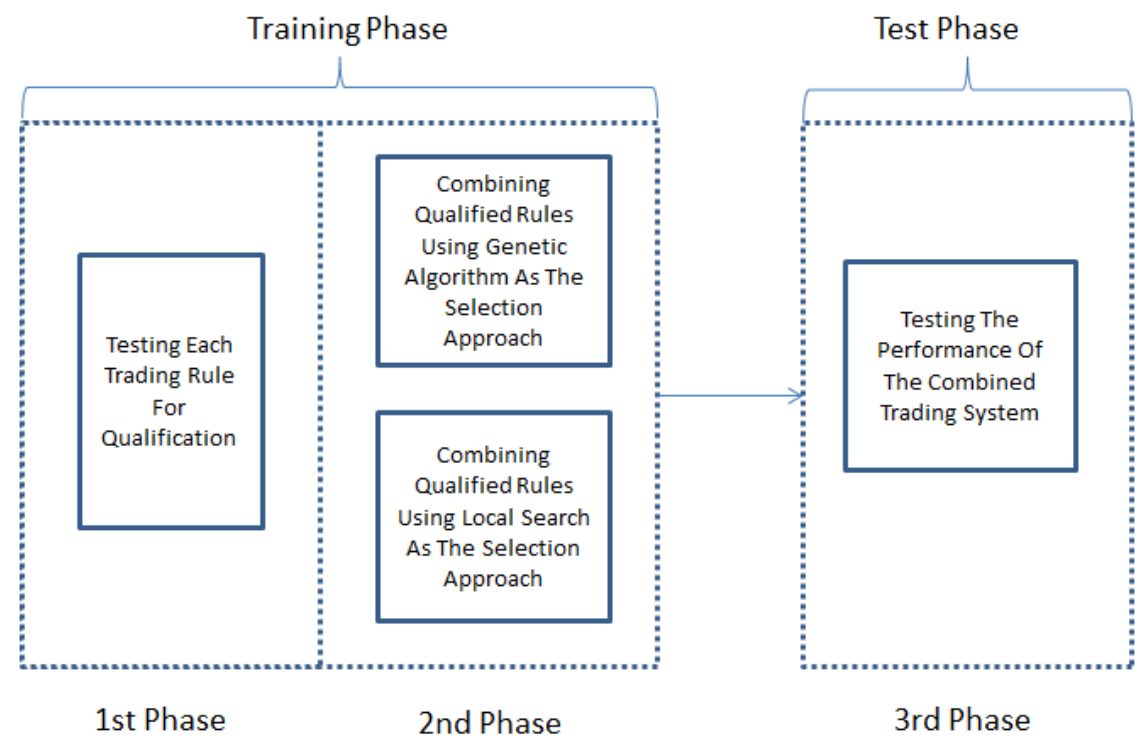

Figure 6.1: The Framework Of The Overall Trading System

\subsection{Testing Each Trading Rule For Qualification}

The objective in this phase is testing and determining the trading rules to qualify for the second phase. There are 2 modules used in this phase: Trading Simulation and Genetic Algorithm Modules. The complete process is given in figure 6.2. In the figure, for each trading rule discussed in chapter 5. GA Module randomly generates 
chromosomes which represent different parameter combinations of a trading rule. Then all these candidate rules with different parameter combinations are simulated over the training data using Trading Simulation module. The output of the Trading Simulation module is Net Profit which is provided as the fitness value to the GA module. Following, the best chromosome having the highest net profit found is examined whether it satisfies the predefined criteria. The predefined criteria are thresholds for number of trades and average profit per trade (discussed in 7.3) which are defined by the user. The rules which don't satisfy the thresholds for these criteria are eliminated. The output of this phase is the set of qualified trading rules with their best parameter(s) considering the net profit values. In the following subsections, GA and Trading Simulation Modules are explained in detail.

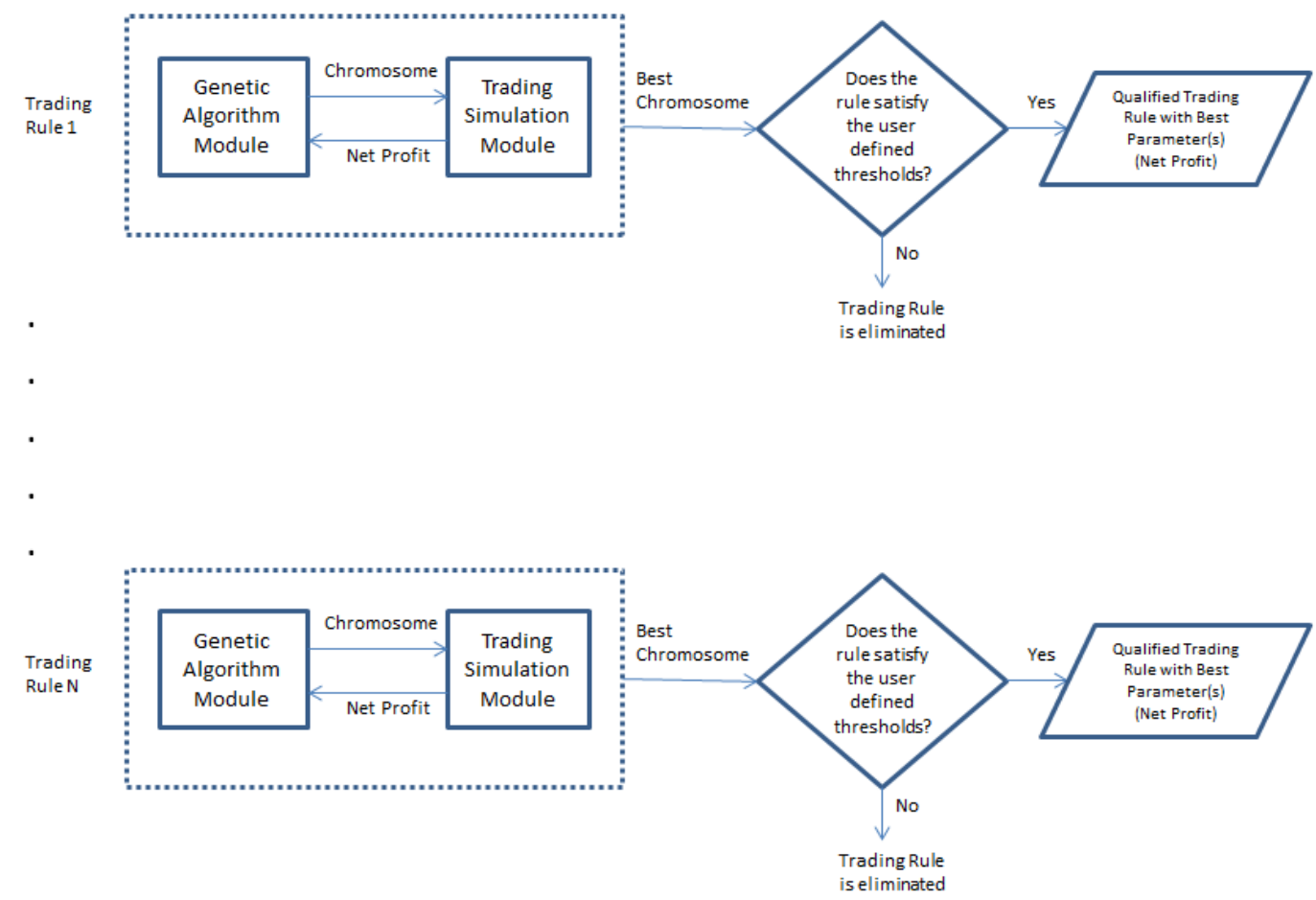

Figure 6.2: Testing Each Trading Rule For Qualification

\subsubsection{Trading Simulation Module}

This module is used to simulate any trading rule on the given time series data to generate buy/sell signals and calculate net profit (in pipettes) as well as other statistics 
(hit rate, average profit etc.) at the end of the simulation. In our proposed system, the net profit of the simulated trading rule is used as fitness value for GA Module. The simulation and calculation of net profit of a trading rule is given in algorithm 4 .

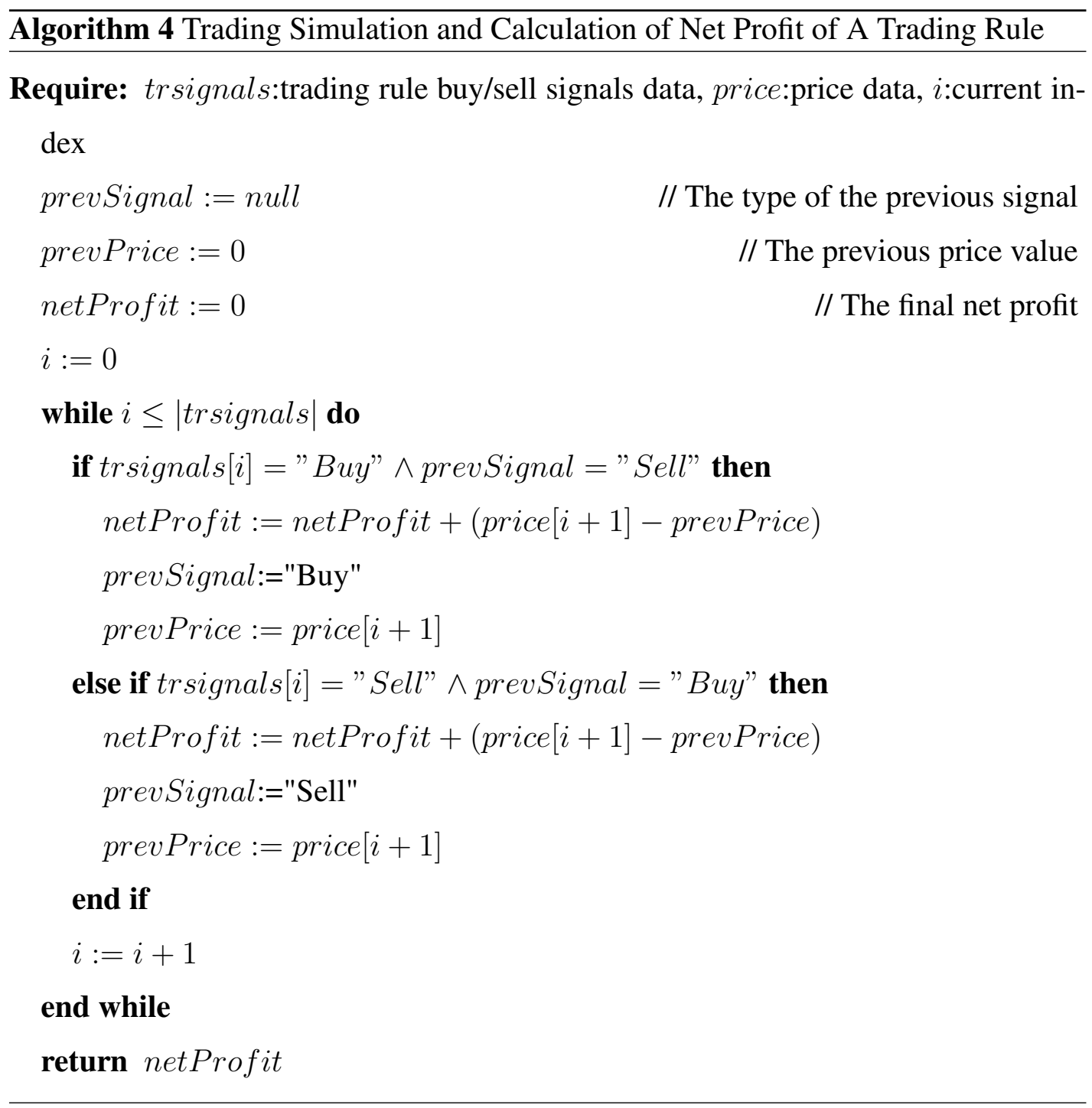

In the above algorithm, when the trading rule's signal is a buy/sell signal in the current time period, the previous signal is checked whether it is the opposite of that signal. If the previous signal is opposite of the current period's signal, the trade is closed by subtracting the previous signal's price value from the next time period's price value. Next period's price value is used in the calculation since a buy or sell instruction in real market conditions can't be executed in the same time with signal generation. The buy/sell strategy is assumed as "Always in the market" in the simulation and profit calculation discussed in chapter 5. If the succeeding signals are of the same type, they are not considered in the profit calculation. Also, if the signal is neither buy nor 
sell, it is implicitly a hold signal and no action is taken. The unit of final net profit is pipettes discussed in chapter 2

\subsubsection{GA Module}

Genetic Algorithm was invented and developed by John Holland which is based on evolution and genetics. In Holland's Adaptation in Natural and Artificial Systems book, he proposed the GA as evolving population of chromosomes (string bits of 0 and 1) using the genetics inspired operators of crossover, mutation and inversion [1].

A GA is a search method which consists of a population of chromosomes that evolve using genetic operators selection, crossover (recombination) and mutation of chromosomes. A chromosome represents a solution in a population which consists of genes having alleles (values). In GA, the population consists of chromosomes which evolve by time based on a fitness value. The population is evolved by using selection, mutation and crossover operators until all the chromosomes agree on a specific chromosome (solution). Selection operator is used to select the chromosomes for reproduction. Crossover operator exchanges the sub-sequences between chromosomes to generate new chromosomes. Mutation operator randomly changes the value of a gene in a chromosome [1, 2].

The GA Module is implemented using a framework for heuristic and evolutionary algorithm called HeuristicLab [56]. The high flexibility of the framework allows the users to create chromosomes having different representations for different types of problems. Thus, GA module is used specifically in the first and second phase. In this phase, GA Module works in cooperation with Trading Simulation Module to find the best parameter(s) of each trading rule. The steps how GA module works is given as follows:

- Firstly, the possible parameter values in each gene of a chromosome is discretized to be represented by integers and the range of the values are defined. The chromosome representation of RSI Crossover rule is illustrated in figure 6.3 as an example.

- Following, the chromosomes which represent the parameter combinations of a 
trading rule are randomly generated to form an initial population.

- Next, the fitness value of each chromosome is calculated and sent by Trading Simulation Module.

- The following steps will repeat until $\mathrm{n}$ number of offsprings are created

- Two candidate chromosomes are selected from the current population.

- Selected chromosomes are crossed over as defined in [57] to form two offsprings.

- Mutation is applied to the created offsprings with a defined mutation probability. Following, the mutated offsprings are placed in the population.

- The fitness values of the crossed and mutated offsprings are calculated and sent by Trading Simulation Module.

- The current population is replaced with the new one and the process starts over.

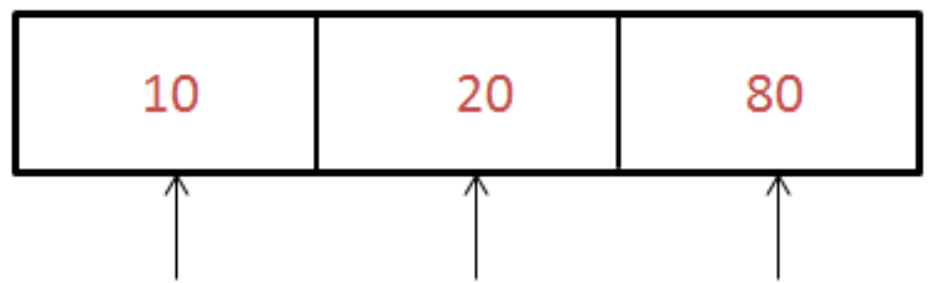

Gene 1: Time Period Gene 2: Buy Limit Gene 3: Sell Limit

Figure 6.3: Chromosome Representation of RSI Crossover Rule

The fitness metric is Net Profit for GA module. The GA module runs until all the chromosomes converge to a common solution or user interruption. The output of this module is a chromosome which has the best fitness value found so far.

\subsection{Combining The Qualified Rules}

The output of the first phase is the set of qualified trading rules with best parameter(s) in terms of net profit satisfying the criteria discussed above. In this phase, the qualified 
rules in the first phase are combined to form a single trading system which represents each constituent rule. There are two aspects in this phase: the selection of the trading rules to be combined and combining the selected rules. Two approaches are used for the selection of the trading rules: Genetic Algorithm and a local search method where these approaches are implemented in GA and Local Search Modules, respectively. In order to combine the selected rules, a weighted majority voting approach is used which is implemented in Combination Module. Both two aspects, namely selection and combination of the trading rules, require the trading rules to be weighted in terms of their Net Profit/Average Profit Per Trade. The weighting process is performed by the Weighting Module.

The combined trading system will be different depending on the selection approach. Therefore in this phase, two alternatives which differ in selection approach are proposed to implement the trading system. These alternatives are illustrated in figures 6.4 and 6.5 .

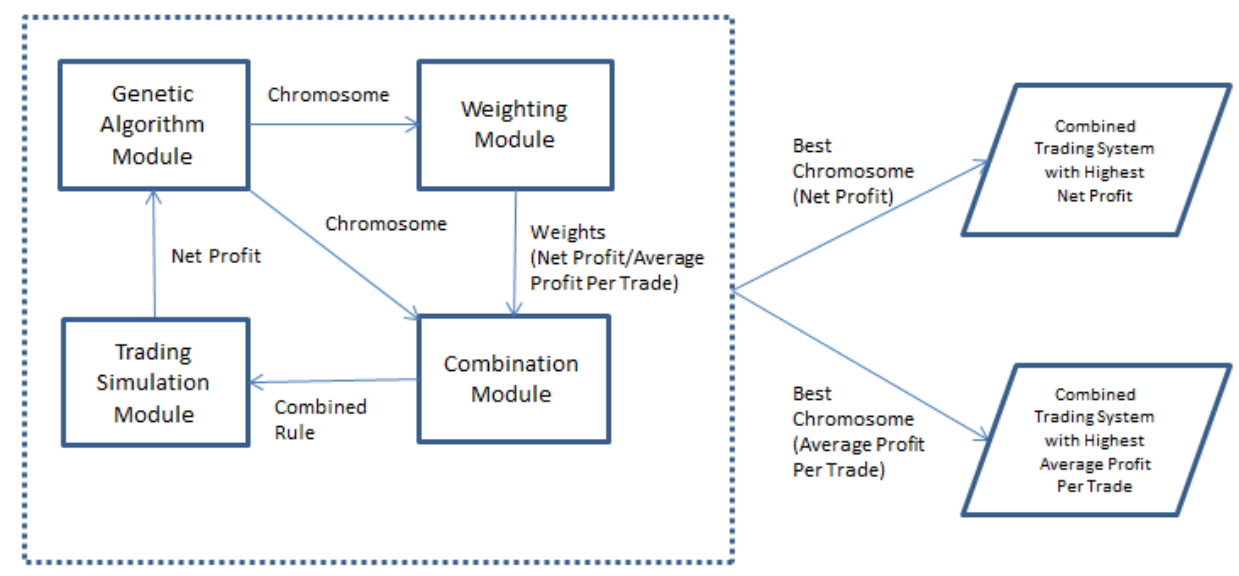

Figure 6.4: Combining Rules Using Genetic Algorithm As The Selection Approach

In figure 6.4. Genetic Algorithm is the approach to select the trading rules for combination. Firstly, GA module randomly generates candidate chromosomes (solutions) where each of them includes different rule selections. Following, these solutions are sent to Weighting Module to obtain the weights of each rule in the solution. There are two alternatives to calculate the weights: Net Profit and Average Profit Per Trade. Next, the chromosome and the weights of the rules in that chromosome is sent to Combination module to form the combined trading system. The output of this mod- 
ule is the combined rule which is evaluated by Trading Simulation module for its performance. This processes will loop until the best chromosomes having the highest the Net Profit and Average Profit Per Trade are obtained. The outputs are the combined trading systems having the highest Net Profit and Average Profit Per Trade.

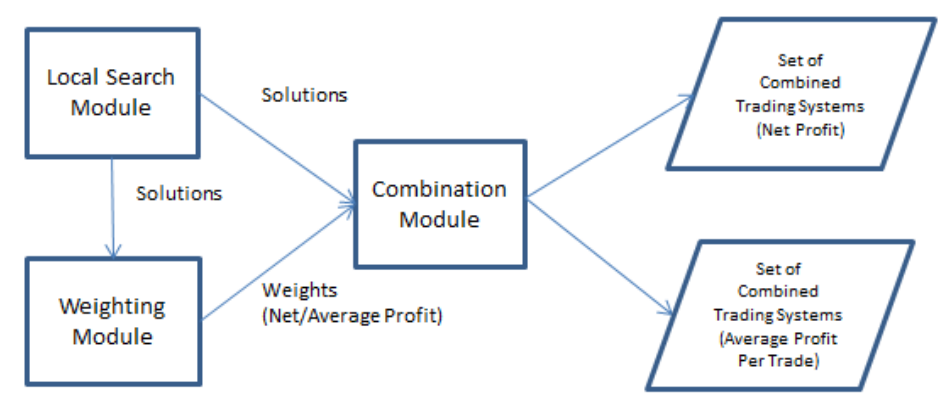

Figure 6.5: Combining Rules Using Local Search As The Selection Approach

In figure 6.5, local search is the approach to select the trading rules for combination. Firstly, Local Search module sorts the trading rules in decreasing order considering their Net Profit/Average Profit Per Trade. Then, it generates a solution including only the best trading rule at first. Then, in each step it incrementally includes a trading rule to generate a new solution. The weights of each rule in each solution is obtained by Weighting module considering their Net Profit/Average Profit Per Trade. The solutions with the weights are sent to Combination module to form the combined trading systems. The outputs of this module are the set of combined trading systems considering Net Profit and Average Profit Per Trade as the weights.

In the following subsections, Genetic Algorithm, Weighting, Combination and Local Search Modules will be explained in depth.

\subsubsection{Genetic Algorithm Module}

Differently from the first phase, GA Module is used to select the rules to be combined in this phase. The steps how GA module works is given as follows:

- Firstly, the possible parameter values in each gene of a chromosome is defined to be either 1 or 0 which denotes whether the trading rule is selected to be 
combined or not. The representation of a chromosome with 20 trading rules is illustrated in figure 6.6 as an example.

- Following, the chromosomes are randomly generated to form an initial population.

- Next, each chromosome is sent to the Weighting and Combination Modules for the purpose of combining the selected rules in the chromosome.

- The fitness values of each candidate combined rules represented by chromosomes are calculated and sent by Trading Simulation Module.

- The following steps will repeat until n number of offsprings are created

- Two candidate chromosomes are selected from the current population.

- Selected chromosomes are crossed over as defined in [57] to form two offsprings.

- Mutation is applied to the created offsprings with a defined mutation probability. Following, the mutated offsprings are placed in the population.

- The fitness values of the crossed and mutated offsprings are provided by Trading Simulation Module.

- The current population is replaced with the new one and the process starts over.

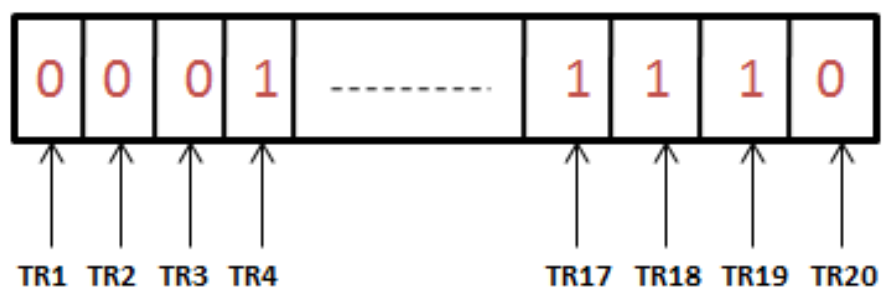

Figure 6.6: Chromosome Representation of A Candidate Combined Rule

The fitness metric is either Net Profit or Average Profit Per Trade for GA module depending on the choice. The GA module runs until all the chromosomes converge to a common solution or user interruption. The output of this module is the chromosome which has the best fitness value found so far and represents the final combined system. 


\subsubsection{Local Search Module}

In this module, the trading rules to be combined are selected using a local search approach. In this approach, the trading rules are sorted in decreasing order in terms of either their Net Profit or Average Profit Per Trade. Following, the rules to be combined are selected starting from the trading rule having highest Net Profit/Average Profit Per Trade value. In each step, the rule with the next highest value is selected in a cumulative manner. In the final step, all the trading rules are selected for the combination. The process is illustrated in figure 6.7. In the figure, $T R_{1}$ through $T R_{N}$ represent the trading rules having the highest through lowest Net Profit/Average Profit Per Trade values.

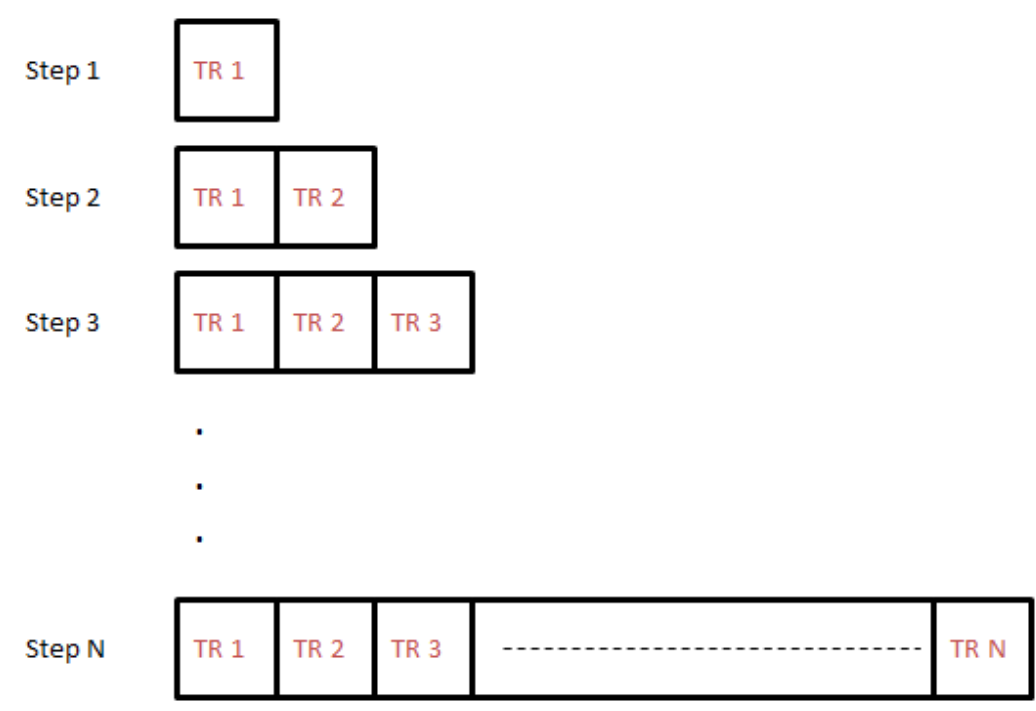

Figure 6.7: Selection of Trading Rules with Local Search

\subsubsection{Weighting Module}

This module calculates and assigns weights to the selected rules to be combined either by using Net Profit or Average Profit Per Trade. The weighting process is performed by firstly summing up Net Profit/Average Profit Per Trade values of all the selected rules. Following, each rule's Net Profit/ Average Profit Per Trade value is divided by 
the total and multiplied by 100 . The final values are assigned as the weights of the rules.

\subsubsection{Combination Module}

This is the key module which combines the selected trading rules to generate buy/sell signals similar to a single trading rule and forms the combined trading system. A weighted majority voting method is used in this module. The whole process is given in algorithm 5

In algorithm 5, the selected trading rules' signals data is used to decide the combined rule's buy/sell decision. The weight total of buy and sell are kept separately. The weight of any trading rule is accumulated to the related total (buy or sell) whenever one or more trading rule generates a buy/sell signal. When the buy or sell weight total is greater than the user defined threshold value, a buy/sell signal is generated and the related total (buy or sell) is set to zero. Successive buy or sell signals are not considered; so if a buy signal is generated by the trading system, it is followed by a sell signal. The buy/sell strategy of the system is "Always in the market" which is explained in chapter 5

\subsection{Testing The Performance Of The Combined Trading System}

In this phase, the performance of the trading system is obtained by experimenting the trading system on the test data. Trading Simulation module is used to evaluate the performance of the trading system on test data. Experiments are carried out on 4 different type of trading systems which arise as the result of the rule selection approach used (Genetic algorithm or local search) and performance metrics of rules (Net profit or average profit per trade) in the second phase. The experiments are discussed in chapter 7 . 


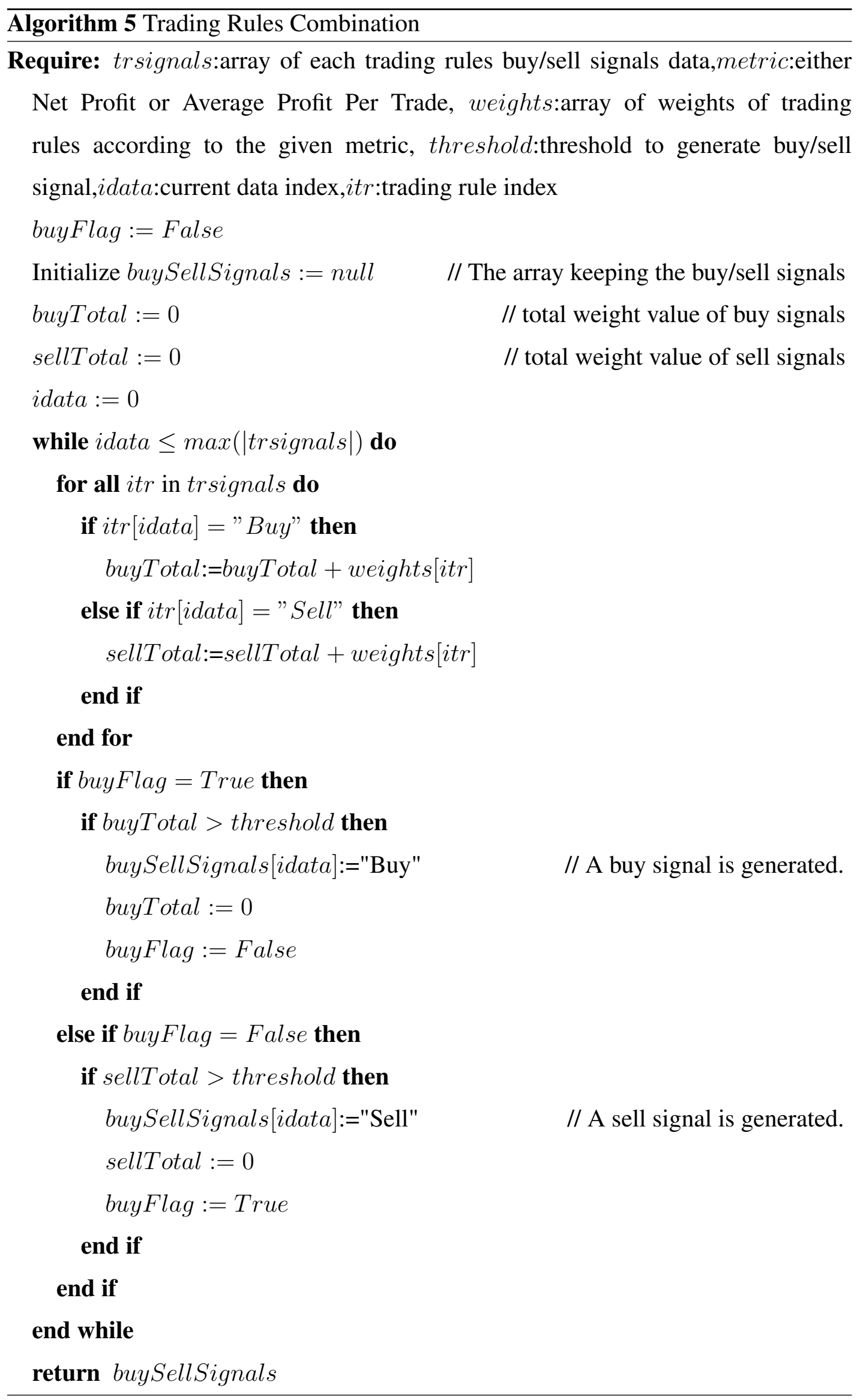




\subsection{A Sample Run of The Trading System}

In this section, a sample run of the trading system is shown with results. The aim is to clarify how the trading system works further. The experiment data as well as the parameters of the trading rules and the results are imaginary.

\section{Testing Each Trading Rule For Qualification}

User defined thresholds are:

- Number of trades should be greater than total data points/1000

- Average profit per trade should be at least 10 pipettes.

Out of 38 trading rules implemented, 4 of them are qualified for the second phase. The rules with their parameters and the performance of each rule are given in table 6.1. The unit of net profit and average profit per trade is pipette.

Table 6.1: Results of phase 1

\begin{tabular}{|c|c|c|c|}
\hline \multirow[b]{2}{*}{ Trading rule name } & \multirow[b]{2}{*}{ Parameters } & \multicolumn{2}{|c|}{ Performance } \\
\hline & & Net profit & $\begin{array}{l}\text { Average profit } \\
\text { per trade }\end{array}$ \\
\hline \multirow{3}{*}{ RSI Crossover } & Time Period $=10$ & \multirow{3}{*}{10000} & \multirow{3}{*}{20} \\
\hline & Buy Limit=30 & & \\
\hline & Sell Limit $=70$ & & \\
\hline \multirow{3}{*}{ Psych. Line Crossover } & Time Period $=20$ & \multirow{3}{*}{20000} & \multirow{3}{*}{50} \\
\hline & Buy Limit $=25$ & & \\
\hline & Sell Limit $=80$ & & \\
\hline \multirow{4}{*}{ Chand. Exit Crossover } & Std. Dev. Period=25 & \multirow{4}{*}{30000} & \multirow{4}{*}{30} \\
\hline & Smooth. Period $=14$ & & \\
\hline & Buy Limit=60 & & \\
\hline & Sell Limit $=40$ & & \\
\hline \multirow{2}{*}{ Bullish Divergence (MFI) } & Buy Limit $=30$ & \multirow{2}{*}{40000} & \multirow{2}{*}{40} \\
\hline & Sell Limit $=80$ & & \\
\hline
\end{tabular}

Combining The Qualified Trading Rules and Testing The Performance Of The Trading System

The user defined threshold to generate buy/sell signal (which is used in combination module) is 25 . The results of combining rules using genetic algorithm as the selection 
approach is given in table 6.2. The results of combining rules using local search as the selection approach is given in table 6.3. In table 6.3, the first selected rule for combination is the one having the highest Net Profit/Average Profit Per Trade. The rules are sorted in decreasing order where one rule is incorporated into the solution in each step.

Table 6.2: Results of combining rules using GA

\begin{tabular}{|l|l|c|c|}
\hline \multirow{2}{*}{$\begin{array}{l}\text { Weight Calc. } \\
\text { Metric }\end{array}$} & Selected Rules & \multicolumn{2}{|c|}{ Performance } \\
& Net profit & $\begin{array}{l}\text { Average profit } \\
\text { per trade }\end{array}$ \\
\hline \multirow{2}{*}{ Net profit } & RSI Cross. & \\
\cline { 2 - 2 } & Psych. Line Cross. & 32000 & 2 \\
\cline { 2 - 2 } & Chand. Exit Cross. & & \\
\hline $\begin{array}{l}\text { Average profit } \\
\text { per trade }\end{array}$ & RSI Cross. & \multirow{2}{*}{25000} & 20 \\
\cline { 2 - 2 } & Bullish Div. (MFI) & & 20 \\
\hline
\end{tabular}


Table 6.3: Results of combining rules using local search

\begin{tabular}{|c|c|c|c|}
\hline \multirow[b]{2}{*}{$\begin{array}{l}\text { Weight Calc. } \\
\text { Metric }\end{array}$} & \multirow[b]{2}{*}{ Selected Rules } & \multicolumn{2}{|c|}{ Performance } \\
\hline & & Net profit & $\begin{array}{l}\text { Average profit } \\
\text { per trade }\end{array}$ \\
\hline \multirow{4}{*}{ Net profit } & Bull. Div. (MFI) & 12000 & 12 \\
\hline & $\begin{array}{l}\text { Bull. Div. (MFI), } \\
\text { Chand. Exit Cr. }\end{array}$ & 15000 & 20 \\
\hline & $\begin{array}{l}\text { Bull. Div. (MFI), } \\
\text { Chand. Exit and } \\
\text { Psych. Line Cr. }\end{array}$ & 12500 & 25 \\
\hline & $\begin{array}{l}\text { Bull. Div. (MFI), } \\
\text { Chand. Exit, } \\
\text { Psych. Line and } \\
\text { RSI Cr. }\end{array}$ & 10000 & 10 \\
\hline \multirow{4}{*}{ Average profit per trade } & Psych. Line Cr. & 16000 & 8 \\
\hline & $\begin{array}{l}\text { Psych. Line Cr., } \\
\text { Bull. Div. (MFI) }\end{array}$ & 28000 & 14 \\
\hline & $\begin{array}{l}\text { Psych. Line Cr., } \\
\text { Bull. Div. (MFI), } \\
\text { Chand. Exit Cr. }\end{array}$ & 19000 & 19 \\
\hline & $\begin{array}{l}\text { Psych. Line Cr., } \\
\text { Bull. Div. (MFI), } \\
\text { Chand. Exit and } \\
\text { RSI Cr. }\end{array}$ & 30000 & 12 \\
\hline
\end{tabular}




\section{CHAPTER 7}

\section{EXPERIMENTS}

\subsection{Experimental Environment}

The experiments are conducted on a PC with a $2.20 \mathrm{GHz}$ quad-core processor, $4 \mathrm{~GB}$ memory and 500 GB disk space.

The proposed trading system is implemented in C\#. MySql version 5.6.13 [58] is used to store the data sets used in the experiments. HeuristicLab version 3.3.10.11173 [56] is used as the genetic algorithm tool.

\subsection{Investment Conditions}

In all the experiments,

- The unit used to calculate the profit/loss of a trade is pipette (explained in subsection 2.3.2.

- The initial capital is $\$ 10000$.

- The investment amount for each transaction (either buy or sell) is $\$ 1000$.

- The amount of leverage (explained in subsection 2.3.2) used is 1:100. Therefore, the investment amount is $100 * 1000=\$ 100000$ for each transaction.

- The trading strategy is "Always in the market" (explained in chapter 5) for the proposed trading system. 
Considering above conditions, the profit/loss calculation of a trade is given in the following example. Suppose the trading system goes long in EUR/USD with a buying price of 1.25603 and closes its position with a selling price of 1.25690 . The trade is profitable since the opening position is long and the price is increased. The profit of the trade is $1.25690-1.25603=0.00087$ which is 87 pipettes. Since each transaction is $\$ 100000$ (due to leverage), the net profit is $100000 * 0.00087=\$ 87$. Therefore, 1 pipette profit/loss in a trade is equal to $\$ 1$ profit/loss in the experiments.

\subsection{Evaluation Metrics}

Experimental results are obtained using 6 evaluation metrics. These metrics are:

- Number of Trades: The total number of trades where 1 trade includes 2 transactions either by closing a long (first buy then sell) or short (first sell then buy) position.

- Gross Profit: The total amount of profits including the profits of all the profitable trades in pipettes.

- Gross Loss: The total amount of losses including the losses of all the unprofitable trades in pipettes.

- Net Profit: The difference of gross profit and gross loss in pipettes.

- Average Profit Per Trade: The average ratio in pipettes which is obtained by dividing net profit by number of trades.

- Profitable Trades (\%): The percentage of the number of profitable trades among all trades.

\subsection{Data Sets}

1-minute EUR/USD and GBP/USD time series close price data sets are used in the experiments. The data sets cover the January 2013-January 2014 (January 2014 ex- 
cluded) period for EUR/USD and January 2014-July 2014 (July 2014 excluded) for GBP/USD. The data sets are obtained from Metatrader 5 software [31].

There are 368440 data points in EUR/USD and 182197 data points in GBP/USD data set. Three experiments are conducted on these data sets:

- Experiments on EUR/USD between January 2013-January 2014 (January 2014 excluded)

- Experiments on EUR/USD between January 2013-July 2013 (July 2013 excluded)

- Experiments on GBP/USD between January 2014-July 2014 (July 2014 excluded)

The data sets are split into two sections: training and test data sets. Training data is used to combine the trading rules. Following, the performance of these combined rules are experimented using test data. The ratio of number of data points of training to test data set is $2: 1$ in the experiments.

\subsection{Results and Discussion}

The experimental results are obtained using:

- GA and local search as the rule selection approaches

- Net profit and average profit per trade as the weight calculation metrics

- 25,50 and 75 as the thresholds to generate buy/sell signals

which are discussed in sections 6.3 and 6.3 .4

In local search approach, the qualified trading rules are sorted in decreasing order considering their Net profit/Average profit per trade values as stated in subsection 6.3.2. The selection is performed starting from the best and incrementally adding a rule in each step through the worst. The rules having the best and worst performance 
are entitled as 1 . and $\mathrm{n}$. considering $\mathrm{n}$ qualified rules. Selecting the best rule only in local search approach gives the same results by using the best rule individually. The results of local search experiments are given in summary including the following selections:

- $1^{\text {st }}$ and $2^{\text {nd }}$ rule

- $1^{\text {st }}$ through $(n / 2)^{t h}$ rule (starting from the best through middle)

- $1^{\text {st }}$ through $(n-1)^{\text {th }}$ rule

- $1^{\text {st }}$ through $n^{\text {th }}$ rule (all rules)

The results of the experiments are summarized in the following subsections where net profit is shown only among the evaluation metrics. In the experiment results, the unit of net profit values is pipette. The experimental results of three individual qualified rules (indicated with their names) which performed the highest performance in training phase are given to compare the trading system's performance with the individual rules. The complete results of experiments are given in appendix.

\subsubsection{Experiments on EUR/USD: 1 Year Data}

The data set covers 1-minute time series data between 01.01.2013-31.12.2013. The total number of data points in the data set is 368440 . The data set is split into training and test sections. The training data set includes data between 01.01.2013-31.08.2013 with a total of 246792 data points. The test data set includes data between 01.09.201331.12.2013 with a total of 121648 data points.

\subsubsection{Results}

28 out of 38 trading rules are qualified for the second phase. The list of qualified and unqualified rules are given in table 7.1

The results of the experiments using net profit and average profit per trade as the weight calculation metrics are given in tables 7.2 and 7.3 , respectively. 
Table 7.1: Qualified and unqualified rules

\begin{tabular}{|c|c|c|}
\hline \multirow{2}{*}{ Rule Type } & \multicolumn{2}{|c|}{ Rule Name } \\
\hline & Qualified rules & Unqualified rules \\
\hline Crossover & $\begin{array}{l}\text { Double moving average, } \\
\text { Triple moving average, } \\
\text { Moving average envelopes, } \\
\text { RSI, Figurelli RSI, } \\
\text { Chandelier exit, } \\
\text { Psychological line, } \\
\text { RVI, Stochastics oscillator, } \\
\text { Ultimate oscillator, } \\
\text { Rate of change, } \\
\text { DeMarker, } \\
\text { Relative vigor index, MFI } \\
\text { Chaikin Oscillator, EMV }\end{array}$ & $\begin{array}{l}\text { Moving average price, } \\
\text { TEMA, MACD, OBV, } \\
\text { ADL, CMF }\end{array}$ \\
\hline $\begin{array}{l}\text { Bollinger Bands, \%b } \\
\text { and Bandwidth } \\
\text { Indicator Based }\end{array}$ & $\begin{array}{l}\text { Method III-reversals, } \\
\% \text { b-MFI }\end{array}$ & $\begin{array}{l}\text { W-type bottom pattern, } \\
\text { M-type top pattern, } \\
\% \text { b(CMF) crossover, } \\
\text { The squeeze and } \\
\text { expansion }\end{array}$ \\
\hline Divergence & $\begin{array}{l}\text { Bullish (RSI), Bearish (RSI), } \\
\text { Bullish (Figurelli RSI), } \\
\text { Bearish (Figurelli RSI), } \\
\text { Bullish (Ultimate oscillator), } \\
\text { Bearish (Ultimate oscillator), } \\
\text { Bullish (DeMarker), } \\
\text { Bearish (DeMarker), } \\
\text { Bullish (MFI), Bearish (MFI) }\end{array}$ & - \\
\hline
\end{tabular}

\subsubsection{Discussion}

The results in table 7.1 indicate that 16 out of 22 crossover rules, 2 out of 6 Bollinger Bands and related indicators based rules and all the divergence rules successfully qualified for the second phase.

In table 7.2, the best results are achieved for genetic algorithm and local search methods when the threshold value is 25 . Local search method produced a negative result but all the other results are are positive showing the profitability of the system. Also, it is obvious that the profits of local search method decreases when the threshold in- 
Table 7.2: Experiment results using net profit

\begin{tabular}{|l|l|r|r|c|}
\hline \multirow{2}{*}{$\begin{array}{l}\text { Rule Selection } \\
\text { Approach }\end{array}$} & \multirow{2}{*}{ Selected Rules } & \multicolumn{3}{|c|}{ Threshold } \\
\cline { 2 - 5 } & & $\mathbf{2 5}$ & $\mathbf{5 0}$ & $\mathbf{7 5}$ \\
\hline \multirow{3}{*}{ Local Search } & $1 .-2$. & 6780 & 4022 & 2614 \\
\cline { 2 - 5 } & $1 .-14$. & 11709 & 7561 & -1648 \\
\cline { 2 - 5 } & $1 .-27$. & 6012 & 5318 & 4191 \\
\cline { 2 - 5 } & $1 .-28$. & 5262 & 10496 & 2481 \\
\hline Genetic Algorithm & - & 8998 & 2534 & 3880 \\
\hline \multirow{2}{*}{ Best rule } & Bullish div. & \multicolumn{3}{|c|}{4619} \\
\hline $2^{\text {nd } \text { Best Rule }}$ & (Fig. RSI) & \multicolumn{3}{|c|}{36147} \\
\hline $3^{\text {rd }}$ Best Rule & RSI cross. & \multicolumn{3}{|c}{} \\
\hline
\end{tabular}

Table 7.3: Experiment results using average profit per trade

\begin{tabular}{|l|l|r|r|r|}
\hline \multirow{2}{*}{$\begin{array}{l}\text { Rule Selection } \\
\text { Approach }\end{array}$} & \multirow{2}{*}{ Selected Rules } & \multicolumn{3}{|c|}{ Threshold } \\
\cline { 3 - 5 } & & $\mathbf{2 5}$ & $\mathbf{5 0}$ & \multicolumn{1}{|c|}{$\mathbf{5 5}$} \\
\hline \multirow{3}{*}{ Local Search } & $1 .-2$. & 1807 & 158 & 4658 \\
\cline { 2 - 5 } & $1 .-14$. & 7488 & 5094 & 15942 \\
\cline { 2 - 5 } & $1 .-27$. & 9496 & 7236 & 477 \\
\cline { 2 - 5 } & $1 .-28$. & 14584 & 977 & 9013 \\
\hline Genetic Algorithm & - & 7660 & 7412 & 2014 \\
\hline \multirow{2}{*}{ Best rule } & $\begin{array}{l}\text { Bullish div. } \\
\text { (Fig. RSI) }\end{array}$ & \multicolumn{3}{|c|}{4619} \\
\hline \multirow{2}{*}{$2^{\text {nd }}$ Best Rule } & $\begin{array}{l}\text { Bullish div. } \\
\text { (DeMarker) }\end{array}$ & \multicolumn{3}{|c|}{-968} \\
\hline $3^{\text {rd }}$ Best Rule & Bullish div. (RSI) & \multicolumn{3}{|c}{} \\
\hline
\end{tabular}

creases. The trading system's performance (including both local search and genetic algorithm) outperformed the three best individual rules in six of the cases.

In table 7.3, the best results are achieved for genetic algorithm and local search methods when the threshold values are 25 and 75, respectively. Genetic algorithm outperformed local search method when the threshold value is 50 . Local search showed a good and stable performance when the first 14 rules (1.-14.) are selected for combination. Genetic algorithm also showed good performance for thresholds 25 and 50 . The trading system's performance (including both local search and genetic algorithm) outperformed the three best individual rules in 10 of the cases.

It is obvious that the performance of the three best individual trading rules decreased 
dramatically in table 7.3 compared with the results in table 7.2 while the trading system's performance increased. It can be concluded that using average profit per trade as the weight calculation metric is more preferable to using net profit. The detailed results of the experiments are given in appendix A.

\subsubsection{Experiments on EUR/USD: 6 Months Data}

The data set covers 1-minute time series data between 01.01.2013-30.06.2013. The total number of data points in the data set is 182567 . The data set is split into training and test sections. The training data set includes data between 01.01.2013-30.04.2013 with a total of 121196 data points. The test data set includes data between 01.05.201330.06.2013 with a total of 61371 data points.

\subsubsection{Results}

28 out of 38 trading rules are qualified for the second phase. The list of qualified and unqualified rules are given in table 7.4

The results of the experiments using net profit and average profit per trade as the weight calculation metrics are given in tables 7.5 and 7.6 , respectively.

\subsubsection{Discussion}

The results in table 7.4 indicate that 15 out of 22 crossover rules, 3 out of 6 Bollinger Bands and related indicators based rules and all the divergence rules successfully qualified for the second phase.

In table 7.5, the best results are achieved for genetic algorithm and local search methods for the thresholds 25 and 75, respectively. Local search method produced a very good and stable performance in all the threshold values where the profitability increases as the threshold increases. Local search results also show that including all the rules in the trading system is a good choice resulting high profits. Three individual rules also showed good performance and it can be concluded that the trading system 
Table 7.4: Qualified and unqualified rules

\begin{tabular}{|c|c|c|}
\hline \multirow{2}{*}{ Rule Type } & \multicolumn{2}{|c|}{ Rule Name } \\
\hline & Qualified rules & Unqualified rules \\
\hline Crossover & $\begin{array}{l}\text { Double moving average, } \\
\text { Triple moving average, } \\
\text { Moving average envelopes, } \\
\text { RSI, Figurelli RSI, } \\
\text { Chandelier exit, } \\
\text { RVI, Stochastics oscillator, } \\
\text { Ultimate oscillator, } \\
\text { Rate of change, } \\
\text { DeMarker, } \\
\text { Relative vigor index, MFI, } \\
\text { Chaikin Oscillator, EMV }\end{array}$ & $\begin{array}{l}\text { Moving average price, } \\
\text { TEMA, MACD, } \\
\text { Psychological line, } \\
\text { OBV, ADL, CMF }\end{array}$ \\
\hline $\begin{array}{l}\text { Bollinger Bands, \%b } \\
\text { and Bandwidth } \\
\text { Indicator Based }\end{array}$ & $\begin{array}{l}\text { W-type bottom pattern, } \\
\text { \% (CMF) crossover, } \\
\text { \%b-MFI }\end{array}$ & $\begin{array}{l}\text { M-type top pattern, } \\
\text { Method III-reversals, } \\
\text { The squeeze and } \\
\text { expansion }\end{array}$ \\
\hline Divergence & $\begin{array}{l}\text { Bullish (RSI), Bearish (RSI), } \\
\text { Bullish (Figurelli RSI), } \\
\text { Bearish (Figurelli RSI), } \\
\text { Bullish (Ultimate oscillator), } \\
\text { Bearish (Ultimate oscillator), } \\
\text { Bullish (DeMarker), } \\
\text { Bearish (DeMarker), } \\
\text { Bullish (MFI), Bearish (MFI) }\end{array}$ & - \\
\hline
\end{tabular}

and the individual rules are in competition.

The results in table 7.6 show that the performance of the individual trading rules and the trading system shows a decrease compared with the net profit results. The negative result in local search method is a clear indication of the situation. Local search method shows a stable performance when the threshold is 25 and outperformed genetic algorithm when the threshold is 50 . The trading system's performance outperformed the three best individual rules in 3 of the cases.

After comparing the results in tables 7.5 and 7.6, it can be concluded that using net profit per trade as the weight calculation metric is more preferable to using average profit per trade. Also, genetic algorithm results are more stable in both net profit and 
Table 7.5: Experiment results using net profit

\begin{tabular}{|l|l|r|r|r|}
\hline \multirow{2}{*}{$\begin{array}{l}\text { Rule Selection } \\
\text { Approach }\end{array}$} & \multirow{2}{*}{ Selected Rules } & \multicolumn{3}{|c|}{ Threshold } \\
\cline { 2 - 5 } & & $\mathbf{2 5}$ & $\mathbf{5 0}$ & $\mathbf{7 5}$ \\
\hline \multirow{3}{*}{ Local Search } & $1 .-2$. & 8021 & 10039 & 9540 \\
\cline { 2 - 5 } & $1 .-14$. & 6671 & 7533 & 9842 \\
\cline { 2 - 5 } & $1 .-27$. & 9000 & 8027 & 12678 \\
\cline { 2 - 5 } & $1 .-28$. & 8926 & 10353 & 11222 \\
\hline Genetic Algorithm & - & 8154 & 7466 & 4611 \\
\hline Best rule & \%b-MFI & \multicolumn{3}{|c|}{3234} \\
\hline $2^{\text {nd }}$ Best Rule & $\begin{array}{l}\text { Rate of change } \\
\text { cross. }\end{array}$ & \multicolumn{3}{|c|}{8947} \\
\hline \multirow{2}{*}{$3^{r d}$ Best Rule } & $\begin{array}{l}\text { Bearish div. } \\
\text { (MFI) }\end{array}$ & \multicolumn{3}{|c}{} \\
\hline
\end{tabular}

Table 7.6: Experiment results using average profit per trade

\begin{tabular}{|l|l|r|r|r|}
\hline \multirow{2}{*}{$\begin{array}{l}\text { Rule Selection } \\
\text { Approach }\end{array}$} & \multirow{2}{*}{ Selected Rules } & \multicolumn{3}{|c|}{ Threshold } \\
\cline { 3 - 5 } & & $\mathbf{2 5}$ & $\mathbf{5 0}$ & $\mathbf{7 5}$ \\
\hline \multirow{3}{*}{ Local Search } & $1 .-2$. & -3729 & 4602 & 1394 \\
\cline { 2 - 5 } & $1 .-14$. & 5923 & 10314 & 7666 \\
\cline { 2 - 5 } & $1 .-27$. & 6576 & 11986 & 13363 \\
\cline { 2 - 5 } & $1 .-28$. & 6531 & 8168 & 7308 \\
\hline Genetic Algorithm & - & 6186 & 3982 & 9365 \\
\hline Best rule & $\begin{array}{l}\text { Chaikin osc. } \\
\text { cross. }\end{array}$ & \multicolumn{3}{|c|}{-1499} \\
\hline \multirow{2}{*}{$2^{\text {nd }}$ Best Rule } & $\begin{array}{l}\text { Bearish div. } \\
\text { (RSI) }\end{array}$ & \multicolumn{3}{|c|}{5824} \\
\hline \multirow{2}{*}{$3^{r d}$ Best Rule } & $\begin{array}{l}\text { Bearish div. } \\
\text { (MFI) }\end{array}$ & \multicolumn{3}{|c|}{} \\
\hline
\end{tabular}

average profit per trade. The detailed results of the experiments are given in appendix B.

\subsubsection{Experiments on GBP/USD: 6 Months Data}

The data set covers 1-minute time series data between 01.01.2014-30.06.2014. The total number of data points in the data set is 182197 . The data set is split into training and test sections. The training data set includes data between 01.01.2014-30.04.2014 with a total of 121129 data points. The test data set includes data between 01.05.2014- 
30.06.2014 with a total of 61068 data points.

\subsubsection{Results}

29 out of 38 trading rules are qualified for the second phase. The list of qualified and unqualified rules are given in table 7.7

Table 7.7: Qualified and unqualified rules

\begin{tabular}{|c|c|c|}
\hline \multirow{2}{*}{ Rule Type } & \multicolumn{2}{|c|}{ Rule Name } \\
\hline & Qualified rules & Unqualified rules \\
\hline Crossover & $\begin{array}{l}\text { Double moving average, } \\
\text { Triple moving average, } \\
\text { Moving average envelopes, } \\
\text { RSI, Figurelli RSI, } \\
\text { Chandelier exit, } \\
\text { Psychological line, } \\
\text { RVI, Stochastics oscillator, } \\
\text { Ultimate oscillator, } \\
\text { Rate of change, } \\
\text { DeMarker, } \\
\text { Relative vigor index, MFI, } \\
\text { Chaikin Oscillator, } \\
\text { CMF, EMV }\end{array}$ & $\begin{array}{l}\text { Moving average price, } \\
\text { TEMA, MACD, OBV, } \\
\text { ADL }\end{array}$ \\
\hline $\begin{array}{l}\text { Bollinger Bands, \%b } \\
\text { and Bandwidth } \\
\text { Indicator Based }\end{array}$ & $\begin{array}{l}\text { W-type bottom pattern, } \\
\% \text { b-MFI }\end{array}$ & $\begin{array}{l}\text { M-type top pattern, } \\
\text { Method III-reversals, } \\
\% \text { b(CMF) crossover, } \\
\text { The squeeze and } \\
\text { expansion }\end{array}$ \\
\hline Divergence & $\begin{array}{l}\text { Bullish (RSI), Bearish (RSI), } \\
\text { Bullish (Figurelli RSI), } \\
\text { Bearish (Figurelli RSI), } \\
\text { Bullish (Ultimate oscillator), } \\
\text { Bearish (Ultimate oscillator), } \\
\text { Bullish (DeMarker), } \\
\text { Bearish (DeMarker), } \\
\text { Bullish (MFI), Bearish (MFI) }\end{array}$ & - \\
\hline
\end{tabular}

The results of the experiments using net profit and average profit per trade as the weight calculation metrics are given in tables 7.8 and 7.9 , respectively. 
Table 7.8: Experiment results using net profit

\begin{tabular}{|l|l|r|r|r|}
\hline \multirow{2}{*}{$\begin{array}{l}\text { Rule Selection } \\
\text { Approach }\end{array}$} & \multirow{2}{*}{ Selected Rules } & \multicolumn{3}{|c|}{ Threshold } \\
\cline { 2 - 5 } & & $\mathbf{2 5}$ & \multicolumn{1}{|c|}{$\mathbf{5 0}$} & $\mathbf{7 5}$ \\
\hline \multirow{3}{*}{ Local Search } & $1 .-2$. & 2971 & 5167 & 910 \\
\cline { 2 - 5 } & $1 .-15$. & 1328 & 6232 & 2743 \\
\cline { 2 - 5 } & $1 .-28$. & 3310 & 316 & 5716 \\
\cline { 2 - 5 } & $1 .-29$. & 3012 & 1994 & 1567 \\
\hline Genetic Algorithm & - & 4856 & 5181 & 3715 \\
\hline Best rule & \%b-MFI & \multicolumn{3}{|c|}{5627} \\
\hline \multirow{2}{*}{$2^{\text {nd }}$ Best Rule } & $\begin{array}{l}|c| \\
\text { Bearish div. } \\
\text { (MFI) }\end{array}$ & \multicolumn{3}{|c|}{34328} \\
\hline $3^{\text {rd }}$ Best Rule & MFI cross. & \multicolumn{3}{|c}{} \\
\hline
\end{tabular}

Table 7.9: Experiment results using average profit per trade

\begin{tabular}{|l|l|r|r|c|}
\hline \multirow{2}{*}{$\begin{array}{l}\text { Rule Selection } \\
\text { Approach }\end{array}$} & \multirow{2}{*}{ Selected Rules } & \multicolumn{3}{|c|}{ Threshold } \\
\cline { 2 - 5 } Local Search & $1 .-2$. & $\mathbf{2 5}$ & $\mathbf{5 0}$ & $\mathbf{7 5}$ \\
\cline { 2 - 5 } & $1 .-15$. & 499 & -3037 & 251 \\
\cline { 2 - 5 } & $1 .-28$. & 3896 & -272 & -672 \\
\cline { 2 - 5 } & $1 .-29$. & 5446 & 343 & -723 \\
\hline Genetic Algorithm & - & 6232 & 3334 & 5312 \\
\hline \multirow{2}{*}{ Best rule } & $\begin{array}{l}\text { Bullish div. } \\
\text { (RSI) }\end{array}$ & \multicolumn{3}{|c|}{-947} \\
\hline \multirow{2}{*}{$2^{\text {nd }}$ Best Rule } & $\begin{array}{l}\text { Bullish div. } \\
\text { (Ultimate osc.) }\end{array}$ & \multicolumn{3}{|c|}{4371} \\
\hline \multirow{2}{*}{$3^{r d}$ Best Rule } & $\begin{array}{l}\text { Bearish div. } \\
\text { (MFI) }\end{array}$ & \multicolumn{3}{|c}{} \\
\hline
\end{tabular}

\subsubsection{Discussion}

The results in table 7.7 indicate that 17 out of 22 crossover rules, 2 out of 6 Bollinger Bands and related indicators based rules and all the divergence rules successfully qualified for the second phase.

In table 7.8, the best results are achieved for genetic algorithm and local search methods when the threshold is 50. Local search method produced stable results when the threshold is 25 . Genetic algorithm indicates more stable performance in all the thresholds. In two cases, the trading system outperformed the three best individual rules. 
In table 7.9, the best results for genetic algorithm and local search method are obtained when the threshold is 25 . The results show a decrease in table 7.9 compared with the results in table 7.8. 3 negative results in local search method justify the situation. Genetic algorithm shows a good and stable performance outperforming the local search method in all the thresholds. The trading system's performance outperformed the three best individual rules in 4 of the cases.

The results in tables 7.8 and 7.9 indicate that using net profit as the weight calculation metric and genetic algorithm as the selection approach is more preferable to achieve stable profits. The detailed results of the experiments are given in appendix $\mathrm{C}$ 


\section{CHAPTER 8}

\section{CONCLUSION AND FUTURE WORK}

In this thesis, a trading system on Forex time series data is developed using trading rules based on technical indicators. A diverse set of technical indicators and various types of trading rules based on these indicators are implemented and used in the system. Among these, crossover rules use mathematical equations whereas divergence and Bollinger Bands and related indicators based rules detect special patterns in the price data.

The proposed trading system combines a potpourri of rules to act as a single rule and carry out buy/sell signals generated by the system. The implementation of the system is realized in three phases. In the first phase, each trading rule is tested for qualification. In this phase, genetic algorithm module is used to test each rule for qualification in collaboration with trading simulation module. In the second phase, the rules qualified in the first phase are subjected to selection process firstly. The selection is carried out using two approaches: genetic algorithm and local search. Genetic algorithm module in this phase is used to select the best combination of rules in collaboration with trading simulation and weighting modules. In local search module, the rules are sorted in decreasing order considering their performance followed by selecting the rule having the best performance in the first step and incrementally adding a rule into the selection in each step. Finally, a weighted majority voting method is used in the combination module which combines the selected rules. This module uses weights of the rules (which is provided by weighting module) to combine the decisions of the selected rules. In the final phase, the combined system is simulated on test data and the performance of the system is obtained. 
The proposed trading system is tested on EUR/USD and GBP/USD currency pairs in 3 different time frames. In two out of three experiments, using net profit is more preferable to using average profit per trade as the weight calculation metric. Both local search and individual rules resulted negative profits (losses) while genetic algorithm produced positive gains in all the experiments. This is an evidence of stable performance of genetic algorithm as the rule selection approach. The trading system outperformed the compared individual rules especially in EUR/USD 1-year data set and showed competitive performance in other data sets. The results considering the threshold values are volatile but 25 as the threshold value produced more stable results in the experiments. One of the most prominent result in the experiments is the superiority of the percentage of profitable trades. When the complete results of the experiments in appendix are evaluated, it can be seen that an average of $60 \%$ of the trades are profitable. This is a promising achievement which allows room for increasing the profit of the trading system with a good cash management strategy.

The proposed trading system doesn't consider transaction costs such as spread, don't apply active order strategies such as take profit and stop loss (discussed in chapter 2) and don't have an active cash management strategy. Improving the profitability and stability of the trading system by incorporating all these factors is a future direction of this study. Another future direction is the improvement of genetic algorithm used in selection of the rules. 


\section{REFERENCES}

[1] M. Mitchell. An Introduction to Genetic Algorithms. MIT Press, 1998.

[2] A.E. Eiben and J. E. Smith. Introduction to Evolutionary Computing. Springer, 2008.

[3] G. Reinelt. The Linear Ordering Problem: Exact and Heuristic Methods in Combinatorial Optimization (Applied Mathematical Sciences). Springer, 2011.

[4] M. D. Archer. Getting Started in Currency Trading. Wiley, 2010.

[5] Bank For International Settlements-Monetary Economic Department. Foreign Exchange Turnover in April 2013: Preliminary Global Results. Technical report, Bank For International Settlements, 2013.

[6] A. Kritzer. Forex for Beginners: A Comprehensive Guide to Profiting from the Global Currency Markets. Apress, 2012.

[7] B. Dolan. Currency Trading For Dummies. Wiley, 2011.

[8] E. Ponsi. Forex Patterns \& Probabilities. Wiley, 2007.

[9] Learn forex trading at the school of pipsology. http://www.babypips.com /school/, last visited on January 2015.

[10] J. J. Murphy. Technical Analysis of The Financial Markets. New York Institute of Finance, 1999.

[11] StockCharts.com Inc. Technical indicators and overlays. http://stockcharts.com /school, last visited on January 2015.

[12] R. J. Sweeney. Beating the foreign exchange market. The Journal of Finance, 41(1):163-182, 1986.

[13] F. Allen and R. Karjalainen. Using genetic algorithms to find technical trading rules. Journal of Financial Economics, 51:245-271, 1999.

[14] S. Papadamoua and G. Stephanides. Improving technical trading systems by using a new matlab-based genetic algorithm procedure. In Proceedings of the International Conference on Computational Methods in Sciences and Engineering 2004, pages 189-197. Mathematical and Computer Modelling, 2004. 
[15] A. Esfahanipour and S. Mousavi. A genetic programming model to generate risk-adjusted technical trading rules in stock markets. Expert Systems with Applications, 38(7):8438-8445, 2011.

[16] C. Schoreels and B. Logan. Agent based genetic algorithm employing financial technical analysis for making trading decisions using historical equity market data. In Proceedings of the IEEE/WIC/ACM International Conference on Intelligent Agent Technology, 2004 (IAT 2004), pages 421-424. IEEE, 2004.

[17] C. Neely, P. Weller, and R. Dittmar. Is technical analysis in the foreign exchange market profitable? a genetic programming approach. Journal of Financial and Quantitative Analysis, 32(4):405-426, 1997.

[18] A. Hryshko and T. Downs. System for foreign exchange trading using genetic algorithms and reinforcement learning. International Journal of Systems Science, 35(13-14):763-774, 2004.

[19] M.A.H. Dempster and C.M. Jones. A real-time adaptive trading system using genetic programming. Quantitative Finance, 1(4):397-413, 2001.

[20] S. Deng, K. Yoshiyama, T. Mitsubuchi, and A. Sakurai. Hybrid method of multiple kernel learning and genetic algorithm for forecasting short-term foreign exchange rates. Computational Economics, 45(1):49-89, 2015.

[21] A. Hirabayashi, C. Aranha, and H. Iba. Optimization of the trading rule in foreign exchange using genetic algorithm. In GECCO '09 Proceedings of the 11th Annual conference on Genetic and evolutionary computation, pages 15291536. ACM, 2009.

[22] $\mathrm{H}$. Ni and H. Yin. Exchange rate prediction using hybrid neural networks and trading indicators. Neurocomputing, 72(13-15):2815-2823, 2009.

[23] H. Thinyane and J. Millin. An investigation into the use of intelligent systems for currency trading. Computational Economics, 37(4):363-374, 2011.

[24] L. Mendes, P. Godinho, and J. Dias. A forex trading system based on a genetic algorithm. Journal of Heuristics, 18(4):327-656, 2012.

[25] R. F. B. de Brito and A. L. I. Oliveira. Comparative study of forex trading systems built with svr+ghsom and genetic algorithms optimization of technical indicators. In Proceedings of the 2012 24th IEEE International Conference on Tools with Artificial Intelligence, pages 351-358. IEEE, 2012.

[26] S. Deng and A. Sakurai. Integrated model of multiple kernel learning and differential evolution for eur/usd trading. The Scientific World Journal, 2014.

[27] S. Deng, Y. Sun, and A. Sakurai. Robustness test of genetic algorithm on generating rules for currency trading. In Proceedings of the International Neural 
Network Society Winter Conference (INNS-WC2012), pages 86-98. Procedia CS, 2012.

[28] A. Kayal. A neural networks filtering mechanism for foreign exchange trading signals. In Proceedings of the 2010 IEEE International Conference on Intelligent Computing and Intelligent Systems (ICIS),, pages 159-167. IEEE, 2010.

[29] S. Deng and A. Sakurai. Foreign exchange trading rules using a single technical indicator from multiple timeframes. In Proceedings of the 2013 27th International Conference on Advanced Information Networking and Applications Workshops, pages 207-212. IEEE, 2013.

[30] R. W. Colby. The Encyclopedia of Technical Market Indicators. McGraw-Hill, 2003.

[31] MetaQuotes Software Corp. http://www.metatrader5.com, last visited on January 2015.

[32] F. Larsen. Automatic stock market trading based on technical analysis. Master's thesis, Norwegian University of Science and Technology, 2007.

[33] P. G. Mulloy. Smoothing data with less lag. Technical Analysis of Stocks and Commodities, 12(2):72-80, 1994.

[34] J. Bollinger. Bollinger on Bollinger Bands. McGraw-Hill, 2002.

[35] G. Appel. Technical Analysis: Power Tools for Active Investors. Financial Times Prentice Hall, 2005.

[36] J. W. Wilder. New Concepts in Technical Trading Systems. Trend Research, 1978.

[37] MetaQuotes Software Corp. Figurelli rsi - indicator for metatrader 4. https://www.mq15.com/en/code/10539, last visited on January 2015.

[38] A. Elder. Come Into My Trading Room: A Complete Guide to Trading. Wiley, 2002.

[39] C. LeBeau and D. Lucas. Technical Traders Guide to Computer Analysis of the Futures Markets. McGraw-Hill, 1991.

[40] K. Muranaka. Opinion oscillator. Futures (Cedar Falls, IA), 29(6):48-50, 2000.

[41] D. Dorsey. The relative volatility index. Technical Analysis of Stocks and Commodities, 11(6):253-256, 1993.

[42] D. Brown. Relative volatility index (rvi). http://etfhq.com/blog/2011 /02/16/relative-volatility-index/, last visited on January 2015. 
[43] L. Williams. The ultimate oscillator. Technical Analysis of Stocks and Commodities, 3(4):140-141, 1985.

[44] T. R. DeMark. New Market Timing Techniques: Innovative Studies in Market Rhythm \& Price Exhaustion. Wiley, 1997.

[45] MahiFX. Demarker indicator. https://mahifx.com/indicators/demarkerindicator, last visited on January 2015.

[46] J. Ehlers. Relative vigor index. Technical Analysis of Stocks and Commodities, 20(1):16-20, 2002.

[47] G. Quong and A. Soudack. The ultimate oscillator. Technical Analysis of Stocks and Commodities, 7(3):76-77, 1989.

[48] J. Granville. Granville’s New Key to Stock Market Profits. Prentice-Hall, 1963.

[49] R. W. Arms. Volume Cycles in the Stock Market: Market Timing Through Equivolume Charting. Irwin Professional Pub, 1983.

[50] L. Sether. SFO Personal Investor Series: Forex Trading. W \& A Publishing, 2009.

[51] Triple moving average crossover. http://www.forexonlinetradingsystems.info/simplesystems/triple-moving-averages-crossover, last visited on January 2015.

[52] M. Carr. Moving average envelopes: Refining a popular trading tool. http://www.investopedia.com/articles/trading/08/moving-averageenvelope.asp, last visited on January 2015.

[53] A. A. Merrill. $M \& W$ Patterns. Analysis Press, 1983.

[54] M. Link. High Probability Trading. McGraw-Hill, 2003.

[55] P. J. Kaufman. Trading Systems and Methods. Wiley, 2013.

[56] S. Wagner. Heuristic Optimization Software Systems-Modeling of Heuristic Optimization Algorithms in the HeuristicLab Software Environment. $\mathrm{PhD}$ thesis, Institute for Formal Models and Verification,Johannes Kepler University,Linz,Austria, 2009.

[57] T. D. Gwiazda. Genetic Algorithms Reference Volume I. Tomasz Gwiazda, 2006.

[58] http://dev.mysql.com/doc/refman/5.6/en/index.html, last visited on January 2015. 


\section{APPENDIX A}

\section{EXPERIMENTS ON EUR/USD DATA BETWEEN \\ 01.01.2013-31.12.2013 (1 YEAR)}

The detailed experiment results are given in tables considering net profit/average profit per trade as the weight calculation metrics and 25, 50 and 75 as the thresholds to generate buy/sell signals (given in parenthesis).

\# value in the first column of the tables corresponds to $\mathrm{k}$ where $1^{\text {st }}$ through $k^{\text {th }}$ rule is selected using local search as the rule selection approach. As an example, if the \# value is 6 ., it corresponds to the results of the combined rule including $1^{\text {st }}$ (best rule) through $6^{\text {th }}$ rules.

The results of genetic algorithm as the rule selection approach are given below the local search results. The last three rows in the tables include the results of the best three individual rules in decreasing order entitled by $1^{\text {st }}, 2^{\text {nd }}$ and $3^{\text {rd }}$, respectively. 
Table A.1: Experiment results using net profit (threshold=25)

\begin{tabular}{|c|c|c|c|c|c|c|}
\hline$\#$ & \# of trades & Gross profit & Gross loss & Net profit & $\begin{array}{l}\text { Avr. profit } \\
\text { per trade }\end{array}$ & $\begin{array}{l}\text { Profitable } \\
\text { trades }(\%)\end{array}$ \\
\hline 2. & 1286 & 43680 & 36900 & 6780 & 5.27 & 55.44 \\
\hline 3. & 2158 & 56345 & 54751 & 1594 & 0.74 & 57.60 \\
\hline 4. & 1455 & 47076 & 40613 & 6463 & 4.44 & 56.49 \\
\hline 5. & 1883 & 57694 & 53035 & 4659 & 2.47 & 58.84 \\
\hline 6. & 2087 & 58628 & 56015 & 2613 & 1.25 & 57.93 \\
\hline 7. & 2560 & 71621 & 60219 & 11402 & 4.45 & 59.02 \\
\hline 8. & 2230 & 67627 & 55929 & 11698 & 5.25 & 59.55 \\
\hline 9. & 2479 & 70702 & 60181 & 10521 & 4.24 & 60.51 \\
\hline 10. & 2753 & 71802 & 64155 & 7647 & 2.78 & 60.62 \\
\hline 11. & 2839 & 70336 & 64203 & 6133 & 2.16 & 59.92 \\
\hline 12. & 2651 & 70545 & 59620 & 10925 & 4.12 & 60.39 \\
\hline 13. & 2647 & 71839 & 60744 & 11095 & 4.19 & 61.20 \\
\hline 14. & 2751 & 73265 & 61556 & 11709 & 4.26 & 60.49 \\
\hline 15. & 2773 & 73099 & 61298 & 11801 & 4.26 & 60.40 \\
\hline 16. & 2679 & 71558 & 61793 & 9765 & 3.65 & 60.58 \\
\hline 17. & 2669 & 71175 & 64356 & 6819 & 2.55 & 60.40 \\
\hline 18. & 2787 & 71898 & 65533 & 6365 & 2.28 & 58.95 \\
\hline 19. & 2791 & 69056 & 65323 & 3733 & 1.34 & 57.97 \\
\hline 20. & 2779 & 71519 & 65128 & 6391 & 2.30 & 59.01 \\
\hline 21. & 2781 & 69968 & 65736 & 4232 & 1.52 & 58.72 \\
\hline 22. & 2821 & 73967 & 64993 & 8974 & 3.18 & 58.88 \\
\hline 23. & 2813 & 75065 & 64651 & 10414 & 3.70 & 59.69 \\
\hline 24. & 2851 & 74150 & 65666 & 8484 & 2.98 & 59.66 \\
\hline 25. & 2861 & 74515 & 65123 & 9392 & 3.28 & 59.66 \\
\hline 26. & 2841 & 72498 & 65594 & 6904 & 2.43 & 59.20 \\
\hline 27. & 2819 & 71712 & 65700 & 6012 & 2.13 & 59.31 \\
\hline 28. & 2819 & 71745 & 66483 & 5262 & 1.87 & 59.24 \\
\hline \multicolumn{7}{|c|}{ Genetic Algorithm } \\
\hline- & 2579 & 71098 & 62100 & 8998 & 3.49 & 59.13 \\
\hline \multicolumn{7}{|c|}{ Best Rules } \\
\hline $1^{\text {st }}$ & 791 & 44119 & 39500 & 4619 & 5.84 & 64.35 \\
\hline $2^{\text {nd }}$ & 1019 & 50540 & 44793 & 5747 & 5.64 & 65.55 \\
\hline $3^{\text {rd }}$ & 1189 & 51863 & 48246 & 3617 & 3.04 & 66.11 \\
\hline
\end{tabular}


Table A.2: Experiment results using net profit (threshold=50)

\begin{tabular}{|c|c|c|c|c|c|c|}
\hline$\#$ & \# of trades & Gross profit & Gross loss & Net profit & $\begin{array}{l}\text { Avr. profit } \\
\text { per trade }\end{array}$ & $\begin{array}{l}\text { Profitable } \\
\text { trades }(\%)\end{array}$ \\
\hline 2. & 912 & 37612 & 33590 & 4022 & 4.41 & 53.51 \\
\hline 3. & 1283 & 48173 & 41636 & 6537 & 5.10 & 58.38 \\
\hline 4. & 1153 & 43825 & 39206 & 4619 & 4.01 & 57.33 \\
\hline 5. & 1387 & 52865 & 41668 & 11197 & 8.07 & 59.41 \\
\hline 6. & 1307 & 49139 & 40724 & 8415 & 6.44 & 58.38 \\
\hline 7. & 1534 & 59829 & 49347 & 10482 & 6.83 & 59.71 \\
\hline 8. & 1495 & 55723 & 50396 & 5327 & 3.56 & 58.46 \\
\hline 9. & 1675 & 59122 & 54019 & 5103 & 3.05 & 60.36 \\
\hline 10. & 1660 & 61347 & 50263 & 11084 & 6.68 & 62.23 \\
\hline 11. & 1708 & 61932 & 51181 & 10751 & 6.29 & 61.12 \\
\hline 12. & 1683 & 59763 & 52919 & 6844 & 4.07 & 61.08 \\
\hline 13. & 1702 & 58145 & 53509 & 4636 & 2.72 & 61.46 \\
\hline 14. & 1668 & 59375 & 51814 & 7561 & 4.53 & 61.99 \\
\hline 15. & 1642 & 61606 & 52790 & 8816 & 5.37 & 61.63 \\
\hline 16. & 1649 & 57830 & 53248 & 4582 & 2.78 & 59.31 \\
\hline 17. & 1643 & 59605 & 54562 & 5043 & 3.07 & 60.38 \\
\hline 18. & 1677 & 61016 & 54710 & 6306 & 3.76 & 61.00 \\
\hline 19. & 1680 & 58159 & 54626 & 3533 & 2.10 & 59.64 \\
\hline 20. & 1695 & 59832 & 52308 & 7524 & 4.44 & 59.47 \\
\hline 21. & 1688 & 56880 & 56779 & 101 & 0.06 & 57.35 \\
\hline 22. & 1690 & 60599 & 55559 & 5040 & 2.98 & 60.36 \\
\hline 23. & 1692 & 60995 & 54643 & 6352 & 3.75 & 61.29 \\
\hline 24. & 1708 & 60250 & 57018 & 3232 & 1.89 & 59.95 \\
\hline 25. & 1712 & 59873 & 55955 & 3918 & 2.29 & 58.94 \\
\hline 26. & 1706 & 61496 & 53242 & 8254 & 4.84 & 60.32 \\
\hline 27. & 1694 & 59742 & 54424 & 5318 & 3.14 & 59.98 \\
\hline 28. & 1684 & 63786 & 53290 & 10496 & 6.23 & 61.22 \\
\hline \multicolumn{7}{|c|}{ Genetic Algorithm } \\
\hline- & 1628 & 58383 & 55849 & 2534 & 1.56 & 61.18 \\
\hline \multicolumn{7}{|c|}{ Best Rules } \\
\hline $1^{\text {st }}$ & 791 & 44119 & 39500 & 4619 & 5.84 & 64.35 \\
\hline $2^{\text {nd }}$ & 1019 & 50540 & 44793 & 5747 & 5.64 & 65.55 \\
\hline $3^{\text {rd }}$ & 1189 & 51863 & 48246 & 3617 & 3.04 & 66.11 \\
\hline
\end{tabular}


Table A.3: Experiment results using net profit (threshold=75)

\begin{tabular}{|c|c|c|c|c|c|c|}
\hline$\#$ & \# of trades & Gross profit & Gross loss & Net profit & $\begin{array}{l}\text { Avr. profit } \\
\text { per trade }\end{array}$ & $\begin{array}{l}\text { Profitable } \\
\text { trades }(\%)\end{array}$ \\
\hline 2. & 814 & 35376 & 32762 & 2614 & 3.21 & 52.58 \\
\hline 3. & 906 & 41796 & 36236 & 5560 & 6.14 & 57.28 \\
\hline 4. & 977 & 40393 & 38508 & 1885 & 1.93 & 57.11 \\
\hline 5. & 1115 & 47390 & 39245 & 8145 & 7.30 & 60.27 \\
\hline 6. & 1060 & 44172 & 41857 & 2315 & 2.18 & 56.23 \\
\hline 7. & 1104 & 50819 & 41156 & 9663 & 8.75 & 59.60 \\
\hline 8. & 1124 & 49698 & 44161 & 5537 & 4.93 & 59.70 \\
\hline 9. & 1210 & 48955 & 46206 & 2749 & 2.27 & 58.18 \\
\hline 10. & 1252 & 52547 & 47719 & 4828 & 3.86 & 61.34 \\
\hline 11. & 1213 & 47873 & 48394 & -521 & -0.43 & 59.44 \\
\hline 12. & 1215 & 50940 & 45361 & 5579 & 4.59 & 59.09 \\
\hline 13. & 1207 & 55264 & 43733 & 11531 & 9.55 & 60.73 \\
\hline 14. & 1203 & 48816 & 50464 & -1648 & -1.37 & 59.52 \\
\hline 15. & 1165 & 48300 & 48684 & -384 & -0.33 & 60.94 \\
\hline 16. & 1177 & 49081 & 49565 & -484 & -0.41 & 61.68 \\
\hline 17. & 1169 & 53080 & 50157 & 2923 & 2.50 & 61.25 \\
\hline 18. & 1194 & 47119 & 52875 & -5756 & -4.82 & 60.80 \\
\hline 19. & 1198 & 48962 & 50495 & -1533 & -1.28 & 60.02 \\
\hline 20. & 1202 & 51809 & 47466 & 4343 & 3.61 & 59.90 \\
\hline 21. & 1204 & 54303 & 48038 & 6265 & 5.20 & 62.21 \\
\hline 22. & 1196 & 50553 & 48995 & 1558 & 1.30 & 61.12 \\
\hline 23. & 1195 & 50585 & 49033 & 1552 & 1.30 & 59.67 \\
\hline 24. & 1202 & 55885 & 48400 & 7485 & 6.23 & 61.56 \\
\hline 25. & 1204 & 54192 & 47821 & 6371 & 5.29 & 59.88 \\
\hline 26. & 1201 & 52859 & 49729 & 3130 & 2.61 & 60.28 \\
\hline 27. & 1182 & 52927 & 48736 & 4191 & 3.55 & 59.31 \\
\hline 28. & 1172 & 51567 & 49086 & 2481 & 2.12 & 59.47 \\
\hline \multicolumn{7}{|c|}{ Genetic Algorithm } \\
\hline- & 1193 & 51035 & 47155 & 3880 & 3.25 & 57.92 \\
\hline \multicolumn{7}{|c|}{ Best Rules } \\
\hline $1^{\text {st }}$ & 791 & 44119 & 39500 & 4619 & 5.84 & 64.35 \\
\hline $2^{\text {nd }}$ & 1019 & 50540 & 44793 & 5747 & 5.64 & 65.55 \\
\hline $3^{\text {rd }}$ & 1189 & 51863 & 48246 & 3617 & 3.04 & 66.11 \\
\hline
\end{tabular}


Table A.4: Experiment results using average profit per trade (threshold=25)

\begin{tabular}{|c|c|c|c|c|c|c|}
\hline \# & \# of trades & Gross profit & Gross loss & Net profit & $\begin{array}{l}\text { Avr. profit } \\
\text { per trade }\end{array}$ & $\begin{array}{l}\text { Profitable } \\
\text { trades }(\%)\end{array}$ \\
\hline 2. & 1493 & 50464 & 48657 & 1807 & 1.21 & 56.46 \\
\hline 3. & 1991 & 60465 & 52158 & 8307 & 4.17 & 57.86 \\
\hline 4. & 1569 & 52361 & 48959 & 3402 & 2.17 & 57.49 \\
\hline 5. & 1951 & 57776 & 55468 & 2308 & 1.18 & 57.97 \\
\hline 6. & 2168 & 62715 & 56688 & 6027 & 2.78 & 59.13 \\
\hline 7. & 2400 & 64301 & 58334 & 5967 & 2.49 & 58.88 \\
\hline 8. & 2056 & 61017 & 55301 & 5716 & 2.78 & 58.51 \\
\hline 9. & 2254 & 64444 & 57485 & 6959 & 3.09 & 58.21 \\
\hline 10. & 2348 & 59522 & 61869 & -2347 & -1.00 & 57.92 \\
\hline 11. & 2502 & 65079 & 57917 & 7162 & 2.86 & 58.27 \\
\hline 12. & 2398 & 65338 & 60386 & 4952 & 2.07 & 59.76 \\
\hline 13. & 2450 & 66942 & 59164 & 7778 & 3.17 & 59.76 \\
\hline 14. & 2574 & 69851 & 62363 & 7488 & 1.91 & 59.13 \\
\hline 15. & 2528 & 66531 & 62058 & 4473 & 1.77 & 58.54 \\
\hline 16. & 2498 & 66383 & 60234 & 6149 & 2.46 & 58.73 \\
\hline 17. & 2542 & 66711 & 63319 & 3392 & 1.33 & 57.59 \\
\hline 18. & 2562 & 69794 & 64075 & 5719 & 2.23 & 57.85 \\
\hline 19. & 2558 & 69548 & 61038 & 8510 & 3.33 & 57.62 \\
\hline 20. & 2572 & 68159 & 62021 & 6138 & 2.39 & 58.44 \\
\hline 21. & 2617 & 70274 & 62324 & 7950 & 3.04 & 58.20 \\
\hline 22. & 2663 & 67709 & 63408 & 4301 & 1.62 & 58.05 \\
\hline 23. & 2709 & 70778 & 63882 & 6896 & 2.55 & 58.10 \\
\hline 24. & 2759 & 71187 & 64739 & 6448 & 2.34 & 58.83 \\
\hline 25. & 2749 & 71081 & 65184 & 5897 & 2.15 & 58.38 \\
\hline 26. & 2711 & 73626 & 63686 & 9940 & 3.67 & 58.80 \\
\hline 27. & 2695 & 73598 & 64102 & 9496 & 3.52 & 58.11 \\
\hline 28. & 2723 & 76677 & 62093 & 14584 & 5.36 & 59.53 \\
\hline \multicolumn{7}{|c|}{ Genetic Algorithm } \\
\hline- & 2887 & 75823 & 68163 & 7660 & 2.65 & 60.79 \\
\hline \multicolumn{7}{|c|}{ Best Rules } \\
\hline $1^{\text {st }}$ & 791 & 44119 & 39500 & 4619 & 5.84 & 64.35 \\
\hline $2^{\text {nd }}$ & 759 & 41264 & 40296 & 968 & 1.28 & 61.40 \\
\hline $3^{\text {rd }}$ & 831 & 42886 & 42984 & -98 & -0.12 & 62.94 \\
\hline
\end{tabular}


Table A.5: Experiment results using average profit per trade (threshold=50)

\begin{tabular}{|c|c|c|c|c|c|c|}
\hline \# & \# of trades & Gross profit & Gross loss & Net profit & $\begin{array}{l}\text { Avr. profit } \\
\text { per trade }\end{array}$ & $\begin{array}{l}\text { Profitable } \\
\text { trades }(\%)\end{array}$ \\
\hline 2. & 937 & 41434 & 41276 & 158 & 0.17 & 55.92 \\
\hline 3. & 1099 & 49215 & 43447 & 5768 & 5.25 & 58.33 \\
\hline 4. & 1132 & 45636 & 44154 & 1482 & 1.31 & 58.83 \\
\hline 5. & 1283 & 53816 & 44979 & 8837 & 6.89 & 60.09 \\
\hline 6. & 1282 & 49996 & 46183 & 3813 & 2.97 & 58.50 \\
\hline 7. & 1359 & 50678 & 50032 & 646 & 0.48 & 57.40 \\
\hline 8. & 1329 & 56004 & 42656 & 13348 & 10.04 & 59.67 \\
\hline 9. & 1429 & 51277 & 49689 & 1588 & 1.11 & 57.38 \\
\hline 10. & 1394 & 54725 & 46721 & 8004 & 5.74 & 59.90 \\
\hline 11. & 1481 & 55369 & 49752 & 5617 & 3.79 & 58.07 \\
\hline 12. & 1493 & 57836 & 48085 & 9751 & 6.53 & 59.75 \\
\hline 13. & 1509 & 57003 & 49403 & 7600 & 5.04 & 59.38 \\
\hline 14. & 1520 & 55434 & 50340 & 5094 & 3.35 & 59.01 \\
\hline 15. & 1520 & 58023 & 51369 & 6654 & 4.38 & 60.53 \\
\hline 16. & 1532 & 58412 & 51186 & 7226 & 4.72 & 58.22 \\
\hline 17. & 1548 & 59016 & 53886 & 5130 & 3.31 & 59.95 \\
\hline 18. & 1526 & 55750 & 53332 & 2418 & 1.58 & 57.80 \\
\hline 19. & 1540 & 51847 & 54029 & -2182 & -1.42 & 57.21 \\
\hline 20. & 1544 & 54958 & 52892 & 2066 & 1.34 & 58.68 \\
\hline 21. & 1563 & 52520 & 56033 & -3513 & -2.25 & 58.54 \\
\hline 22. & 1593 & 55687 & 56546 & -859 & -0.54 & 58.69 \\
\hline 23. & 1611 & 60996 & 53703 & 7293 & 4.53 & 58.91 \\
\hline 24. & 1639 & 55473 & 54904 & 569 & 0.35 & 59.12 \\
\hline 25. & 1649 & 59474 & 54303 & 5171 & 3.14 & 60.04 \\
\hline 26. & 1618 & 57489 & 55371 & 2118 & 1.31 & 59.33 \\
\hline 27. & 1601 & 60310 & 53074 & 7236 & 4.52 & 62.09 \\
\hline 28. & 1609 & 56627 & 55650 & 977 & 0.61 & 58.55 \\
\hline \multicolumn{7}{|c|}{ Genetic Algorithm } \\
\hline- & 1683 & 62954 & 55542 & 7412 & 4.40 & 61.85 \\
\hline \multicolumn{7}{|c|}{ Best Rules } \\
\hline $1^{\text {st }}$ & 791 & 44119 & 39500 & 4619 & 5.84 & 64.35 \\
\hline $2^{\text {nd }}$ & 759 & 41264 & 40296 & 968 & 1.28 & 61.40 \\
\hline $3^{\text {rd }}$ & 831 & 42886 & 42984 & -98 & -0.12 & 62.94 \\
\hline
\end{tabular}


Table A.6: Experiment results using average profit per trade (threshold=75)

\begin{tabular}{|c|c|c|c|c|c|c|}
\hline \# & \# of trades & Gross profit & Gross loss & Net profit & $\begin{array}{l}\text { Avr. profit } \\
\text { per trade }\end{array}$ & $\begin{array}{l}\text { Profitable } \\
\text { trades }(\%)\end{array}$ \\
\hline 2. & 765 & 42790 & 38132 & 4658 & 6.09 & 60.13 \\
\hline 3. & 764 & 39213 & 36327 & 2886 & 3.78 & 56.68 \\
\hline 4. & 890 & 40231 & 42983 & -2752 & -3.09 & 55.84 \\
\hline 5. & 901 & 44975 & 41219 & 3756 & 4.17 & 56.71 \\
\hline 6. & 947 & 48136 & 41822 & 6314 & 6.67 & 56.81 \\
\hline 7. & 949 & 48599 & 40009 & 8590 & 9.05 & 60.17 \\
\hline 8. & 992 & 45110 & 40363 & 4747 & 4.79 & 60.99 \\
\hline 9. & 995 & 50844 & 39127 & 11717 & 11.78 & 60.70 \\
\hline 10. & 1025 & 46803 & 42084 & 4719 & 4.60 & 59.90 \\
\hline 11. & 1045 & 46230 & 44533 & 1697 & 1.62 & 60.10 \\
\hline 12. & 1076 & 46475 & 45646 & 829 & 0.77 & 59.67 \\
\hline 13. & 1074 & 49742 & 41481 & 8261 & 7.69 & 58.75 \\
\hline 14. & 1088 & 55988 & 40046 & 15942 & 14.65 & 60.57 \\
\hline 15. & 1077 & 50480 & 41210 & 9270 & 8.62 & 59.98 \\
\hline 16. & 1082 & 50018 & 45056 & 4962 & 4.59 & 59.61 \\
\hline 17. & 1084 & 47980 & 46156 & 1824 & 1.68 & 56.92 \\
\hline 18. & 1071 & 45615 & 45731 & -116 & -0.11 & 56.96 \\
\hline 19. & 1084 & 50089 & 46352 & 3737 & 3.45 & 60.52 \\
\hline 20. & 1087 & 47780 & 47030 & 750 & 0.69 & 58.23 \\
\hline 21. & 1105 & 52387 & 43078 & 9309 & 8.42 & 60.09 \\
\hline 22. & 1121 & 49851 & 46179 & 3672 & 3.28 & 59.14 \\
\hline 23. & 1138 & 55233 & 42494 & 12739 & 11.19 & 60.63 \\
\hline 24. & 1149 & 51187 & 45537 & 5650 & 4.92 & 61.01 \\
\hline 25. & 1146 & 53249 & 47947 & 5302 & 4.63 & 60.91 \\
\hline 26. & 1130 & 51824 & 46327 & 5497 & 4.86 & 60.44 \\
\hline 27. & 1117 & 49249 & 48772 & 477 & 0.43 & 59.36 \\
\hline 28. & 1131 & 53403 & 44390 & 9013 & 7.97 & 61.18 \\
\hline \multicolumn{7}{|c|}{ Genetic Algorithm } \\
\hline- & 1277 & 53013 & 50999 & 2014 & 1.58 & 61.79 \\
\hline \multicolumn{7}{|c|}{ Best Rules } \\
\hline $1^{\text {st }}$ & 791 & 44119 & 39500 & 4619 & 5.84 & 64.35 \\
\hline $2^{\text {nd }}$ & 759 & 41264 & 40296 & 968 & 1.28 & 61.40 \\
\hline $3^{\text {rd }}$ & 831 & 42886 & 42984 & -98 & -0.12 & 62.94 \\
\hline
\end{tabular}




\section{APPENDIX B}

\section{EXPERIMENTS ON EUR/USD DATA BETWEEN \\ 01.01.2013-30.06.2013 (6 MONTHS)}

The detailed experiment results are given in tables considering net profit/average profit per trade as the weight calculation metrics and 25, 50 and 75 as the thresholds to generate buy/sell signals (given in parenthesis).

\# value in the first column of the tables corresponds to $\mathrm{k}$ where $1^{\text {st }}$ through $k^{\text {th }}$ rule is selected using local search as the rule selection approach. As an example, if the \# value is 6 ., it corresponds to the results of the combined rule including $1^{\text {st }}$ (best rule) through $6^{\text {th }}$ rules.

The results of genetic algorithm as the rule selection approach are given below the local search results. The last three rows in the tables include the results of the best three individual rules in decreasing order entitled by $1^{\text {st }}, 2^{\text {nd }}$ and $3^{\text {rd }}$, respectively. 
Table B.1: Experiment results using net profit (threshold=25)

\begin{tabular}{|c|c|c|c|c|c|c|}
\hline$\#$ & \# of trades & Gross profit & Gross loss & Net profit & $\begin{array}{l}\text { Avr. profit } \\
\text { per trade }\end{array}$ & $\begin{array}{l}\text { Profitable } \\
\text { trades }(\%)\end{array}$ \\
\hline 2. & 1633 & 57218 & 49197 & 8021 & 4.91 & 59.95 \\
\hline 3. & 1991 & 59294 & 52391 & 6903 & 3.47 & 58.76 \\
\hline 4. & 1272 & 46201 & 44995 & 1206 & 0.95 & 59.28 \\
\hline 5. & 1478 & 50306 & 44182 & 6124 & 4.14 & 59.74 \\
\hline 6. & 1632 & 50174 & 46324 & 3850 & 2.36 & 57.41 \\
\hline 7. & 1718 & 52420 & 45572 & 6848 & 3.99 & 57.45 \\
\hline 8. & 1576 & 52301 & 46294 & 6007 & 3.81 & 58.57 \\
\hline 9. & 1455 & 52075 & 43822 & 8253 & 5.67 & 58.90 \\
\hline 10. & 1457 & 51544 & 43883 & 7661 & 5.26 & 58.13 \\
\hline 11. & 1545 & 50463 & 44688 & 5775 & 3.74 & 57.61 \\
\hline 12. & 1528 & 51213 & 45124 & 6089 & 3.98 & 57.85 \\
\hline 13. & 1451 & 50053 & 44265 & 5788 & 3.99 & 58.65 \\
\hline 14. & 1490 & 50672 & 44001 & 6671 & 4.48 & 58.86 \\
\hline 15. & 1518 & 50801 & 44484 & 6317 & 4.16 & 59.09 \\
\hline 16. & 1528 & 52166 & 44191 & 7975 & 5.22 & 59.95 \\
\hline 17. & 1524 & 50255 & 45276 & 4979 & 3.27 & 58.99 \\
\hline 18. & 1534 & 51607 & 44634 & 6973 & 4.55 & 59.97 \\
\hline 19. & 1534 & 50579 & 45020 & 5559 & 3.62 & 60.17 \\
\hline 20. & 1523 & 48254 & 45713 & 2541 & 1.67 & 59.42 \\
\hline 21. & 1542 & 53630 & 43915 & 9715 & 6.30 & 60.44 \\
\hline 22. & 1546 & 50865 & 46087 & 4778 & 3.09 & 59.57 \\
\hline 23. & 1540 & 54933 & 42674 & 12259 & 7.96 & 60.65 \\
\hline 24. & 1532 & 55422 & 42879 & 12543 & 8.19 & 61.23 \\
\hline 25. & 1530 & 54002 & 43133 & 10869 & 7.10 & 60.98 \\
\hline 26. & 1566 & 52999 & 44276 & 8723 & 5.57 & 60.34 \\
\hline 27. & 1570 & 52911 & 43911 & 9000 & 5.73 & 61.40 \\
\hline 28. & 1582 & 53314 & 44388 & 8926 & 5.64 & 60.11 \\
\hline \multicolumn{7}{|c|}{ Genetic Algorithm } \\
\hline- & 1430 & 49296 & 41142 & 8154 & 5.70 & 58.11 \\
\hline \multicolumn{7}{|c|}{ Best Rules } \\
\hline $1^{\text {st }}$ & 605 & 34895 & 31661 & 3234 & 5.35 & 64.13 \\
\hline $2^{\text {nd }}$ & 1133 & 58311 & 45854 & 12457 & 10.99 & 66.64 \\
\hline $3^{\text {rd }}$ & 411 & 32619 & 23674 & 8945 & 21.76 & 66.18 \\
\hline
\end{tabular}


Table B.2: Experiment results using net profit (threshold=50)

\begin{tabular}{|c|c|c|c|c|c|c|}
\hline \# & \# of trades & Gross profit & Gross loss & Net profit & $\begin{array}{l}\text { Avr. profit } \\
\text { per trade }\end{array}$ & $\begin{array}{l}\text { Profitable } \\
\text { trades }(\%)\end{array}$ \\
\hline 2. & 960 & 46678 & 36639 & 10039 & 10.46 & 60.31 \\
\hline 3. & 1040 & 47592 & 42826 & 4766 & 4.58 & 59.62 \\
\hline 4. & 931 & 43850 & 38793 & 5057 & 5.43 & 61.65 \\
\hline 5. & 1044 & 45282 & 40651 & 4631 & 4.44 & 62.07 \\
\hline 6. & 1010 & 46690 & 37789 & 8901 & 8.81 & 60.40 \\
\hline 7. & 990 & 46809 & 37425 & 9384 & 9.48 & 60.61 \\
\hline 8. & 968 & 45586 & 37531 & 8055 & 8.32 & 59.92 \\
\hline 9. & 934 & 45632 & 37795 & 7837 & 8.39 & 60.60 \\
\hline 10. & 937 & 42824 & 37820 & 5004 & 5.34 & 58.70 \\
\hline 11. & 919 & 42783 & 36667 & 6116 & 6.66 & 59.63 \\
\hline 12. & 930 & 46817 & 34986 & 11831 & 12.72 & 61.72 \\
\hline 13. & 908 & 45697 & 35482 & 10215 & 11.25 & 61.23 \\
\hline 14. & 918 & 44395 & 36862 & 7533 & 8.21 & 62.75 \\
\hline 15. & 916 & 43395 & 35548 & 7847 & 8.57 & 58.95 \\
\hline 16. & 920 & 43934 & 36479 & 7455 & 8.10 & 61.30 \\
\hline 17. & 930 & 43987 & 36282 & 7705 & 8.28 & 61.72 \\
\hline 18. & 925 & 43116 & 36640 & 6476 & 7.00 & 61.84 \\
\hline 19. & 935 & 48780 & 35689 & 13091 & 14.00 & 63.74 \\
\hline 20. & 919 & 47444 & 34329 & 13115 & 14.27 & 64.42 \\
\hline 21. & 929 & 41739 & 38346 & 3393 & 3.65 & 60.82 \\
\hline 22. & 927 & 43457 & 36573 & 6884 & 7.43 & 62.46 \\
\hline 23. & 927 & 44672 & 34397 & 10275 & 11.08 & 63.86 \\
\hline 24. & 917 & 40413 & 37060 & 3353 & 3.66 & 59.98 \\
\hline 25. & 915 & 43788 & 36587 & 7201 & 7.87 & 60.77 \\
\hline 26. & 939 & 46564 & 34241 & 12323 & 13.12 & 61.66 \\
\hline 27. & 937 & 44041 & 36014 & 8027 & 8.57 & 61.47 \\
\hline 28. & 935 & 46305 & 35952 & 10353 & 11.07 & 60.86 \\
\hline \multicolumn{7}{|c|}{ Genetic Algorithm } \\
\hline- & 966 & 46923 & 39457 & 7466 & 7.73 & 60.56 \\
\hline \multicolumn{7}{|c|}{ Best Rules } \\
\hline $1^{\text {st }}$ & 605 & 34895 & 31661 & 3234 & 5.35 & 64.13 \\
\hline $2^{\text {nd }}$ & 1133 & 58311 & 45854 & 12457 & 10.99 & 66.64 \\
\hline $3^{\text {rd }}$ & 411 & 32619 & 23674 & 8945 & 21.76 & 66.18 \\
\hline
\end{tabular}


Table B.3: Experiment results using net profit (threshold=75)

\begin{tabular}{|c|c|c|c|c|c|c|}
\hline \# & \# of trades & Gross profit & Gross loss & Net profit & $\begin{array}{l}\text { Avr. profit } \\
\text { per trade }\end{array}$ & $\begin{array}{l}\text { Profitable } \\
\text { trades }(\%)\end{array}$ \\
\hline 2. & 844 & 45075 & 35535 & 9540 & 11.30 & 60.78 \\
\hline 3. & 703 & 43733 & 33065 & 10668 & 15.17 & 63.02 \\
\hline 4. & 708 & 35248 & 34249 & 999 & 1.41 & 56.36 \\
\hline 5. & 788 & 43797 & 31192 & 12605 & 16.00 & 62.44 \\
\hline 6. & 740 & 42020 & 31781 & 10239 & 13.84 & 61.76 \\
\hline 7. & 668 & 39763 & 32005 & 7758 & 11.61 & 59.13 \\
\hline 8. & 699 & 40891 & 32886 & 8005 & 11.45 & 60.80 \\
\hline 9. & 683 & 40698 & 33487 & 7211 & 10.56 & 61.05 \\
\hline 10. & 650 & 41231 & 32974 & 8257 & 12.70 & 61.54 \\
\hline 11. & 656 & 42198 & 31573 & 10625 & 16.20 & 61.59 \\
\hline 12. & 658 & 35148 & 35095 & 53 & 0.08 & 59.42 \\
\hline 13. & 644 & 36372 & 33547 & 2825 & 4.39 & 60.09 \\
\hline 14. & 646 & 40452 & 30610 & 9842 & 15.24 & 61.92 \\
\hline 15. & 646 & 42389 & 28362 & 14027 & 21.71 & 62.38 \\
\hline 16. & 650 & 42341 & 30263 & 12078 & 18.58 & 64.31 \\
\hline 17. & 650 & 40101 & 30016 & 10085 & 15.52 & 63.23 \\
\hline 18. & 653 & 38901 & 31733 & 7168 & 10.98 & 58.35 \\
\hline 19. & 654 & 36437 & 34007 & 2430 & 3.72 & 57.95 \\
\hline 20. & 650 & 42240 & 30799 & 11441 & 17.60 & 63.69 \\
\hline 21. & 652 & 37601 & 32445 & 5156 & 7.91 & 59.36 \\
\hline 22. & 646 & 37585 & 32675 & 4910 & 7.60 & 58.36 \\
\hline 23. & 644 & 37350 & 32364 & 4986 & 7.74 & 58.54 \\
\hline 24. & 639 & 42433 & 27965 & 14468 & 22.64 & 61.50 \\
\hline 25. & 639 & 40703 & 29355 & 11348 & 17.76 & 63.69 \\
\hline 26. & 654 & 42107 & 30469 & 11638 & 17.80 & 63.30 \\
\hline 27. & 654 & 42932 & 30254 & 12678 & 19.39 & 61.62 \\
\hline 28. & 650 & 41105 & 29883 & 11222 & 17.26 & 60.46 \\
\hline \multicolumn{7}{|c|}{ Genetic Algorithm } \\
\hline- & 656 & 37464 & 32853 & 4611 & 7.03 & 60.98 \\
\hline \multicolumn{7}{|c|}{ Best Rules } \\
\hline $1^{\text {st }}$ & 605 & 34895 & 31661 & 3234 & 5.35 & 64.13 \\
\hline $2^{\text {nd }}$ & 1133 & 58311 & 45854 & 12457 & 10.99 & 66.64 \\
\hline $3^{\text {rd }}$ & 411 & 32619 & 23674 & 8945 & 21.76 & 66.18 \\
\hline
\end{tabular}


Table B.4: Experiment results using average profit per trade (threshold=25)

\begin{tabular}{|c|c|c|c|c|c|c|}
\hline \# & \# of trades & Gross profit & Gross loss & Net profit & $\begin{array}{l}\text { Avr. profit } \\
\text { per trade }\end{array}$ & $\begin{array}{l}\text { Profitable } \\
\text { trades }(\%)\end{array}$ \\
\hline 2. & 732 & 34906 & 38635 & -3729 & -5.09 & 54.64 \\
\hline 3. & 1093 & 48212 & 36773 & 11439 & 10.47 & 59.65 \\
\hline 4. & 943 & 44091 & 32455 & 11636 & 12.34 & 58.43 \\
\hline 5. & 1101 & 43128 & 40604 & 2524 & 2.29 & 58.76 \\
\hline 6. & 1073 & 42047 & 35663 & 6384 & 5.95 & 60.30 \\
\hline 7. & 1130 & 46443 & 35488 & 10955 & 9.69 & 59.91 \\
\hline 8. & 1178 & 43652 & 38015 & 5637 & 4.79 & 59.42 \\
\hline 9. & 1194 & 43178 & 38477 & 4701 & 3.94 & 57.79 \\
\hline 10. & 1249 & 47900 & 37496 & 10404 & 8.33 & 61.17 \\
\hline 11. & 1225 & 49515 & 35639 & 13876 & 11.33 & 61.39 \\
\hline 12. & 1254 & 45451 & 39072 & 6379 & 5.09 & 60.69 \\
\hline 13. & 1268 & 47639 & 38732 & 8907 & 7.02 & 58.20 \\
\hline 14. & 1255 & 46237 & 40314 & 5923 & 4.72 & 59.20 \\
\hline 15. & 1295 & 48580 & 37490 & 11090 & 8.56 & 60.00 \\
\hline 16. & 1313 & 46665 & 38315 & 8350 & 6.36 & 59.25 \\
\hline 17. & 1292 & 48572 & 38816 & 9756 & 7.55 & 58.67 \\
\hline 18. & 1296 & 46280 & 40088 & 6192 & 4.78 & 58.02 \\
\hline 19. & 1324 & 46435 & 40236 & 6199 & 4.68 & 58.61 \\
\hline 20. & 1344 & 49589 & 40144 & 9445 & 7.03 & 60.79 \\
\hline 21. & 1361 & 49359 & 37834 & 11525 & 8.47 & 61.87 \\
\hline 22. & 1430 & 48218 & 40433 & 7785 & 5.44 & 59.79 \\
\hline 23. & 1452 & 50931 & 40552 & 10379 & 7.15 & 62.19 \\
\hline 24. & 1458 & 50568 & 42081 & 8487 & 5.82 & 61.04 \\
\hline 25. & 1466 & 50810 & 41866 & 8944 & 6.10 & 60.23 \\
\hline 26. & 1632 & 57454 & 43107 & 14347 & 8.79 & 62.01 \\
\hline 27. & 1697 & 52572 & 45996 & 6576 & 3.88 & 57.87 \\
\hline 28. & 1679 & 53248 & 46717 & 6531 & 3.89 & 59.32 \\
\hline \multicolumn{7}{|c|}{ Genetic Algorithm } \\
\hline- & 1489 & 49650 & 43464 & 6186 & 4.15 & 57.42 \\
\hline \multicolumn{7}{|c|}{ Best Rules } \\
\hline $\mathbf{1}^{\mathrm{st}}$ & 408 & 31573 & 33072 & -1499 & -3.67 & 56.86 \\
\hline $2^{\text {nd }}$ & 332 & 28933 & 23109 & 5824 & 17.54 & 64.76 \\
\hline $3^{\text {rd }}$ & 411 & 32619 & 23674 & 8945 & 21.76 & 66.18 \\
\hline
\end{tabular}


Table B.5: Experiment results using average profit per trade (threshold=50)

\begin{tabular}{|c|c|c|c|c|c|c|}
\hline \# & \# of trades & Gross profit & Gross loss & Net profit & $\begin{array}{l}\text { Avr. profit } \\
\text { per trade }\end{array}$ & $\begin{array}{l}\text { Profitable } \\
\text { trades }(\%)\end{array}$ \\
\hline 2. & 457 & 31527 & 26925 & 4602 & 10.07 & 59.30 \\
\hline 3. & 566 & 37452 & 30743 & 6709 & 11.85 & 60.42 \\
\hline 4. & 601 & 39209 & 26041 & 13168 & 21.91 & 61.23 \\
\hline 5. & 649 & 34088 & 32342 & 1746 & 2.69 & 62.71 \\
\hline 6. & 696 & 37819 & 30660 & 7159 & 10.29 & 62.36 \\
\hline 7. & 694 & 36090 & 30533 & 5557 & 8.01 & 60.37 \\
\hline 8. & 737 & 35540 & 35580 & -40 & -0.05 & 60.24 \\
\hline 9. & 742 & 39185 & 33145 & 6040 & 8.14 & 62.67 \\
\hline 10. & 760 & 38676 & 34626 & 4050 & 5.33 & 61.97 \\
\hline 11. & 754 & 41065 & 30092 & 10973 & 14.55 & 65.78 \\
\hline 12. & 764 & 41613 & 31360 & 10253 & 13.42 & 61.39 \\
\hline 13. & 757 & 41085 & 31799 & 9286 & 12.27 & 61.03 \\
\hline 14. & 762 & 41290 & 30976 & 10314 & 13.54 & 63.52 \\
\hline 15. & 772 & 42410 & 30913 & 11497 & 14.89 & 61.79 \\
\hline 16. & 780 & 43529 & 30946 & 12583 & 16.13 & 64.23 \\
\hline 17. & 782 & 42373 & 32835 & 9538 & 12.20 & 61.25 \\
\hline 18. & 780 & 41359 & 33354 & 8005 & 10.26 & 62.05 \\
\hline 19. & 787 & 38724 & 33936 & 4788 & 6.08 & 58.96 \\
\hline 20. & 810 & 38961 & 33279 & 5682 & 7.01 & 59.01 \\
\hline 21. & 819 & 37987 & 35194 & 2793 & 3.41 & 59.10 \\
\hline 22. & 863 & 44545 & 31847 & 12698 & 14.71 & 64.77 \\
\hline 23. & 875 & 40763 & 34981 & 5782 & 6.61 & 62.97 \\
\hline 24. & 869 & 42997 & 32709 & 10288 & 11.84 & 64.44 \\
\hline 25. & 883 & 42404 & 34754 & 7650 & 8.66 & 61.16 \\
\hline 26. & 975 & 42572 & 39352 & 3220 & 3.30 & 60.82 \\
\hline 27. & 1008 & 49036 & 37050 & 11986 & 11.89 & 62.70 \\
\hline 28. & 1002 & 46514 & 38346 & 8168 & 8.15 & 61.08 \\
\hline \multicolumn{7}{|c|}{ Genetic Algorithm } \\
\hline- & 1009 & 43159 & 39177 & 3982 & 3.95 & 59.96 \\
\hline \multicolumn{7}{|c|}{ Best Rules } \\
\hline $1^{\text {st }}$ & 408 & 31573 & 33072 & -1499 & -3.67 & 56.86 \\
\hline $2^{\text {nd }}$ & 332 & 28933 & 23109 & 5824 & 17.54 & 64.76 \\
\hline $3^{\text {rd }}$ & 411 & 32619 & 23674 & 8945 & 21.76 & 66.18 \\
\hline
\end{tabular}


Table B.6: Experiment results using average profit per trade (threshold=75)

\begin{tabular}{|c|c|c|c|c|c|c|}
\hline \# & \# of trades & Gross profit & Gross loss & Net profit & $\begin{array}{l}\text { Avr. profit } \\
\text { per trade }\end{array}$ & $\begin{array}{l}\text { Profitable } \\
\text { trades }(\%)\end{array}$ \\
\hline 2. & 367 & 26695 & 25301 & 1394 & 3.80 & 55.04 \\
\hline 3. & 381 & 31869 & 23899 & 7970 & 20.92 & 58.53 \\
\hline 4. & 441 & 30146 & 25186 & 4960 & 11.25 & 57.14 \\
\hline 5. & 507 & 31581 & 28976 & 2605 & 5.14 & 57.20 \\
\hline 6. & 504 & 35118 & 27239 & 7879 & 15.63 & 59.33 \\
\hline 7. & 505 & 34067 & 26652 & 7415 & 14.68 & 62.18 \\
\hline 8. & 530 & 33042 & 28662 & 4380 & 8.26 & 58.87 \\
\hline 9. & 534 & 31507 & 30805 & 702 & 1.31 & 58.24 \\
\hline 10. & 537 & 31953 & 31235 & 718 & 1.34 & 58.29 \\
\hline 11. & 534 & 31791 & 28750 & 3041 & 5.69 & 59.36 \\
\hline 12. & 538 & 31655 & 28596 & 3059 & 5.69 & 56.32 \\
\hline 13. & 537 & 30598 & 28744 & 1854 & 3.45 & 57.91 \\
\hline 14. & 536 & 35733 & 28067 & 7666 & 14.30 & 58.21 \\
\hline 15. & 542 & 33550 & 27554 & 5996 & 11.06 & 55.72 \\
\hline 16. & 548 & 35148 & 27130 & 8018 & 14.63 & 61.31 \\
\hline 17. & 546 & 36476 & 25335 & 11141 & 20.40 & 63.55 \\
\hline 18. & 546 & 32082 & 31053 & 1029 & 1.88 & 56.96 \\
\hline 19. & 554 & 39149 & 24009 & 15140 & 27.33 & 62.82 \\
\hline 20. & 563 & 33240 & 29726 & 3514 & 6.24 & 60.21 \\
\hline 21. & 572 & 32421 & 30988 & 1433 & 2.51 & 60.14 \\
\hline 22. & 601 & 34519 & 30220 & 4299 & 7.15 & 62.23 \\
\hline 23. & 610 & 36141 & 31242 & 4899 & 8.03 & 62.46 \\
\hline 24. & 608 & 36087 & 31581 & 4506 & 7.41 & 61.18 \\
\hline 25. & 615 & 37171 & 29029 & 8142 & 13.24 & 63.58 \\
\hline 26. & 678 & 39216 & 32554 & 6662 & 9.83 & 59.88 \\
\hline 27. & 702 & 44495 & 31132 & 13363 & 19.04 & 61.97 \\
\hline 28. & 698 & 39194 & 31886 & 7308 & 10.47 & 60.32 \\
\hline \multicolumn{7}{|c|}{ Genetic Algorithm } \\
\hline- & 627 & 38702 & 29337 & 9365 & 14.93 & 62.20 \\
\hline \multicolumn{7}{|c|}{ Best Rules } \\
\hline $1^{\text {st }}$ & 408 & 31573 & 33072 & -1499 & -3.67 & 56.86 \\
\hline $2^{\text {nd }}$ & 332 & 28933 & 23109 & 5824 & 17.54 & 64.76 \\
\hline $3^{\text {rd }}$ & 411 & 32619 & 23674 & 8945 & 21.76 & 66.18 \\
\hline
\end{tabular}




\section{APPENDIX C}

\section{EXPERIMENTS ON GBP/USD DATA BETWEEN \\ 01.01.2014-30.06.2014 (6 MONTHS)}

The detailed experiment results are given in tables considering net profit/average profit per trade as the weight calculation metrics and 25, 50 and 75 as the thresholds to generate buy/sell signals (given in parenthesis).

\# value in the first column of the tables corresponds to $\mathrm{k}$ where $1^{\text {st }}$ through $k^{\text {th }}$ rule is selected using local search as the rule selection approach. As an example, if the \# value is 6 ., it corresponds to the results of the combined rule including $1^{\text {st }}$ (best rule) through $6^{\text {th }}$ rules.

The results of genetic algorithm as the rule selection approach are given below the local search results. The last three rows in the tables include the results of the best three individual rules in decreasing order entitled by $1^{\text {st }}, 2^{\text {nd }}$ and $3^{\text {rd }}$, respectively. 
Table C.1: Experiment results using net profit (threshold=25)

\begin{tabular}{|c|c|c|c|c|c|c|}
\hline \# & \# of trades & Gross profit & Gross loss & Net profit & $\begin{array}{l}\text { Avr. profit } \\
\text { per trade }\end{array}$ & $\begin{array}{l}\text { Profitable } \\
\text { trades }(\%)\end{array}$ \\
\hline 2. & 1076 & 26221 & 23250 & 2971 & 2.76 & 57.62 \\
\hline 3. & 1488 & 28666 & 25794 & 2872 & 1.93 & 56.12 \\
\hline 4. & 1255 & 29225 & 24924 & 4301 & 3.43 & 56.89 \\
\hline 5. & 1173 & 30548 & 24784 & 5764 & 4.91 & 59.34 \\
\hline 6. & 1402 & 30538 & 27178 & 3360 & 2.40 & 59.34 \\
\hline 7. & 1546 & 32399 & 28347 & 4052 & 2.62 & 59.25 \\
\hline 8. & 1379 & 31692 & 26147 & 5545 & 4.02 & 58.16 \\
\hline 9. & 1328 & 31751 & 25297 & 6454 & 4.86 & 60.09 \\
\hline 10. & 1371 & 31542 & 24992 & 6550 & 4.78 & 59.08 \\
\hline 11. & 1419 & 32773 & 26695 & 6078 & 4.28 & 58.91 \\
\hline 12. & 1362 & 30410 & 27512 & 2898 & 2.13 & 58.66 \\
\hline 13. & 1334 & 31054 & 27544 & 3510 & 2.63 & 58.85 \\
\hline 14. & 1337 & 30224 & 25960 & 4264 & 3.19 & 59.01 \\
\hline 15. & 1332 & 28885 & 27557 & 1328 & 1.00 & 58.26 \\
\hline 16. & 1306 & 27593 & 27697 & -104 & -0.08 & 57.27 \\
\hline 17. & 1282 & 29732 & 25605 & 4127 & 3.22 & 58.89 \\
\hline 18. & 1288 & 31704 & 24710 & 6994 & 5.43 & 58.70 \\
\hline 19. & 1335 & 28925 & 27299 & 1626 & 1.22 & 55.28 \\
\hline 20. & 1329 & 29525 & 26667 & 2858 & 2.15 & 55.68 \\
\hline 21. & 1341 & 29841 & 26279 & 3562 & 2.66 & 57.49 \\
\hline 22. & 1329 & 30350 & 27274 & 3076 & 2.31 & 58.01 \\
\hline 23. & 1365 & 28407 & 27063 & 1344 & 0.98 & 57.00 \\
\hline 24. & 1369 & 28966 & 26982 & 1984 & 1.45 & 57.63 \\
\hline 25. & 1353 & 30734 & 26706 & 4028 & 2.98 & 58.91 \\
\hline 26. & 1358 & 30018 & 26798 & 3220 & 2.37 & 58.69 \\
\hline 27. & 1352 & 30356 & 26128 & 4228 & 3.13 & 58.06 \\
\hline 28. & 1359 & 30149 & 26839 & 3310 & 2.44 & 58.20 \\
\hline 29. & 1368 & 30253 & 27241 & 3012 & 2.20 & 58.99 \\
\hline \multicolumn{7}{|c|}{ Genetic Algorithm } \\
\hline- & 1358 & 32392 & 27536 & 4856 & 3.58 & 60.53 \\
\hline \multicolumn{7}{|c|}{ Best Rules } \\
\hline $\mathbf{1}^{\mathrm{st}}$ & 700 & 26289 & 20662 & 5627 & 8.04 & 67.86 \\
\hline $2^{\text {nd }}$ & 448 & 20629 & 16301 & 4328 & 9.66 & 60.94 \\
\hline $3^{\text {rd }}$ & 552 & 22552 & 19120 & 3432 & 6.22 & 64.86 \\
\hline
\end{tabular}


Table C.2: Experiment results using net profit (threshold=50)

\begin{tabular}{|c|c|c|c|c|c|c|}
\hline \# & \# of trades & Gross profit & Gross loss & Net profit & $\begin{array}{l}\text { Avr. profit } \\
\text { per trade }\end{array}$ & $\begin{array}{l}\text { Profitable } \\
\text { trades }(\%)\end{array}$ \\
\hline 2. & 741 & 24413 & 19246 & 5167 & 6.97 & 63.16 \\
\hline 3. & 800 & 23999 & 20836 & 3163 & 3.95 & 58.38 \\
\hline 4. & 833 & 23597 & 23575 & 22 & 0.03 & 57.38 \\
\hline 5. & 827 & 27797 & 21807 & 5990 & 7.24 & 60.34 \\
\hline 6. & 852 & 24908 & 21842 & 3066 & 3.60 & 60.92 \\
\hline 7. & 868 & 27792 & 22326 & 5466 & 6.30 & 62.90 \\
\hline 8. & 861 & 27783 & 22289 & 5494 & 6.38 & 61.56 \\
\hline 9. & 857 & 26091 & 24211 & 1880 & 2.19 & 58.69 \\
\hline 10. & 847 & 25217 & 23421 & 1796 & 2.12 & 58.32 \\
\hline 11. & 800 & 24961 & 24564 & 397 & 0.50 & 58.88 \\
\hline 12. & 820 & 25856 & 23369 & 2487 & 3.03 & 60.12 \\
\hline 13. & 810 & 26644 & 22440 & 4204 & 5.19 & 62.35 \\
\hline 14. & 794 & 27528 & 22575 & 4953 & 6.24 & 60.96 \\
\hline 15. & 775 & 26953 & 20721 & 6232 & 8.04 & 62.84 \\
\hline 16. & 774 & 26667 & 22222 & 4445 & 5.74 & 60.72 \\
\hline 17. & 763 & 23745 & 22683 & 1062 & 1.39 & 60.29 \\
\hline 18. & 770 & 25194 & 22080 & 3114 & 4.04 & 58.83 \\
\hline 19. & 784 & 23788 & 22588 & 1200 & 1.53 & 57.27 \\
\hline 20. & 784 & 23913 & 22573 & 1340 & 1.71 & 57.27 \\
\hline 21. & 787 & 24331 & 22952 & 1379 & 1.75 & 59.09 \\
\hline 22. & 792 & 23392 & 23472 & -80 & -0.10 & 56.82 \\
\hline 23. & 811 & 24615 & 21668 & 2947 & 3.63 & 60.17 \\
\hline 24. & 813 & 24773 & 22351 & 2422 & 2.98 & 59.41 \\
\hline 25. & 802 & 24439 & 23266 & 1173 & 1.46 & 58.85 \\
\hline 26. & 802 & 23098 & 23520 & -422 & -0.53 & 58.60 \\
\hline 27. & 790 & 24373 & 22775 & 1598 & 2.02 & 58.23 \\
\hline 28. & 802 & 23171 & 22855 & 316 & 0.39 & 58.48 \\
\hline 29. & 797 & 24823 & 22829 & 1994 & 2.50 & 60.23 \\
\hline \multicolumn{7}{|c|}{ Genetic Algorithm } \\
\hline- & 804 & 26202 & 21021 & 5181 & 6.44 & 59.83 \\
\hline \multicolumn{7}{|c|}{ Best Rules } \\
\hline $1^{\text {st }}$ & 700 & 26289 & 20662 & 5627 & 8.04 & 67.86 \\
\hline $2^{\text {nd }}$ & 448 & 20629 & 16301 & 4328 & 9.66 & 60.94 \\
\hline $3^{\text {rd }}$ & 552 & 22552 & 19120 & 3432 & 6.22 & 64.86 \\
\hline
\end{tabular}


Table C.3: Experiment results using net profit (threshold=75)

\begin{tabular}{|c|c|c|c|c|c|c|}
\hline \# & \# of trades & Gross profit & Gross loss & Net profit & $\begin{array}{l}\text { Avr. profit } \\
\text { per trade }\end{array}$ & $\begin{array}{l}\text { Profitable } \\
\text { trades }(\%)\end{array}$ \\
\hline 2. & 562 & 19866 & 18956 & 910 & 1.62 & 55.69 \\
\hline 3. & 548 & 19588 & 18188 & 1400 & 2.55 & 58.94 \\
\hline 4. & 600 & 23605 & 17779 & 5826 & 9.71 & 62.17 \\
\hline 5. & 616 & 23346 & 20603 & 2743 & 4.45 & 59.42 \\
\hline 6. & 615 & 24478 & 19152 & 5326 & 8.66 & 60.16 \\
\hline 7. & 598 & 23279 & 20409 & 2870 & 4.80 & 61.20 \\
\hline 8. & 609 & 24886 & 17723 & 7163 & 11.76 & 61.90 \\
\hline 9. & 614 & 22048 & 19755 & 2293 & 3.73 & 57.65 \\
\hline 10. & 589 & 24051 & 18873 & 5178 & 8.79 & 61.63 \\
\hline 11. & 560 & 20887 & 21912 & -1025 & -1.83 & 58.21 \\
\hline 12. & 578 & 21937 & 19540 & 2397 & 4.15 & 59.86 \\
\hline 13. & 572 & 21986 & 20631 & 1355 & 2.37 & 61.19 \\
\hline 14. & 548 & 23361 & 19035 & 4326 & 7.89 & 61.50 \\
\hline 15. & 548 & 22224 & 19481 & 2743 & 5.01 & 59.31 \\
\hline 16. & 543 & 21257 & 20611 & 646 & 1.19 & 58.93 \\
\hline 17. & 536 & 20658 & 21673 & -1015 & -1.89 & 57.84 \\
\hline 18. & 541 & 20625 & 20896 & -271 & -0.50 & 56.93 \\
\hline 19. & 546 & 22574 & 19293 & 3281 & 6.01 & 58.79 \\
\hline 20. & 546 & 24184 & 17987 & 6197 & 11.35 & 60.81 \\
\hline 21. & 555 & 23459 & 18440 & 5019 & 9.04 & 60.54 \\
\hline 22. & 552 & 22534 & 18557 & 3977 & 7.20 & 60.87 \\
\hline 23. & 566 & 22238 & 19133 & 3105 & 5.49 & 59.72 \\
\hline 24. & 562 & 23678 & 18364 & 5314 & 9.46 & 61.57 \\
\hline 25. & 558 & 19040 & 21101 & -2061 & -3.69 & 58.60 \\
\hline 26. & 556 & 24227 & 18371 & 5856 & 10.53 & 62.95 \\
\hline 27. & 550 & 22653 & 20230 & 2423 & 4.41 & 60.18 \\
\hline 28. & 555 & 23685 & 17969 & 5716 & 10.30 & 60.54 \\
\hline 29. & 554 & 22049 & 20482 & 1567 & 2.83 & 62.09 \\
\hline \multicolumn{7}{|c|}{ Genetic Algorithm } \\
\hline- & 505 & 21769 & 18054 & 3715 & 7.36 & 59.01 \\
\hline \multicolumn{7}{|c|}{ Best Rules } \\
\hline $\mathbf{1}^{\text {st }}$ & 700 & 26289 & 20662 & 5627 & 8.04 & 67.86 \\
\hline $2^{\text {nd }}$ & 448 & 20629 & 16301 & 4328 & 9.66 & 60.94 \\
\hline $3^{\text {rd }}$ & 552 & 22552 & 19120 & 3432 & 6.22 & 64.86 \\
\hline
\end{tabular}


Table C.4: Experiment results using average profit per trade (threshold=25)

\begin{tabular}{|c|c|c|c|c|c|c|}
\hline \# & \# of trades & Gross profit & Gross loss & Net profit & $\begin{array}{l}\text { Avr. profit } \\
\text { per trade }\end{array}$ & $\begin{array}{l}\text { Profitable } \\
\text { trades }(\%)\end{array}$ \\
\hline 2. & 557 & 17932 & 16933 & 999 & 1.79 & 55.30 \\
\hline 3. & 990 & 25591 & 21523 & 4068 & 4.11 & 58.18 \\
\hline 4. & 1012 & 24647 & 22951 & 1696 & 1.68 & 56.72 \\
\hline 5. & 876 & 23546 & 22159 & 1387 & 1.58 & 56.96 \\
\hline 6. & 1059 & 24923 & 23280 & 1643 & 1.55 & 56.94 \\
\hline 7. & 1129 & 27775 & 22056 & 5719 & 5.07 & 56.78 \\
\hline 8. & 1063 & 26453 & 21946 & 4507 & 4.24 & 57.67 \\
\hline 9. & 1001 & 26405 & 22042 & 4363 & 4.36 & 59.34 \\
\hline 10. & 1105 & 27042 & 23301 & 3741 & 3.39 & 57.38 \\
\hline 11. & 1105 & 27042 & 23301 & 3741 & 3.39 & 57.38 \\
\hline 12. & 1127 & 27798 & 23173 & 4625 & 4.10 & 57.94 \\
\hline 13. & 1077 & 27451 & 22656 & 4795 & 4.45 & 58.50 \\
\hline 14. & 1127 & 28539 & 22730 & 5809 & 5.15 & 58.03 \\
\hline 15. & 1168 & 28667 & 23708 & 4959 & 4.25 & 57.45 \\
\hline 16. & 1192 & 28573 & 23622 & 4951 & 4.15 & 56.12 \\
\hline 17. & 1176 & 29148 & 23769 & 5379 & 4.57 & 58.67 \\
\hline 18. & 1215 & 24654 & 25811 & -1157 & -0.95 & 55.64 \\
\hline 19. & 1221 & 26573 & 25962 & 611 & 0.50 & 56.67 \\
\hline 20. & 1239 & 27724 & 25695 & 2029 & 1.64 & 56.98 \\
\hline 21. & 1217 & 28808 & 24906 & 3902 & 3.21 & 59.08 \\
\hline 22. & 1233 & 28675 & 24673 & 4002 & 3.25 & 59.29 \\
\hline 23. & 1221 & 29382 & 24824 & 4558 & 3.73 & 58.48 \\
\hline 24. & 1233 & 28232 & 24886 & 3346 & 2.71 & 56.61 \\
\hline 25. & 1256 & 29303 & 24355 & 4948 & 3.94 & 58.76 \\
\hline 26. & 1279 & 30445 & 25471 & 4974 & 3.89 & 57.54 \\
\hline 27. & 1295 & 30439 & 25619 & 4820 & 3.72 & 56.22 \\
\hline 28. & 1284 & 30604 & 26708 & 3896 & 3.03 & 57.63 \\
\hline 29. & 1309 & 31513 & 26067 & 5446 & 4.16 & 58.52 \\
\hline \multicolumn{7}{|c|}{ Genetic Algorithm } \\
\hline- & 1346 & 33744 & 27512 & 6232 & 4.63 & 58.69 \\
\hline \multicolumn{7}{|c|}{ Best Rules } \\
\hline $1^{\text {st }}$ & 288 & 14676 & 15623 & -947 & -3.29 & 58.33 \\
\hline $2^{\text {nd }}$ & 299 & 14277 & 14848 & -571 & -1.91 & 57.86 \\
\hline $3^{\text {rd }}$ & 448 & 20629 & 16301 & 4328 & 9.66 & 60.94 \\
\hline
\end{tabular}


Table C.5: Experiment results using average profit per trade (threshold=50)

\begin{tabular}{|c|c|c|c|c|c|c|}
\hline$\#$ & \# of trades & Gross profit & Gross loss & Net profit & $\begin{array}{l}\text { Avr. profit } \\
\text { per trade }\end{array}$ & $\begin{array}{l}\text { Profitable } \\
\text { trades }(\%)\end{array}$ \\
\hline 2. & 348 & 13163 & 16200 & -3037 & -8.73 & 56.03 \\
\hline 3. & 509 & 18327 & 17789 & 538 & 1.06 & 58.35 \\
\hline 4. & 537 & 21225 & 17742 & 3483 & 6.49 & 59.40 \\
\hline 5. & 603 & 18700 & 21554 & -2854 & -4.73 & 57.05 \\
\hline 6. & 616 & 21467 & 18160 & 3307 & 5.37 & 61.20 \\
\hline 7. & 639 & 21151 & 19411 & 1740 & 2.72 & 57.75 \\
\hline 8. & 629 & 21289 & 19496 & 1793 & 2.85 & 58.51 \\
\hline 9. & 642 & 20143 & 20972 & -829 & -1.29 & 56.85 \\
\hline 10. & 647 & 20371 & 19702 & 669 & 1.03 & 57.34 \\
\hline 11. & 633 & 20458 & 20029 & 429 & 0.68 & 57.19 \\
\hline 12. & 664 & 22883 & 20010 & 2873 & 4.33 & 57.38 \\
\hline 13. & 651 & 21231 & 20124 & 1107 & 1.70 & 57.45 \\
\hline 14. & 691 & 22643 & 19756 & 2887 & 4.18 & 58.61 \\
\hline 15. & 690 & 21011 & 20184 & 827 & 1.20 & 58.84 \\
\hline 16. & 711 & 23228 & 19683 & 3545 & 4.99 & 58.65 \\
\hline 17. & 711 & 21139 & 21512 & -373 & -0.52 & 57.67 \\
\hline 18. & 725 & 24457 & 19567 & 4890 & 6.74 & 59.17 \\
\hline 19. & 725 & 25022 & 20345 & 4677 & 6.45 & 60.00 \\
\hline 20. & 733 & 24268 & 20982 & 3286 & 4.48 & 60.44 \\
\hline 21. & 722 & 23730 & 20641 & 3089 & 4.28 & 57.89 \\
\hline 22. & 731 & 24951 & 20584 & 4367 & 5.97 & 59.64 \\
\hline 23. & 719 & 23467 & 21057 & 2410 & 3.35 & 59.94 \\
\hline 24. & 728 & 24129 & 21217 & 2912 & 4.00 & 58.93 \\
\hline 25. & 742 & 22371 & 21797 & 574 & 0.77 & 59.70 \\
\hline 26. & 755 & 22495 & 21665 & 830 & 1.10 & 59.07 \\
\hline 27. & 762 & 22988 & 21552 & 1436 & 1.88 & 56.43 \\
\hline 28. & 751 & 21955 & 22227 & -272 & -0.36 & 55.66 \\
\hline 29. & 768 & 23466 & 23123 & 343 & 0.45 & 59.11 \\
\hline \multicolumn{7}{|c|}{ Genetic Algorithm } \\
\hline- & 772 & 26114 & 22780 & 3334 & 4.32 & 58.81 \\
\hline \multicolumn{7}{|c|}{ Best Rules } \\
\hline $1^{\text {st }}$ & 288 & 14676 & 15623 & -947 & -3.29 & 58.33 \\
\hline $2^{\text {nd }}$ & 299 & 14277 & 14848 & -571 & -1.91 & 57.86 \\
\hline $3^{\text {rd }}$ & 448 & 20629 & 16301 & 4328 & 9.66 & 60.94 \\
\hline
\end{tabular}


Table C.6: Experiment results using average profit per trade (threshold=75)

\begin{tabular}{|c|c|c|c|c|c|c|}
\hline \# & \# of trades & Gross profit & Gross loss & Net profit & $\begin{array}{l}\text { Avr. profit } \\
\text { per trade }\end{array}$ & $\begin{array}{l}\text { Profitable } \\
\text { trades }(\%)\end{array}$ \\
\hline 2. & 284 & 14093 & 13842 & 251 & 0.88 & 56.69 \\
\hline 3. & 340 & 17160 & 13945 & 3215 & 9.46 & 59.41 \\
\hline 4. & 375 & 17579 & 15903 & 1676 & 4.47 & 58.40 \\
\hline 5. & 447 & 18058 & 17939 & 119 & 0.27 & 55.93 \\
\hline 6. & 460 & 18351 & 17984 & 367 & 0.80 & 59.78 \\
\hline 7. & 433 & 18105 & 17953 & 152 & 0.35 & 56.58 \\
\hline 8. & 440 & 18871 & 17458 & 1413 & 3.21 & 59.32 \\
\hline 9. & 454 & 17738 & 18171 & -433 & -0.95 & 58.37 \\
\hline 10. & 467 & 19223 & 18028 & 1195 & 2.56 & 58.67 \\
\hline 11. & 459 & 20470 & 17369 & 3101 & 6.76 & 60.13 \\
\hline 12. & 459 & 17344 & 18297 & -953 & -2.08 & 56.43 \\
\hline 13. & 457 & 20166 & 17511 & 2655 & 5.81 & 60.61 \\
\hline 14. & 483 & 19747 & 18229 & 1518 & 3.14 & 58.39 \\
\hline 15. & 491 & 19686 & 17750 & 1936 & 3.94 & 60.90 \\
\hline 16. & 499 & 21791 & 17174 & 4617 & 9.25 & 58.72 \\
\hline 17. & 499 & 17960 & 18495 & -535 & -1.07 & 56.91 \\
\hline 18. & 510 & 21149 & 18014 & 3135 & 6.15 & 59.22 \\
\hline 19. & 507 & 22050 & 17164 & 4886 & 9.64 & 59.57 \\
\hline 20. & 516 & 20311 & 17444 & 2867 & 5.56 & 59.69 \\
\hline 21. & 502 & 20984 & 16744 & 4240 & 8.45 & 56.97 \\
\hline 22. & 509 & 18931 & 19040 & -109 & -0.21 & 56.78 \\
\hline 23. & 502 & 22962 & 17311 & 5651 & 11.26 & 62.95 \\
\hline 24. & 507 & 22326 & 17640 & 4686 & 9.24 & 60.75 \\
\hline 25. & 516 & 20331 & 18209 & 2122 & 4.11 & 59.30 \\
\hline 26. & 517 & 19502 & 18846 & 656 & 1.27 & 59.96 \\
\hline 27. & 522 & 17167 & 20981 & -3814 & -7.31 & 55.17 \\
\hline 28. & 522 & 19795 & 20467 & -672 & -1.29 & 57.09 \\
\hline 29. & 529 & 19511 & 20234 & -723 & -1.37 & 58.79 \\
\hline \multicolumn{7}{|c|}{ Genetic Algorithm } \\
\hline - & 547 & 23694 & 18382 & 5312 & 9.71 & 58.87 \\
\hline \multicolumn{7}{|c|}{ Best Rules } \\
\hline $1^{\text {st }}$ & 288 & 14676 & 15623 & -947 & -3.29 & 58.33 \\
\hline $2^{\text {nd }}$ & 299 & 14277 & 14848 & -571 & -1.91 & 57.86 \\
\hline $3^{\text {rd }}$ & 448 & 20629 & 16301 & 4328 & 9.66 & 60.94 \\
\hline
\end{tabular}

